\title{
A University Consortium on Low Temperature Combustion for High Efficiency, Ultra-Low Emission Engines
}

\author{
DE- FC26-06NT42629 \\ Final Report \\ January 1, 2006 - December 31, 2009
}

Participating Universities

University of Michigan (lead)

Massachusetts Institute of Technology

Stanford University

University of California, Berkeley

Principal Investigators (in alphabetical order)

Dennis N. Assanis* (UM)

Arvind Atreya (UM)

Jyh-Yuan Chen (UCB)

Wai K. Cheng (MIT)

Robert W. Dibble (UCB)

Chris Edwards (SU)

Zoran S. Filipi (UM)

Christian Gerdes (SU)

Hong G. Im (UM)

George A. Lavoie (UM)

Margaret S. Wooldridge (UM)

*Principal Investigator to whom all correspondence should be addressed:

Prof. Dennis N. Assanis

Department of Mechanical Engineering

University of Michigan/2043 WE Lay Auto Lab

Ann Arbor MI 48109-2133

(734) 763-7880 (Office), (734)764-4256 (Fax), assanis@ umich.edu 


\section{DISCLAIMER}

This report was prepared as an account of work sponsored by an agency of the United States Government. Neither the United States Government nor any agency thereof, nor any of their employees, makes any warranty, express or implied, or assumes any legal liability or responsibility for the accuracy, completeness, or usefulness of any information, apparatus, product, or process disclosed, or represents that its use would not infringe privately owned rights. Reference herein to any specific commercial product, process, or service by trade name, trademark, manufacturer, or otherwise does not necessarily constitute or imply its endorsement, recommendation, or favoring by the United States Government or any agency thereof. The views and opinions of authors expressed herein do not necessarily state or reflect those of the United States Government or any agency thereof. 


\section{PROJECT SUMMARY}

\section{Objective:}

The objective of the University consortium was to investigate the fundamental processes that determine the practical boundaries of Low Temperature Combustion (LTC) engines and develop methods to extend those boundaries to improve the fuel economy of these engines, while operating with ultra low emissions. This work involved studies of thermal effects, thermal transients and engine management, internal mixing and stratification, and direct injection strategies for affecting combustion stability. This work also examined spark-assisted Homogenous Charge Compression Ignition (HCCI) and exhaust after-treatment so as to extend the range and maximize the benefit of Homogenous Charge Compression Ignition (HCCI)/ Partially Premixed Compression Ignition (PPCI) operation. In summary the overall goals were:

- Investigate the fundamental processes that determine the practical boundaries of Low Temperature Combustion (LTC) engines.

- Develop methods to extend LTC boundaries to improve the fuel economy of HCCI engines fueled on gasoline and alternative blends, while operating with ultra low emissions.

- Investigate alternate fuels, ignition and after-treatment for LTC and Partially Premixed compression Ignition (PPCI) engines.

\section{Approach:}

The Multi-University Research Consortium included The University of Michigan (UM) acting as lead, Massachusetts Institute of Technology (MIT), Stanford University (SU), and the University of California at Berkeley (UCB). A combined experimental and analytical approach was used. Engines and laboratory combustion devices at the team universities were used to explore targeted issues depending on the respective capabilities to isolate the phenomena of interest. Engine and kinetic modeling was employed as needed, while an overall system model was developed at UM. The system model integrates the knowledge gained at the universities and industry partners and has been used to assess the benefits of selected engine management strategies.

The research addresses the following tasks: 1) Wall heat transfer, precision temperature control and thermal management of an LTC engine for extended range of operation (UM); 2) Improving combustion stability and reducing emissions at low load (UM); 3) Engine control for extended HCCI operation (MIT); 4) Increased power density by turbo/supercharging and temperature control (UCB); 5) Direct injection to increase load limits and efficiency for HCCI engines (SU); 6) Emission control devices for PPCI engines (UM); 7) Spark-assisted HCCI for enhancing range and control of LTC engine (UM); 8) Fuel pretreatment strategies, non-petroleum based fuels and fuel-blends for use in advanced LTC engine strategies.

The eight tasks noted above were performed by the prime and the three subcontractors that make up the Multi-University Research Consortium.

\section{Key Accomplishments:}

Extension of low load limit - Single cylinder experimental results and a modeling study showed that pilot injection of fuel during Negative Valve Overlap (NVO) can be used to extend the lower load limit of HCCI operation to near 1 bar NMEP. The recompression reactions believed responsible have been explored in detail using a reduced chemical kinetic model for $\mathrm{n}$-heptane to simulate the reactions and heat release during both the NVO period and the subsequent main combustion event. It was found that ignition on the next cycle can be advanced or retarded depending on the overall oxygen concentration and the NVO temperature. 
Extension of high load limit - multi-cylinder experiments at UCB and single cylinder experiments at MIT have demonstrated that the high load limit can be extended to near 6 bar by boosting intake to 7 bar absolute intake pressure. The key to this increase is to add proportionally more air or EGR than fuel as the load is increased. This keeps the ringing index within constraints but permits higher load. Since the completion of the work described here, this limit has been extended by more than 2 bar NMEP to 8.7 bar in multi-cylinder tests. These findings validate the boosted modeling results described in the section on HCCI system modeling.

Work at MIT on a boosted HCCI engine with electro-magnetic valve control has resulted in the formulation of a scaling law relating the Maximum Pressure Rise Rate (MPRR) in a boosted engine to the Net Indicated Mean Effective Pressure (NIMEP) and heat release time scale. Additional analysis of the engine data was used to establish the dependence of MPRR on engine operating parameters: charge oxygen and fuel mole fractions, compression temperature and pressure. It was also found that the high load limit and the misfire limit occur at the same operating point (at the intersection of the constraining MPRR contour and the misfire limit contour). Finally the dependence of the high load limit on EGR and boost was established, with the highest load attainable of 5.7 bar at 21\% EGR and 1.7 bar inlet pressure.

CFD modeling - A coupled CFD/chemistry model has been used to show and quantify the burn rate behavior and combustion efficiency in an idealized HCCI engine. Modes of combustion failure have been identified and the influence of naturally occurring internal temperature stratification on burn characteristics has been explored. The most important engine operating characteristics affecting burn rate were found to be combustion phasing, equivalence ratio, EGR, and RPM. Combustion efficiency was found to be a function of peak average cylinder temperature, regardless of other variables. A correlation incorporating these findings and based on the large database of CFD runs was formulated for use in subsequent system modeling.

HCCI system modeling - A multi-cylinder engine simulation based on GT-Power ${ }^{\circledR}$ and enhanced with user derived HCCI combustion and heat transfer models has been used to demonstrate the effects of transient wall temperature excursions on ignition timing and combustion rates. The simulation shows that an open loop controller can improve the combustion phasing and overall fuel economy of a vehicle in normal driving cycle. Different valve timing strategies for achieving HCCI have been explored using an engine simulation based on GT-Power ${ }^{\circledR}$ model. Studies indicate that load limits are strongly affected by complex interactions between sensible residual gas heat, effective compression ratio associated with the particular valve strategy employed, and cycle-to-cycle feedback of residual gas. The model was further used to generate performance maps for various proposed valve actuation schemes subject to ignition, NOx and knock constraints as well as combustion stability considerations. The model has also been coupled to a simplified turbocharger model. Results showed that the high load limit can be extended without knock provided the mixture is leaned out or diluted as pressure is increased.

Stratified CI combustion modeling - For direct injection (DI) and partially premixed compression ignition (PPCI) engine applications an improved flamelet combustion model has been developed to describe the interaction between spray and combustion. The proposed spray-interactive reduced dimension model (SIRDM) includes the spray source terms, such that droplet vaporization history can be properly accounted for in the reaction space. The results show good agreement with stratified DI HCCI experiments reported in the literature.

Spark assisted HCCI - Spark assist was observed in UM optical engine experiments to have an effect in stabilizing combustion under certian conditions. The high speed images show that although a small flame is present at the spark plug, the main combustion event begins at other locations in the chamber. A thermodynamic analysis has been carried out to delineate the combustion regimes for Spark Assisted (SA) HCCI. The analysis confirms optical engine experiments reported last year and indicates that the regime 
for SA exists between normal SI operation and HCCI. These findings have been captured in a multi-mode combustion diagram which delineates the characteristic regimes of combustion including SI, HCCI and Spark Assisted Compression Ignition (SACI). Together with experimental optical engine observations reported previously, the analysis indicates that spark assist is likely to be primarily useful as an ignition helper when not enough sensible heat is available for auto ignition.

To investigate the SACI process analytically, the interaction of a laminar flame and auto igniting gas has been modeled using HCT, a one dimensional transient reacting gas code. The results demonstrate independence of the flame and autoignition process up to the autoignition event itself. Based on the results under conditions where a steady flame was observed, a laminar flame speed correlation has been developed in this region of dilute - high unburned temperatures where no experimental data is available. The resulting correlation will be employed in future work to develop a CFD model of SACI based on the flame surface density approach.

Emission control devices for PCI engines - An after-treatment model has been developed for PCI combustion products which successfully describes the performance of a production-type low temperature diesel oxidation catalyst (DOC) under PCI and normal diesel operation. A first generation model of a Urea SCR catalyst has been assembled using AVL Boost with appropriate chemical equations drawn in part from previous work at UM and from the literature. The model was then used to explore the effect of catalyst size on effectiveness in a typical engine application and validated against second-by-second experimental engine exhaust data from a 6.0L International V-8 engine over an FTP 75 driving cycle.

Fuel blends for use in advanced LTC engines - Rapid compression ignition delay measurements have been made for a number of isomers of simple five and six carbon esters representative of future bio-derived fuels. The range of ignition delays is significant, and blending with n-heptane shows non linear effects which may be useful in designing future fuels. These studies have been extended to include speciation studies of the intermediates formed during ignition of methylbutanoate and air mixtures. The results are the first of their kind to provide quantitative insight into the reaction pathways important during ester combustion and have been used to improve available kinetic models by Westbrook et al. at LLNL. 


\section{Task 1: Wall heat transfer, precision temperature control and thermal management of LTC engine for extended range of operation (UM)}

Objective: The objective of this task is to investigate fundamental wall heat transfer effects on Low Temperature Combustion (LTC), such as thermal stratification effects on combustion rates and overall impact on heat loss and cycle efficiency, and to subsequently develop strategies and methodologies for extending the load range of HCCI operation, as well as for thermal management and transient control of mixed-mode engines (SI+HCCI) in vehicles.

\section{Effect of Combustion Chamber Deposits on HCCI Combustion}

(Note that this portion of the LTC consortium was carried out with General Motors sponsorship and is cost shared with the Consortium). Homogenous Charge Compression Ignition (HCCI) engines offer a good potential for achieving high fuel efficiency while virtually eliminating NOx and soot emissions from the exhaust. However, realizing the full fuel economy potential at the vehicle level depends on the size of the HCCI operating range. The usable HCCI range is determined by the knock limit on the upper end and the misfire limit at the lower end. Previously proven high sensitivity of the HCCI process to thermal conditions leads to a hypothesis that combustion chamber deposits (CCD) could directly affect HCCI combustion, and that insight about this effect can be helpful in expanding the low-load limit. A combustion chamber conditioning process was carried out in a single-cylinder, gasoline-fueled engine with exhaust rebreathing to study CCD formation rates and their effect on combustion. Burn rates accelerated significantly over the forty hours of running under typical HCCI operating conditions as shown in Figure 1. Variations of burn rates diminished after approximately 36 hours, thus indicating equilibrium conditions. Observed trends suggest that deposits change dynamic thermal boundary conditions at the wall and this in turn strongly affects chemical kinetics and bulk burning.

From a practical point of view, the deposits have a major effect on the load limits of viable HCCI operation. Tests were carried out with the fully conditioned engine and compared with clean engine limits. The low limit was defined by $\mathrm{COV}$

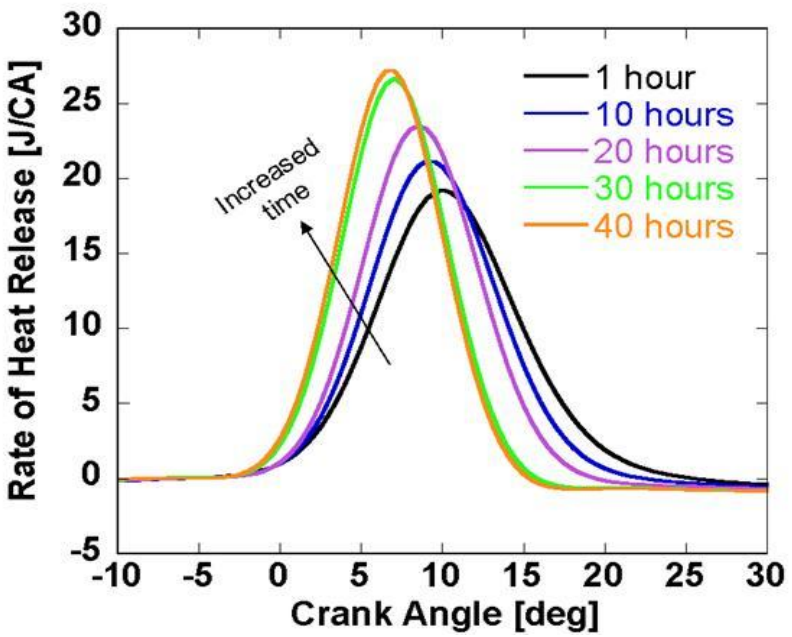

Fig. 1. Rate of heat release as a function of running hours showing the effect of surface deposit buildup. Guralp et al. (2006)

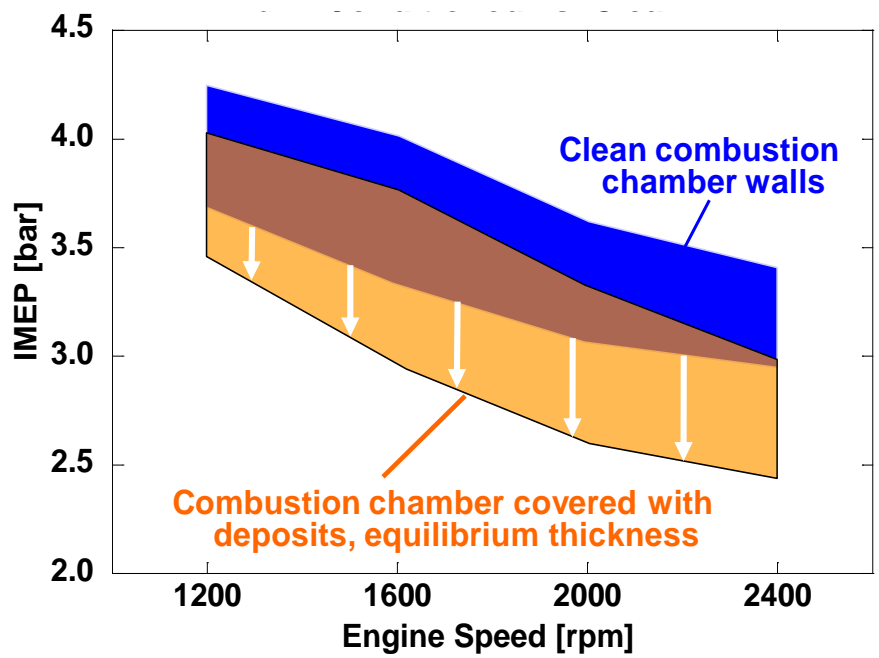

Fig. 2. Operation range of HCCI engine with and without combustion chamber deposits. 
of NMEP while the high limit was defined by the ringing index. The results are shown in Figure 2. Note that both high and low load limits decrease with deposits. This is similar to earlier studies of the effect of wall temperature.

Understanding the mechanisms responsible for the strong impact of deposits on HCCI combustion requires additional information about the effect that chamber deposits have on surface heat transfer. In the experiments heat flux probes are mounted on the metal surface. As deposits grow, they form a thermal barrier on top of the probe. Therefore, measurements do not reflect conditions at the gas-surface interface; rather they characterize the effect of CCD on heat transfer and enable evaluation of deposit properties.

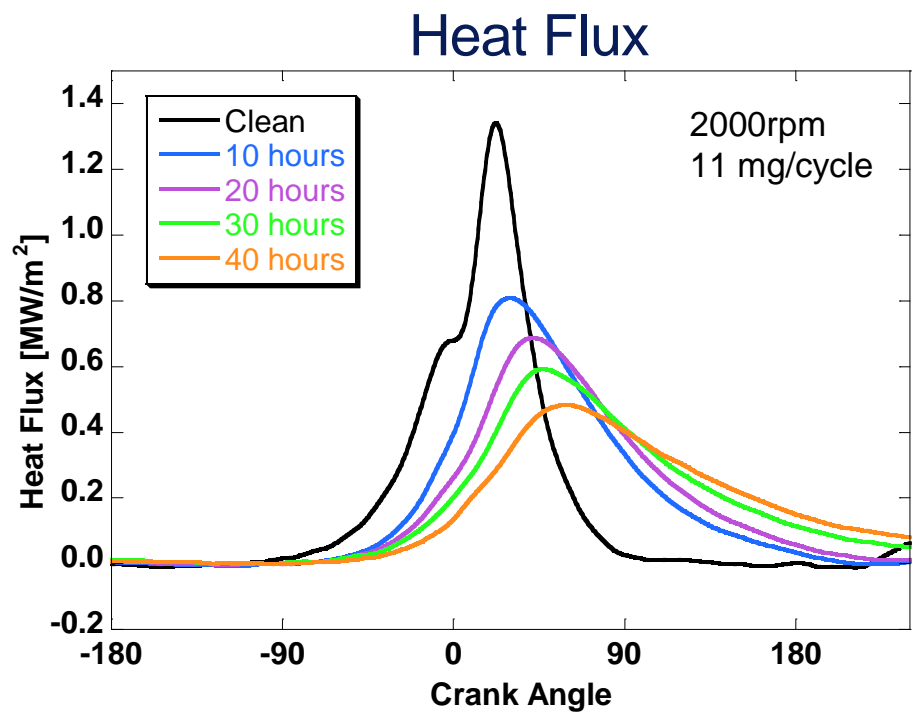

Fig. 3. Measured surface heat flux during deposit buildup, showing retarded phasing and reduction in peak heat flux values. Guralp et al., (2006)

Two probes were used to track instantaneous temperature and heat flux throughout the test. The results from one probe are shown in Figure 3 and they indicate significant changes over the 40 hours of operation. As deposit material grows over the probe surface, the heat flux signal measured at the junction location becomes dampened. During the first hour, it is easy to see the heat flux shape mimicking heat release in the chamber. But as hours accumulate and deposit material thickens, the peak levels decrease and the phasing becomes more and more retarded. Essentially, the fast response surface thermocouple is being insulated from the high temperatures of combustion. Since burn rates increase as deposits grow (see Fig. 1), the external surface temperature of the deposits appears to be increasing and insulating the charge from heat transfer. Estimations of the instantaneous temperature are being carried out; however the value depends on knowledge of the conductivity of the deposits which is unknown due to uncertainties in the properties. Current work is aimed at measuring the deposit conductivity in a custom made test facility. 


\section{Modeling and simulation tools for HCCI}

Coupled CFD/Kinetic Modeling - In an effort to understand the complex interactions of heat transfer, mixing, and ignition kinetics we have exercised a fully couple CFD/Kinetic model developed earlier to investigate the behavior of combustion rate and combustion efficiency near the combustion limits with particular attention paid to the role of heat transfer and internal temperature distribution. A parametric study was carried out of an initially uniform mixture compressed from intake valve closing, through ignition and the combustion process. Extensive data was gathered from over 400 simulations for variables such as engine speed, equivalence ratio, turbulence level, wall temperature and piston shape. Figure 4 shows pressure traces and corresponding combustion efficiencies for a typical timing sweep made by varying inlet temperature, at $1200 \mathrm{RPM}, \Phi=0.26,5 \% \mathrm{RGF}$, and $\mathrm{CR}=12.5$. The numbers identify three cases with high, medium and low combustion efficiency.

A plot of the maximum temperature distribution in the cylinder provides insight into how the combustion begins to fail under marginal conditions. Figure $4 \mathrm{c}$ shows the maximum temperature envelopes for the three cases. For the healthiest combustion case (1) the temperature distribution has a smooth shape and suggests a well developed boundary layer. For the other two cases $(2,3)$ there is a decided kink in the curves which appears to occur at or near the point of local ignition $(1000-1100 \mathrm{~K})$. This point is also close to a value of cumulative mass distribution equal to the amount unburned, i.e. (1-Comb. Eff/100). In this case it appears that locally, combustion is limited by ignition failure.

Combustion Correlation - The CFD generated results were used to develop a correlation of combustion burn rates and combustion efficiency (Babajimopoulos, 2009) that we have applied to a system studies of HCCI limit behavior (next section). This novel correlation is unique in that it includes not only the effect of main operating variables such as ignition timing, RPM, and equivalence ratio on burn rate variables but also includes the physically plausible finding that combustion efficiency is primarily a function of peak cylinder temperature. Ignition is described by a suitable autoignition integral.
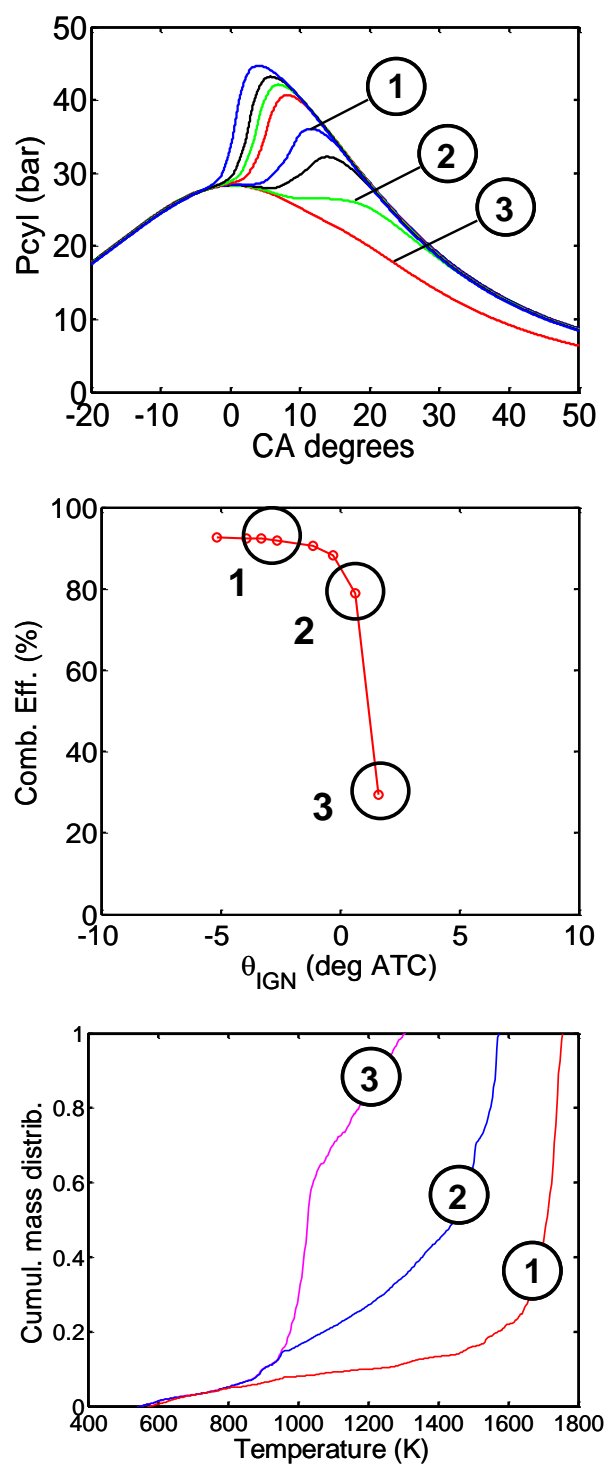

Fig. 4. Coupled CFD/kinetic results for an HCCI timing sweep; a) pressure traces; b) corresponding combustion efficiencies; c) corresponding maximum in-cylinder temperature distributions. Numbers identify three cycles with high, medium and low efficiency.

Ignition in the HCCI engine is predicted using an auto-ignition integral approach, originally proposed by Livengood and $\mathrm{Wu}$ (1955). In this approach, it is assumed that there is a product species that leads to 
ignition when a certain accumulated concentration is reached. The rate of production of this product species is defined by an ignition delay time, over which the critical concentration is reached at the conditions of interest. The expression for the ignition delay, $\tau$, is typically given in Arrhenius form:

$$
\tau=A \cdot P^{-a} \cdot \mathrm{e}^{\frac{E}{R \cdot T}}
$$

where $A$ is a pre-exponential factor that is a function of composition and temperature, $P$ is pressure, $T$ is temperature, $E$ is an activation energy, $R$ is the universal gas constant, and $\alpha$ is an exponent on the order of unity. Occurrence of ignition, $t_{I G N}$, is defined as the time when the auto-ignition integral reaches the value of 1:

$$
\int_{0}^{t_{I G N}} \frac{1}{\tau} d t=1
$$

The ignition delay expression used was developed by He et al. (2005), based on experiments in a rapid compression machine with iso-octane $/ \mathrm{N}_{2} / \mathrm{O}_{2}$ mixtures:

$$
\tau=1.3 \cdot 10^{-7} \cdot P^{-1.05} \cdot \Phi_{F O}{ }^{-0.77} \cdot \chi_{O_{2}}^{-1.41} \cdot \mathrm{e}^{\frac{33700}{R \cdot T}}
$$

where $P$ is pressure (atm), $T$ is temperature $(\mathrm{K}), \Phi_{F O}$ is the fuel/oxygen equivalence ratio, $\chi_{O_{2}}$ is the oxygen mole fraction (\%), $R$ is the universal gas constant (cal/mol/K), and $\tau$ is the ignition delay time (s). Note that EGR enters the equation indirectly through its effect on $\Phi_{F O}$ and $\chi_{O_{2}}$. To take into account differences in fuels we have introduced a temperature adjustment such that the temperature in Equation (3) is replaced by $T_{K I N}$ for kinetics:

$$
T_{K I N} \equiv T_{A V G}\left(1+\frac{\Delta T_{A D J}}{300}\right)
$$

This also reflects the fact that the average cylinder temperature employed in the simulation does not represent the maximum local temperature where ignition would take place. This calibration adjustment is made once for a given fuel and engine. Typically, the value for $\Delta T_{A D J}$ is about $10-20 \mathrm{~K}$.

Once the ignition timing is determined, the heat release curve and combustion efficiency are estimated using correlations developed at the University of Michigan based on analysis of the extensive parametric sweeps noted above using KIVA-3V-MZ. Specifically the effects of key parameters, such as equivalence ratio, residual gas fraction level, engine speed. The results were compiled and analyzed and correlations were developed that capture the key HCCI combustion characteristics as a function of ignition timing, composition, engine speed.

Over the range of parameters $(0.2<\Phi<0.6,750<\mathrm{RPM}<4000$, and $0<\mathrm{RGF}<40 \%)$, analysis of the results showed that the most important factors determining burn rate characteristics were ignition timing $\theta_{i g n}$ because of the volume effect, equivalence ratio $\Phi$ because of its effect on burned gas temperature, and $R P M$ because of kinetics effects. 
It was found that the combustion data could be scaled by RPM and equivalence ratio to generate well defined relationships suitable for curve fitting as indicated in Figures 5 and 6 . The results also showed that the effect of residual gas could be included by using a modified definition of equivalence ratio, $\Phi$, i.e.

$$
\Phi^{\prime} \equiv \Phi(1-R G F)
$$

where RGF is the residual gas fraction. The new parameter $\Phi^{\prime}$ represents the energy density of the charge and is used in the correlations. Figure 5

Figure shows the relationship defining the $0-50 \%$ burn interval $\left(\theta_{0-50}\right)$ vs. ignition timing $\left(\theta_{I G N}\right)$, scaled by RPM and $\Phi^{\prime}$ :

$$
\theta_{0-50}=f_{1}\left(\theta_{I G N}\right)\left(\frac{R P M}{2000}\right)^{0.3}\left(\frac{\Phi^{\prime}}{0.3}\right)^{-1.5}
$$

Figure 6 defines the $0-90 \%$ burn interval $\left(\theta_{0-90}\right)$ vs. location of $50 \%$ heat release $\left(\theta_{50}\right)$, scaled by $\Phi^{\prime}$ :

$$
\theta_{0-90}=f_{2}\left(\theta_{50}\right)\left(\frac{\Phi^{\prime}}{0.3}\right)^{-1.1}
$$

Together, the two relationships in these figures define the $50 \%$ and $90 \%$ heat release points, once the ignition crank angle $\left(\theta_{I G N}\right)$ is determined by the ignition delay integral.

Since the crank angles of 50\% and $90 \%$ heat release refer to the total amount of energy released, the combustion efficiency must be known in order to define the energy release on an absolute basis. For the same range of data used for the burn data, a very good correlation was found for combustion efficiency as a function of peak mean cylinder temperature, as shown in Figure . Below a $T_{\text {peak }}$ of $1500 \mathrm{~K}$, the combustion efficiency falls off rapidly. This behavior is similar to that observed and modeled by Sjöberg and Dec (2005) and appears to be due to the failure of $\mathrm{CO}$ to $\mathrm{CO}_{2}$ conversion at low temperatures. By curve fitting the relationship shown in Figure, the combustion efficiency, $\eta_{c o m b}$, may be represented by:

$$
\eta_{\text {comb }}=f_{3}\left(T_{\text {peak }}\right)
$$

In order to supply the simulation with the required fuel mass fraction burned $x_{b}$, at each crank angle, a Wiebe function is used:

$$
x_{b}=\eta_{c o m b} \cdot\left[1-\mathrm{e}^{\left(-\left(\frac{\theta-\theta_{I G N}}{\Delta \theta}\right)^{W+1}\right)}\right]
$$

where $W$ and $\Delta \theta$ are determined by fitting the burn curve through the $50 \%$, and $90 \%$ burned points. 


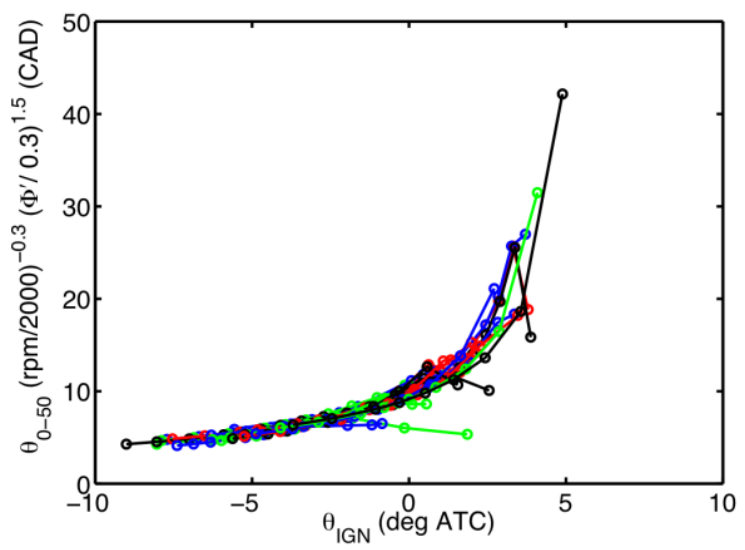

Figure 5. Plot of location of $0-50 \%$ burn duration $\left(\boldsymbol{\theta}_{\mathbf{0}-\mathbf{5 0}}\right)$, scaled by RPM and $\boldsymbol{\Phi}^{\prime}$, vs. ignition timing $\left(\boldsymbol{\theta}_{I G N}\right)$

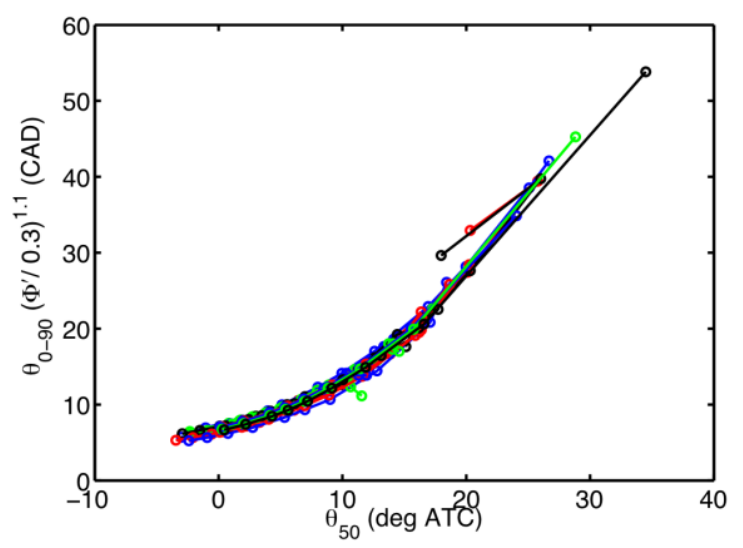

Figure 6. Plot of 0-90 burn duration $\left(\boldsymbol{\theta}_{\mathbf{0}-\mathbf{9 0}}\right)$, scaled by $\boldsymbol{\Phi}^{\prime}$, vs. location of $50 \%$ heat release $\left(\boldsymbol{\theta}_{50}\right)$

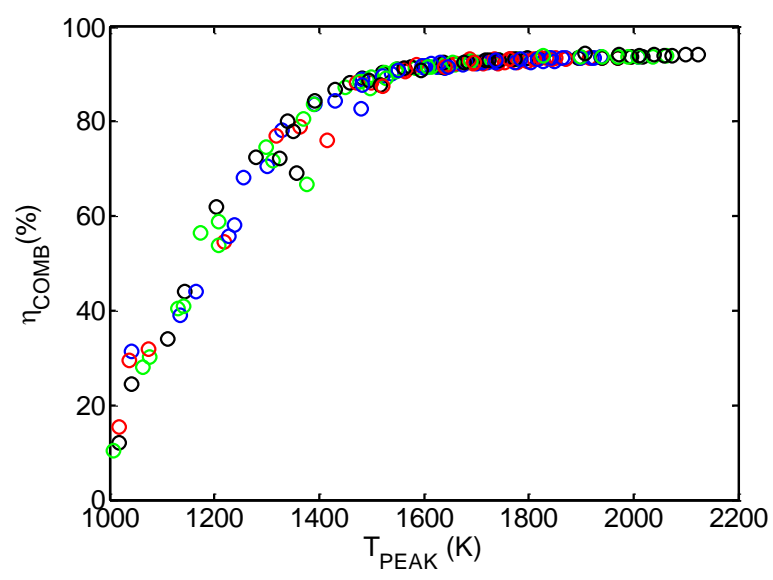

Figure 7. Plot of combustion efficiency $\left(\boldsymbol{\eta}_{\text {comb }}\right)$ vs. mean peak temperature $\left(\boldsymbol{T}_{\text {peak }}\right)$ 
GT-Power® based engine model - The combustion correlation was incorporated into a GT-Power® based engine model and combines in a computationally efficient way, the chemically determined combustion limits, as well as the engine features which determine the thermodynamics. A knock model and a NOx model were also added to the engine system model to account for roughness and emission constraints.

The model has been used to explore the load limits of several valve timing strategies for internal EGR. Figure 8 shows the limit behavior of two strategies for providing residual gas fraction (RGF) control: the first employs recompression or negative valve overlap; the second uses rebreathing enabled by a second exhaust valve event, open during the normal intake stroke. The figure shows NMEP phasing sweeps for a number of fueling levels at $2000 \mathrm{rpm}$.

(a) RECOMPRESSION

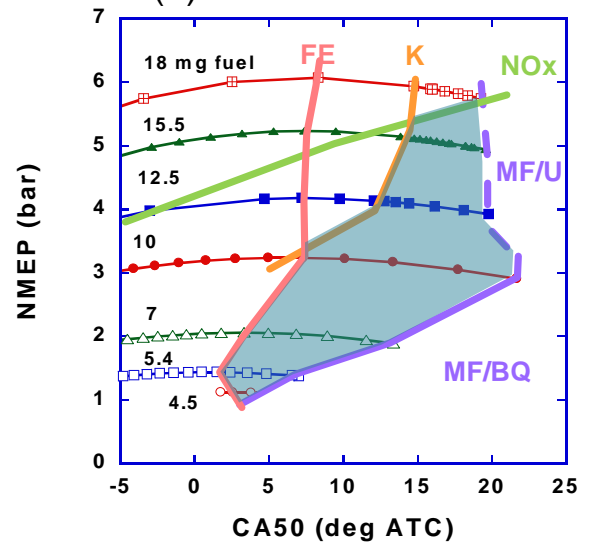

(b) REBREATHING

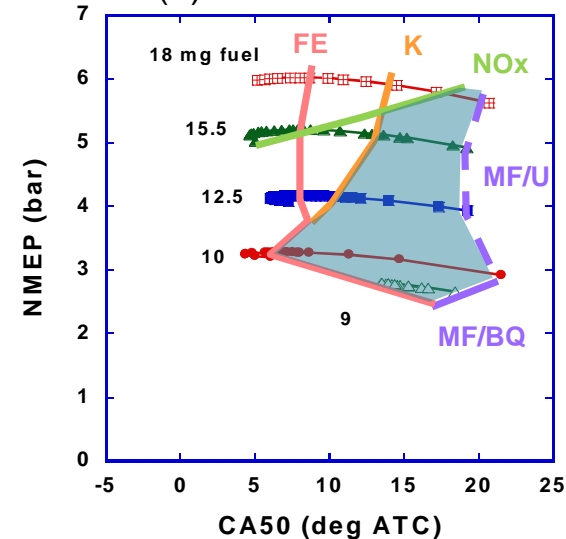

Fig. 8. Calculated NMEP timing sweeps for two valve strategies: (a) recompression, and (b) rebreathing, for different fueling levels using UM combustion correlation. Constraints for fuel economy (FE), knock (K), NOx, misfire/unstable (MF/U), and misfire/bulk quench (MF/BQ) define the region of viable operation for each strategy.

Superposed on the NMEP curves are a number of limit lines. The line labeled FE denotes the phasing for best fuel economy for the particular fueling employed. The knock and NOx constraint lines are labeled $\mathrm{K}$ and NOx, respectively. In general these limit the maximum upper load achieved. At any given condition as the combustion is retarded, misfire eventually develops. At higher loads this appears first as unstable operation in which the cycles oscillate between strong and weak combustion. Eventually full misfire develops. This misfire, unstable limit is denoted by the dashed line labeled MF/U. At low loads the unstable behavior does not appear before misfire and bulk quench occurs. This solid line is indicated by MF/BQ. Together these lines define the regions for viable HCCI operation, shown shaded.

Figure 8 shows that in this case, the upper limits are similar for the two strategies while the lower limits are much reduced for the rebreathing strategy due to the excessive heat losses sustained by the re-inducted exhaust gas which is in contact with the exhaust port and pipe walls. Based on studies of other valve strategies, these results are not general and are sensitive to the details of the valve strategy such as effective compression ratio, pumping work, and heat transfer. Currently, additional strategies are being evaluated. 
Application to turbocharged engines - In modeling work focused on high load limits, we have extended the GT Power@ based model to include a simplified turbocharger model which assumes fixed efficiencies for compression and expansion. Three calculated load sweeps are shown in Fig. 9 for manifold pressures of 1.1, 1.5 and 2.0 bar. As indicated in the figure, turbocharging to $2.0 \mathrm{bar}$ can potentially raise the load limit to near 8 bar NMEP. The figure also shows that for low loads, higher turbocharging is less efficient. In general our work with the model indicates that the high load limit is complicated by a number of factors such as the NOx constraint, the knocking constraint, as well as breathing limitations either for fresh charge or for internal EGR. The result is that conclusions are specific to each particular engine valve arrangement and external thermal assumptions. In our future work we will use the model to further identify and quantify the fundamental combustion limitations and link them to the external design parameters to better assess potential implementation schemes.

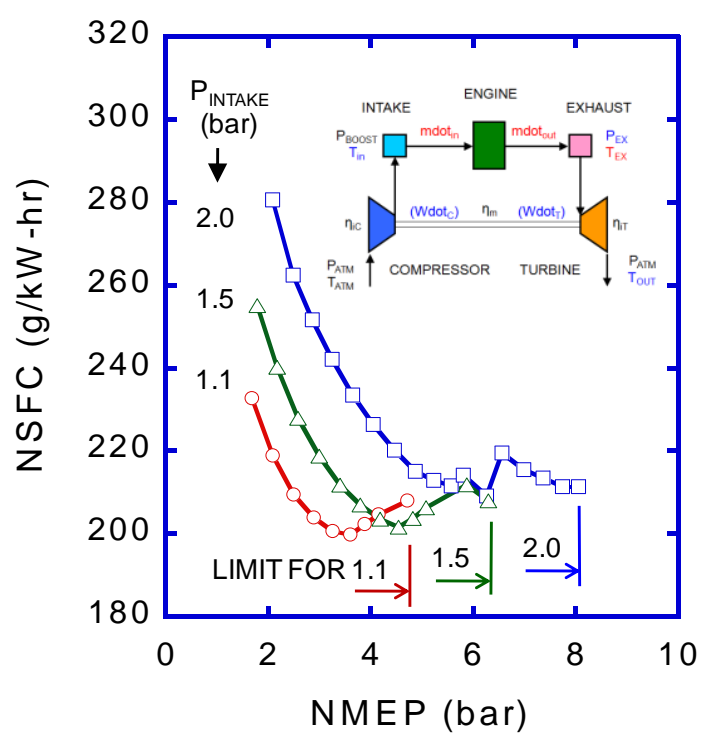

Fig. 9. Predicted high load limits and fuel economy using an idealized turbocharger, as computed by the GT Power HCCI model with UM developed combustion model.

\section{References}

Guralp, O. A., et al. (2006) Characterizing the Effect of Combustion Chamber Deposits on a Gasoline HCCI Engine. SAE Paper No. 2006-01-3277.

He, X., Donovan, M.T., Zigler, B.T., Palmer, T.R., Walton, S.M., Wooldridge, M.S., and Atreya, A., (2005), "An Experimental and Modeling Study of Iso-octane Ignition Delay Times at Homogeneous Charge Compression Ignition Conditions," Combustion and Flame, 142(3), pp. 266-275.

Livengood, J.C., and Wu, P.C., (1955), "Correlation of Autoignition Phenomena in Internal Combustion Engines and Rapid Compression Machines," Proceedings of the Combustion Institute, 5, pp. 347356.

Sjöberg, M., and Dec, J.E., (2005), “An Investigation Into Lowest Acceptable Combustion Temperatures for Hydrocarbon Fuels in HCCI Engines." Proceedings of the Combustion Institute, 30(2), pp. 27192726. 


\section{Task 2: Improving combustion stability and reducing emissions at low load (UM)}

Objective: This task will carry out analytical investigations with an integrated CFD-multi-zone model to investigate the effect on combustion rate and combustion efficiency near the limits of stability. The focus will be on the degree and quality of compositional stratification and temperature distributions which has been shown to be key factors affecting ignition and combustion at near-idle conditions.

The work in this task was divided up into two main parts: the first is concerned with computational modeling of autoignition and combustion behavior in low temperature combustion engine environments; the second is numerical modeling of DI/PPCI in low temperature combustion engines to extend the low load limit. These efforts will be described below.

\section{Computational Modeling of Autoignition and Combustion Behavior in Low Temperature Combustion Engine Environments}

Computational studies are performed to obtain an in-depth understanding of the fundamental characteristics of autoignition and subsequent combustion behavior under conditions relevant to Low Temperature Combustion (LTC) engines. Models of various levels of complexity are employed, ranging from a homogenous zero-dimensional (0-D) model to one-dimensional (1-D) counterflow configuration to high-fidelity two-dimensional (2-D) direct numerical simulations (DNS).

\section{Autoignition response to flow/scalar fluctuations}

1. Autoignition of homogeneous $\mathrm{H}_{2}$-air mixture subjected to unsteady temperature fluctuations [1] - As a first step, a homogeneous constant-volume ignition of hydrogen-air mixture subjected to imposed sinusoidal oscillation in the temperature is investigated. Relevance of such a simplified model to practical LTC engine application can be justified based on the following aspects. For both premixed and nonpremixed systems, the ignition kernel can be approximated as a homogeneous mixture pocket subjected to heat and mass transport with the surroundings; such that the subsequent evolution of the ignition event may be described by a Lagrangian description of an ignition kernel whose uniform thermodynamic conditions undergo temporal variations during the ignition delay period. Among the many thermodynamic variables, temperature is chosen in this study because reaction is most sensitive to temperature. In IC engine applications, the time-varying temperature may also represent the isentropic heating of the combustion chamber during the compression stroke. Hydrogen-air mixture is chosen because of the following two reasons. First, hydrogen can be blended into gasoline, diesel and other alternative fuels as a means to control ignition, combustion and pollutant formation characteristics of the engine. Secondly, the ignition chemistry of hydrogen-air mixture is well understood and forms the building block in understanding more complex hydrocarbon fuels. Parametric studies are conducted to examine the unsteady ignition characteristics of hydrogen-air mixture in response to the imposed sinusoidal temperature oscillations at various frequencies. The resulting system with detailed chemistry and thermodynamic properties are integrated numerically. In addition, analytic closed-form solutions are also obtained using activation energy asymptotics. Fig. 1 shows the plot of non-dimensional ignition 
delay as a function of non-dimensional frequency. It is observed that ignition delay $\left(t_{i g n}\right)$ shows a harmonic response to the frequency $(f)$ of imposed temperature fluctuation and the response monotonically attenuates as frequency increases. Also, closed form results obtained from asymptotic analysis closely match results of direct computation. Fig. 2 shows the ignition delay response at different initial pressures: $\mathrm{p}=10,15,20$, and $25 \mathrm{~atm}$, for which the reference ignition delay is found to be 14.34, 12.05, 10.29, and $8.975 \mathrm{msec}$, respectively.

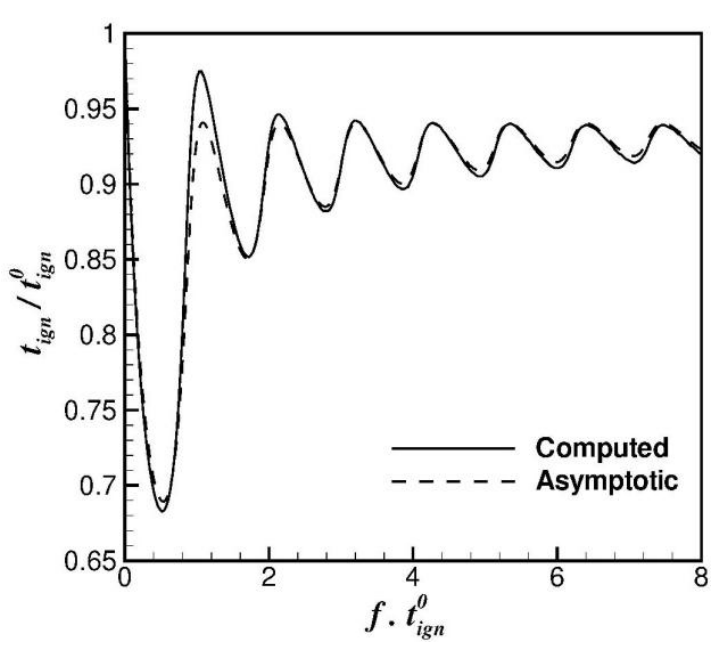

Fig. 1 Ignition delay response to frequency. Initial pressure $10 \mathrm{~atm}$.

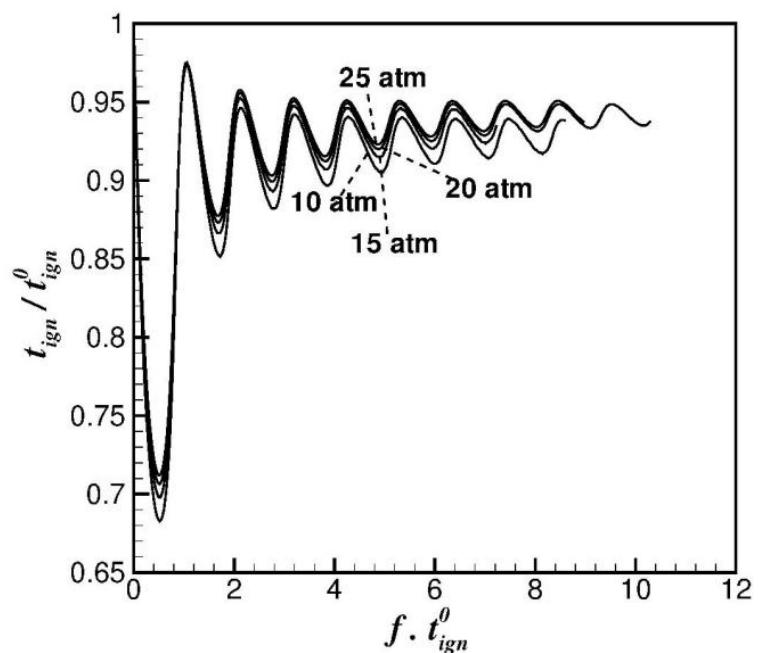

Fig. 2 Ignition delay response at various pressures.

2. Autoignition of nonpremixed fuel-air subjected to unsteady scalar dissipation rate $[2,3]$ Next, to understand the autoignition behavior in response to the flow turbulence, the effects of scalar dissipation rate $(\chi)$ fluctuations on the ignition of nonpremixed fuel-air is studied in a 1-D counterflow configuration. Firstly, nonpremixed hydrogen-air autoignition is studied. Response of the ignition delay to the frequency of the $\chi$ oscillation is found to be highly non-monotonic with distinct behaviors in low-, intermediate-, and high-frequency regimes of $\chi$ fluctuation. Fig. 3 shows the plots of ignition delay and mean scalar dissipation rate $(\bar{\chi})$ in the induction period, as a function of frequency. It is observed that for very low and very high frequencies (regions I and III in the figure) ignition delay response is quasi-steady in that the mean scalar dissipation rate $(\bar{\chi})$ correlates well with the ignition delay in that frequency range. To characterize ignition response in the intermediate frequency range (region II) a newly defined ignitability parameter is proposed based on the ignition kernel Damkohler number such that all the unsteady effects can be uniquely mapped to this parameter. $n$-Heptane, which exhibits a two-stage ignition behavior is studied next using similar configuration. Fig. 4 shows a plot of maximum temperature in the domain as a function of time for different values of scalar dissipation rate at stoichiometric mixture fraction $\left(\chi_{\mathrm{st}}\right)$, for steady $\chi$ conditions. As can be seen in Fig. 4, the first-stage ignition is found to be insensitive to variation in $\chi_{\mathrm{st}}$, while the second-stage ignition is affected significantly. Similar to hydrogen case, the response of the ignition delay to frequency of $\chi$ fluctuation is found to be highly non-monotonic, and the same ignitability parameter is used to characterize the unsteady ignition response. 
Interestingly, two-stage ignition is observed even at significantly high initial temperatures $(\mathrm{T}=920 \mathrm{~K})$ when the ignition kernel is subjected to unsteady $\chi$. This can be observed in Fig. 5, which shows the plot of maximum temperature time history for various frequencies of $\chi$ fluctuation. Mechanism for two-stage ignition at high temperatures in unsteady $\chi$ conditions is found to be not chemical (as in homogeneous systems), but is attributed to the spatial broadening of the ignition kernel and subsequent radical losses.

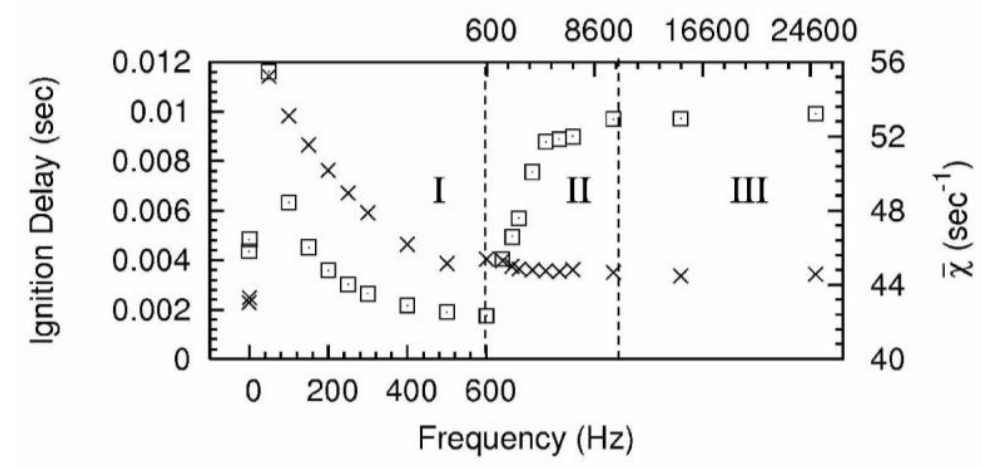

Fig. 3 Ignition delay $(\tau)$ and $\bar{\chi}(\times)$ as a function of frequency.

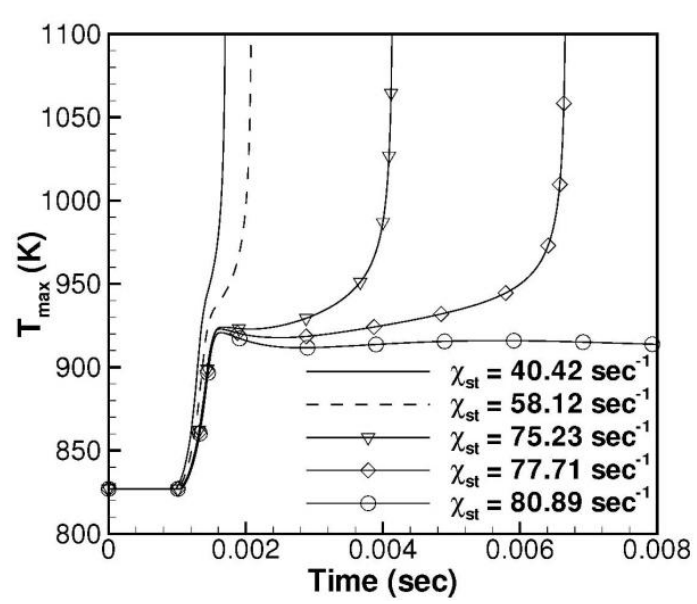

Fig. 4 Maximum temperature history for different values of $\chi_{\mathrm{st}}$

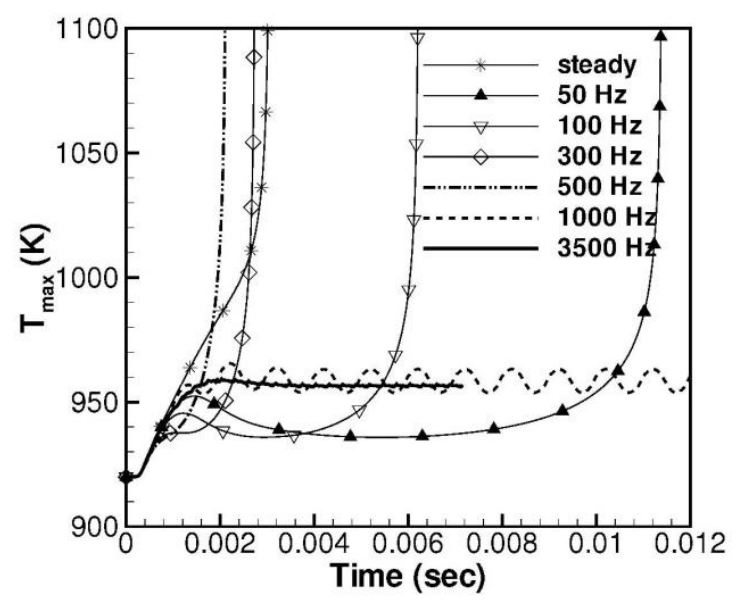

Fig. 5 Maximum temperature history for different frequencies

\section{DNS investigation of autoignition and front propagation in LTC enivronments}

1. Kiva Simulations [4]

First, non-reacting 3D engine simulations are conducted using Kiva-3v to investigate different mixture formation scenarios that might exist in LTC engines prior to autoignition. Effects of start of injection (SOI) timing on mixture formation characteristics close to TDC are investigated. Figs. 6 (a) and (b) show the scatter plots of evaporated fuel mass fraction vs. temperature, within the engine cylinder, for SOI of 270 bTDC and 90 
bTDC, respectively. The scatter plots are shown at 15 bTDC. It is clearly seen that early SOI results in a largely uncorrelated fuel mass fraction - temperature fields, whereas, late SOI results in a negatively-correlated fuel mass fraction - temperature fields, prior to autoignition.

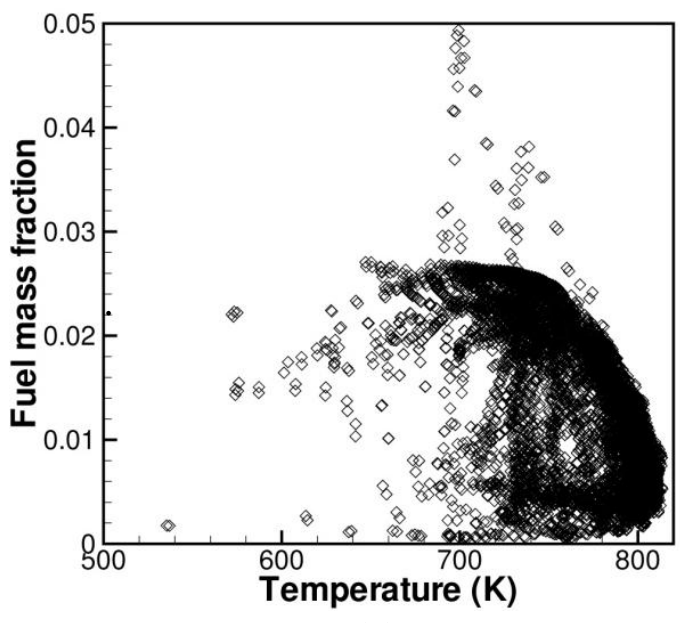

(a)

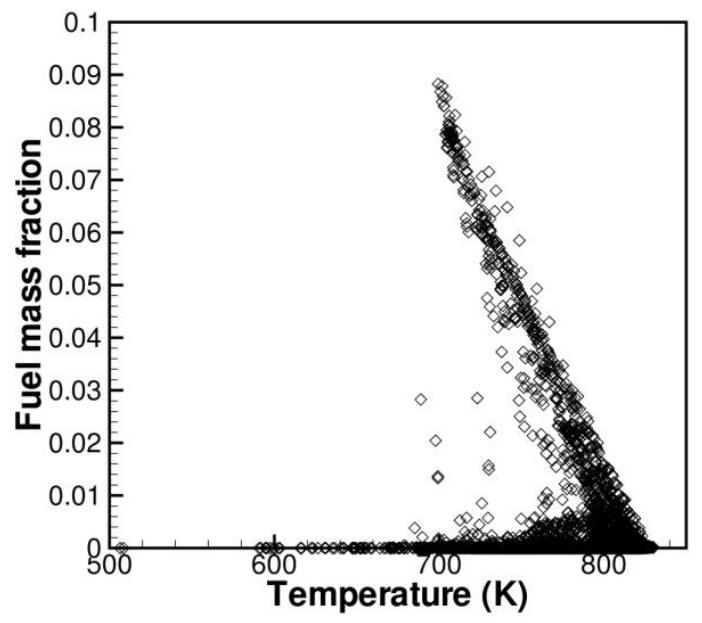

(b)

Fig. 6 Scatter plot of fuel mass fraction vs. temperature at 15 bTDC. (a): SOI $=270$ bTDC, (b): SOI $=90$ bTDC.

2. DNS Results [4,5]

Small-scale effects of different mixture formation scenarios observed in \#1 above on the autoignition and subsequent front propagation are then studied using high-fidelity 2D direct numerical simulation (DNS). To reduce computational cost, hydrogen is used as a fuel. DNS is initialized as follows. Turbulence spectrum is imposed on the zero initial mean flow velocities. Random temperature $(T)$ and equivalence ratio $(\Phi)$ distribution is imposed on the mean fields. Initially mean temperature, mean equivalence ratio, and pressure are fixed to $1070 \mathrm{~K}, 0.1$, and 41 atm, respectively. Three different cases: case (A) uniform $\Phi$ field, case (B) uncorrelated T- $\Phi$ fields, and case (C) negatively-correlated T$\Phi$ fields are studied. Fig. 7 shows the initial temperature field, which is same for all the three cases. Fig. 8 shows the scatter plot of initial T- $\Phi$ fields for the three cases.

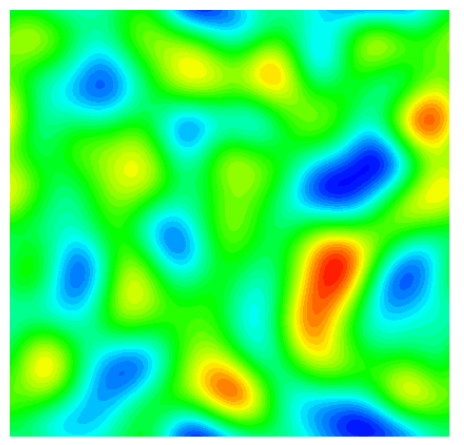

Fig. 7 Initial temperature field for DNS. Levels ranging from $1033 \mathrm{~K}$ (blue) to $1116 \mathrm{~K}$ (red). 


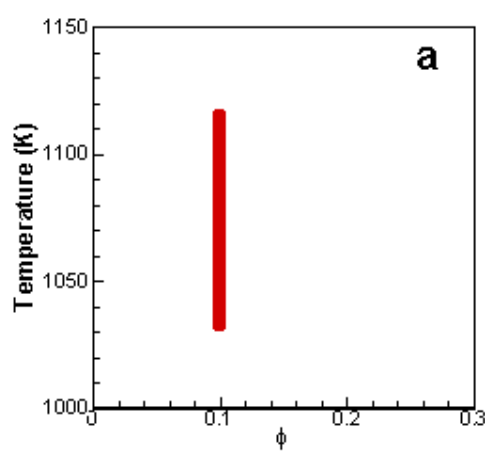

(a)

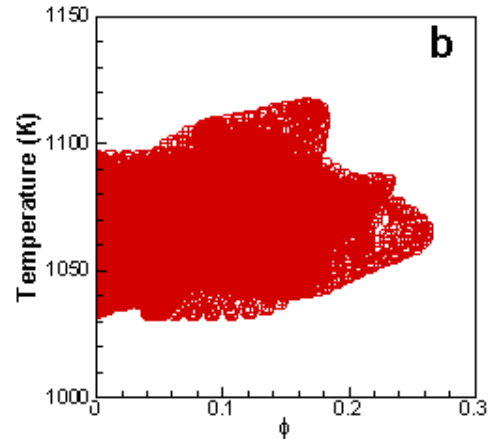

(b)

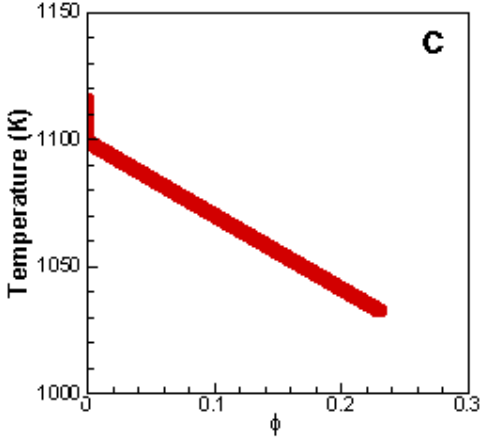

(c)

Fig. 8 Initial T- $\Phi$ scatter plots: (a) case (A), (b) case (B), and (c) case (C).
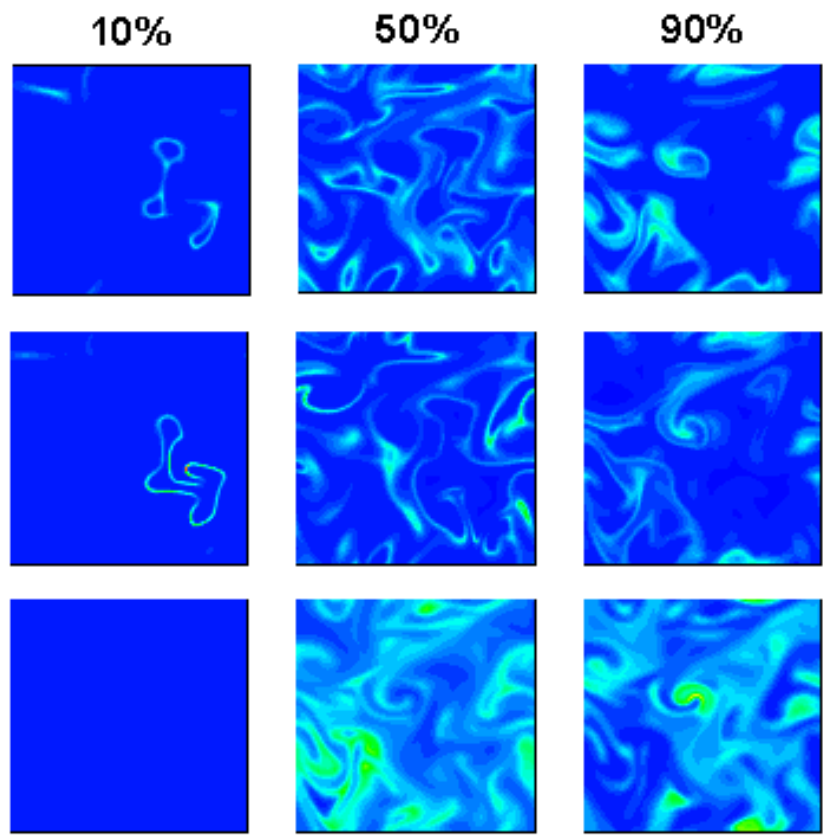

Fig. 9 Heat release rate fields at time instants corresponding to $10 \%, 50 \%$ and $90 \%$ of total heat release. Top row: case (A), middle row: case (B), and bottom row: case (C). Levels ranging from low (blue) to high (red).

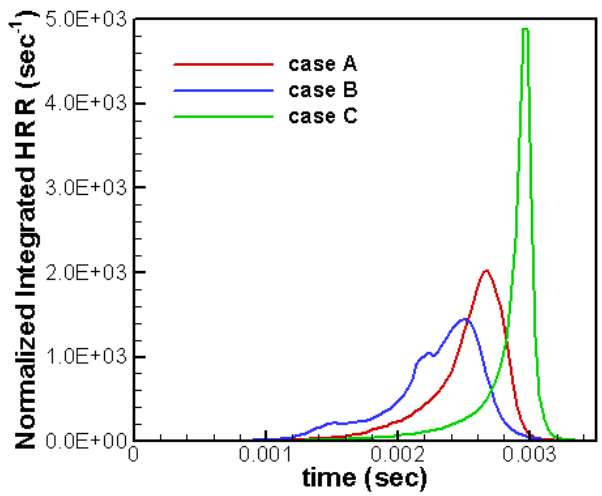

Fig. 10 Normalized integrate heat release rate as a function of time for the three cases 
Fig. 9 shows the heat release rate (HRR) fields at time instants corresponding to $10 \%, 50 \%$ and $90 \%$ of total heat release. While cases (A) and (B) show presence of thin front-like propagation, a more homogeneous ignition like behavior is observed for case (C). Fig. 10 shows the spatially integrated heat release rate normalized by total heat release as a function of time. Ignition delay is increased for case (C) and reduced for case (B), compared to case (A). To decipher whether the front observed is a spontaneous ignition front or a premixed flame, numerical diagnostics are developed based on a Damkohler number. Fig. 11 shows the results. In this figure black contours correspond to spontaneous ignition front propagation and gray contour correspond to premixed flame propagation. Color field in the background is HRR. Regions of high HRR where no contour is overlaid are homogeneous ignition regions.

$10 \%$
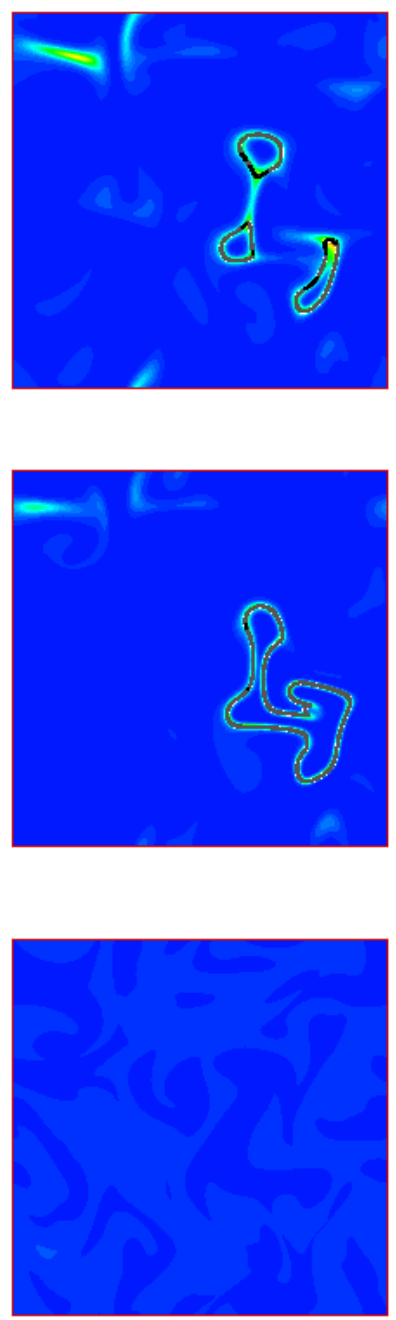

$30 \%$
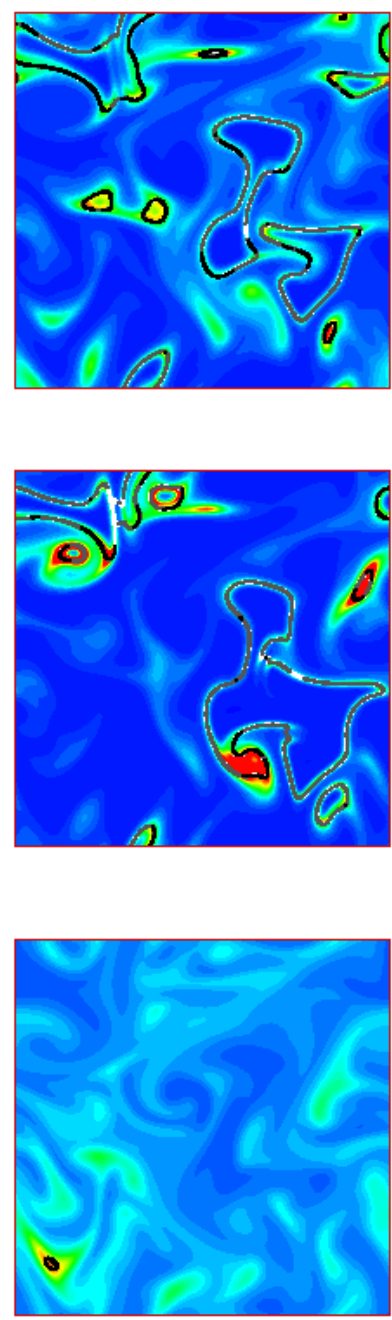

$50 \%$
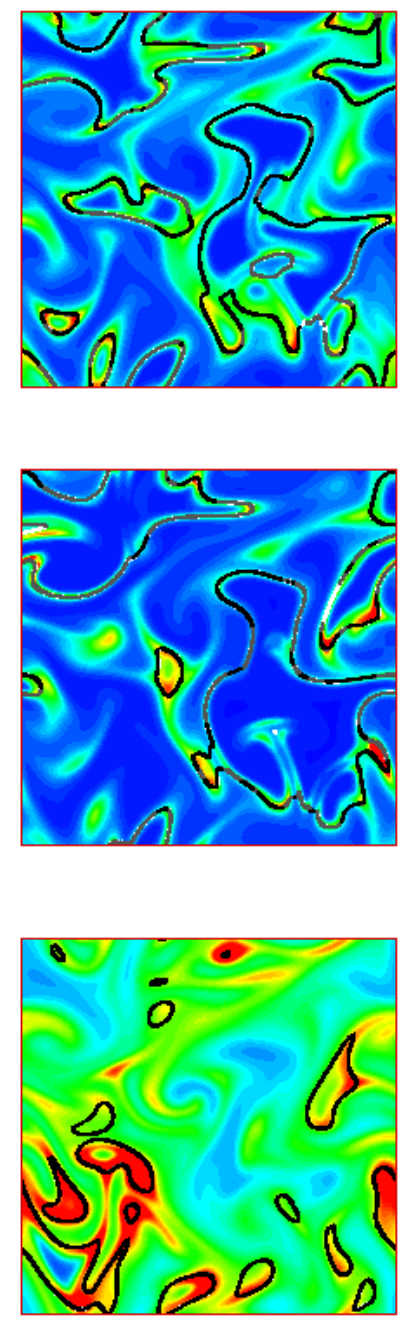

Fig. 11 Results shown at time instants corresponding to $10 \%, 30 \%$ and $50 \%$ of total heat release. Top row: case (A), middle row: case (B), and bottom row: case (C). HRR (color field), levels ranging from low (blue) to high (red). Gray contour: premixed flame; black contour: spontaneous ignition front. 


\section{Principal Component Analysis on high-fidelity DNS data [6]}

A novel principal component analysis (PCA) based approach is used to identify intrinsic low-dimensional manifolds in the complex autoigniting system. PCA is applied to DNS database of autoignition in inhomogeneous mixtures (\#2 above). Fig. 12 shows the plots of reactive scalars as a function of first two principal components $\left(\mathrm{p}_{1}\right.$. and $\left.\mathrm{p}_{2}\right)$. It is observed that only these two principal components very well parameterize all the reactive scalars; the scatter within any color is observed to be small. PCA is thus found to be a useful technique to reduce the chemical complexity of the autoignition system. A PCA based turbulent combustion closure model for autoignition in inhomogeneous mixtures is currently under development.

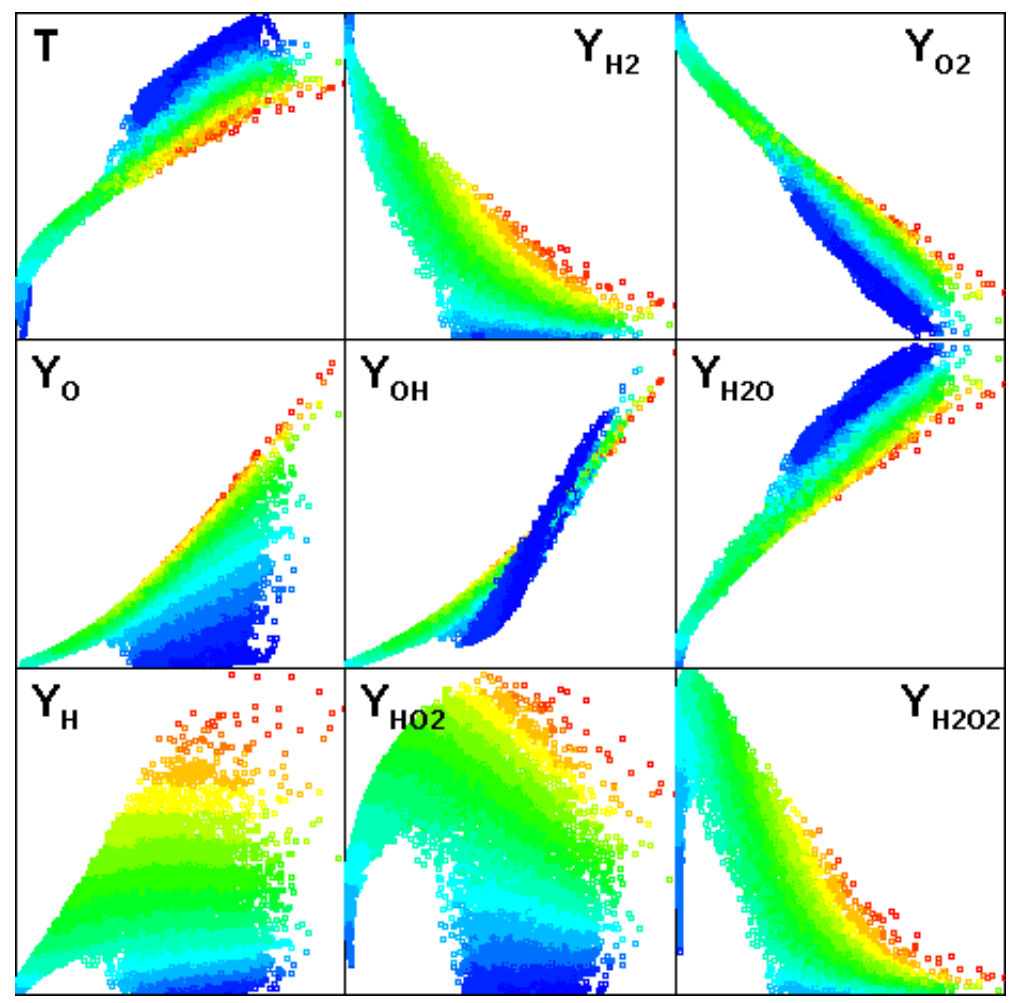

Fig. 12 Parameterization of reactive scalars using $\mathrm{p}_{1}$. and $\mathrm{p}_{2}$. The horizontal axis in all the figures is $\mathrm{p}_{1}$ and the vertical axis is the indicated reactive scalar. The color represents $\mathrm{p}_{2}$, with values increasing from blue to red. 


\section{References:}

[1] Bansal G., Im H. G., and Lee S. R, Autoignition of Homogeneous Hydrogen/Air Mixture subjected to Unsteady Temperature Fluctuations, Combustion Theory and Modelling (in press) (2009).

[2] Bansal G., Im H. G., and Lee S. R., Effects of Scalar Dissipation Rate Fluctuations on Autoignition of Hydrogen-Air Mixture, AIAA Journal, v. 47, No. 2, pp. 468-472 (2009).

[3] Bansal G., Im H. G., and Lee S. R., Autoignition of Nonpremixed n-Heptane Counterflow subjected to Unsteady Scalar Dissipation Rate, Proceedings of the Combustion Institute, v. 32, pp. 1083-1090 (2009).

[4] Bansal G. and Im H. G., Autoignition of Hydrogen-Air Mixture with Temperature and Composition Inhomogeneities, AIAA Paper 2009-1559, $47^{\text {th }}$ AIAA Aerospace Sciences Meeting and Exhibit, January 58, 2009, Orlando, FL

[5] Bansal G. and Im H. G., Direct Numerical Simulation of Autoignition and Front Propagation in Hydrogen-Air Mixture with Thermal and Compositional Inhomogeneities, Proceedings of the $6^{\text {th }}$ US National Combustion Meeting, May 17 - 20, 2009, Ann Arbor, MI

[6] Bansal G., Im H. G., and Sutherland J. C., Modeling of Autoignition in Inhomogeneous Turbulent Mixtures using Principal Component Analysis, Proceedings of the $6^{\text {th }}$ US National Combustion Meeting, May 17 - 20, 2009, Ann Arbor, MI 


\section{Task 2. (Cont'd) Numerical Modeling of DI/PPCI in Low Temperature Combustion Engines to Extend the Low Load Limit}

HCCI (Homogeneous Charge Compression Ignition) engines have shown promise in reducing both $\mathrm{NO}_{\mathrm{x}}$ and soot emissions while retaining efficiency. However, the operating range of an HCCI engine is limited by knock at high load conditions, and by combustion instability and misfire at low load conditions. The current study aims to suggest a strategy for low load limit extension along with a well-developed numerical model. Stratification of the in-cylinder charge using direct injection has been investigated as a possible extension strategy. A spray combustion model, which can predict wide range of stratification level with the effect of evaporation, is proposed for modeling combustion. Simulation of stratified combustion with different level of incylinder charge stratification using direct injection has been conducted to examine the effect of charge stratification on combustion.

\section{Model development}

Under conventional HCCI engine operating conditions, it has been assumed that in-cylinder combustion is controlled only by chemistry, with no turbulence interaction. A number of multidimensional numerical models $[3,4]$ have been suggested based on the assumption of chemistryturbulence separation. However, such assumption may not represent HCCI with direct injection, or PPCI (Partially Premixed Charge Combustion), which is the main objective of the current research. Under DI/PPCI conditions, droplets with high velocity interact with in-cylinder charge to increase the turbulence. As a result, a turbulence-chemistry closure mode is required for numerically modeling DI/PPCI.

In this research, the flamelet model of Peters [5] was chosen as the numerical modeling framework. The flamelet model, commonly referred to as the RIF (Representative Interactive Flamelet) model, enables separate consideration of chemistry and turbulence. Details of the classic RIF approach can be found in [5], and only modifications to the classic RIF model regarding spray combustion will be described.

In the classic RIF approach, the effect of spray evaporation on the reaction space has been ignored. However, in the current study in DI/HCCI case, the fuel species may experience partial reaction during the injection period, which should be considered for accurate prediction of the combustion phenomenon. For the purpose, the effect of evaporation in the reaction space should be considered as well as turbulent combustion. Governing equations in the RIF approach have been re-drived considering the spray evaporation term $\dot{\rho}_{l}$ in the species conservation equation and the $\tilde{Z}$ conservation equation as [5]. The flamelet equation, or the reaction equation, was re-derived following the coordinate-transformation methodology described in [6]. The re-drived equation is shown below.

$$
\rho \frac{\partial Y_{i}}{\partial t}+\dot{\rho_{Z}} \frac{\partial Y_{i}}{\partial Z}=\rho \frac{\chi}{2} \frac{\partial^{2} Y_{i}}{\partial Z^{2}}+\dot{\rho}_{\iota}+\omega_{i}
$$

Two additional terms to the classic flamelet equation have been identified by considering the effect of spray source terms in the reaction space. A convection-like term on the LHS determines 
the amount of fuel at given $Z$ value before the vaporization, while the spray source term on the RHS accounts for the amount of added fuel by evaporation. Consideration of these two terms provides fuel amount properly reflecting the change by evaporation in the reaction space, by adding fuel amount before evaporation and fuel amount added by evaporation. By considering these two additional terms, the evaporation history can be properly accounted in the reaction space.

The proposed model has been implemented into a multi-dimensional CFD solver, KIVA3v. The current version of KIVA3v has been modified in the W. E. Lay Automotive Laboratory in the University of Michigan, which includes implementation of the Wave breakup model [7] for accurate modeling of high pressure injection. The CFD code has been further modified to have the flamelet approach with evaporation source terms implemented by solving $\tilde{Z}$ and ${\widetilde{Z^{\prime \prime}}}^{2}$ conservation equations in the physical space, instead of species conservation equations. The CFD solver also determines turbulence and evaporation variables required in the reaction solver, such as pressure, scalar dissipation rate $\chi$, and evaporation source term $\dot{\rho}_{l}$.

The chemistry information $Y_{i}(Z)$ is stored in the reaction space and updated at each time step by solving the reaction solver. The reaction solver considers both the effect of droplet evaporation, and the chemical reaction including ignition and turbulent combustion. An ODE solver was integrated into the reaction solver with Chemkin to solve chemical kinetics. A code flowchart is shown in Figure 1.

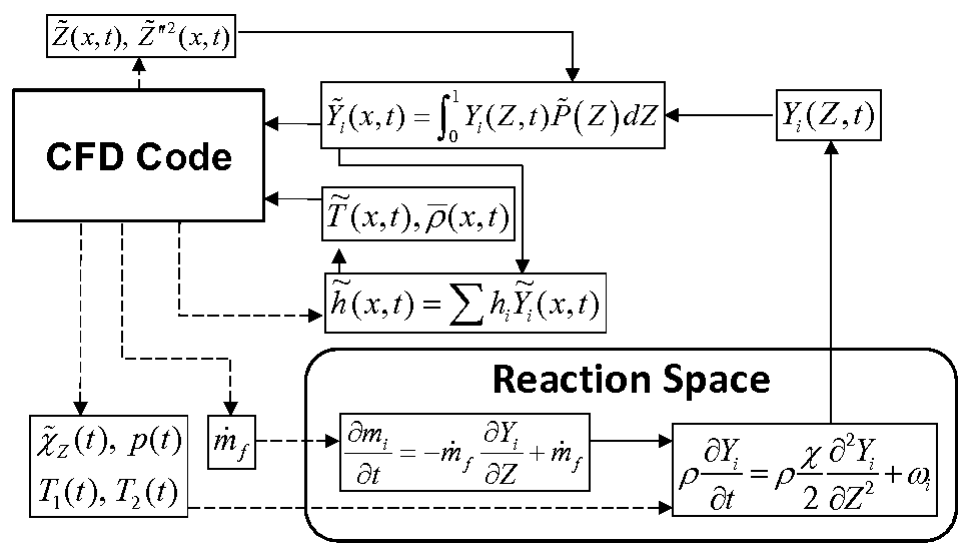

Figure 1 Code Flow Chart

\section{Validation Study}

The proposed model was validated against the experimental study of Akiyama et al. [1], where a Rapid Compression Machine (RCM) with an injector was used to study spray combustion in a diesel-like environment. A schematic diagram of the RCM experimental setup is shown in Figure 2 at the end of compression stroke. A fuel injector is attached to the side wall of the RCM combustion chamber for direct injection.

Numerical experiments were carried out to reproduce the experimental observation using the proposed model. The fuel species was modeled as h-heptane based on the cetane number 
similarity. A reaction mechanism for n-heptane with 46 species, which was suggested by Liu [8], was used to model the chemical kinetics.

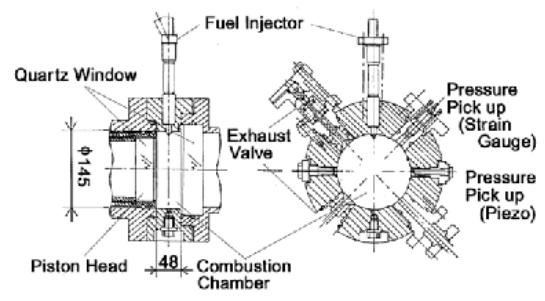

Figure 2 RCM Schematic

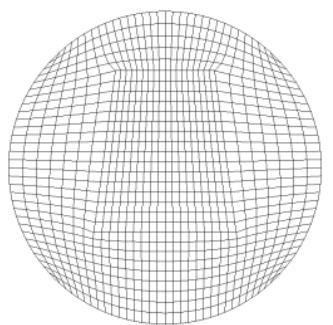

Figure 3 Computational mesh of RCM

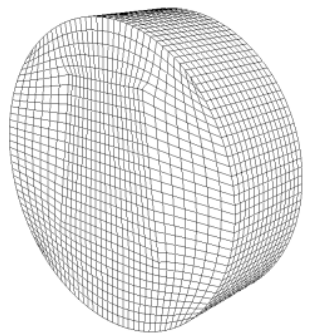

M

A three-dimensional computational mesh was prepared for the numerical study, as shown in Figure 3. The computational mesh has grid points concentrated along the spray path for modeling the spray penetration.

The pressure histories are shown in Figure 4. The experimental data is plotted in a dotted line, while numerical results are shown in the solid line. For comparison purpose, the result from the classic RIF model without evaporation source terms is also shown in Figure 4 using a dashed line. The RIF model with evaporation source terms will be referred to as SIRD model (SprayInteractive Reduced Dimension mapping) for distinction from the classic RIF model.

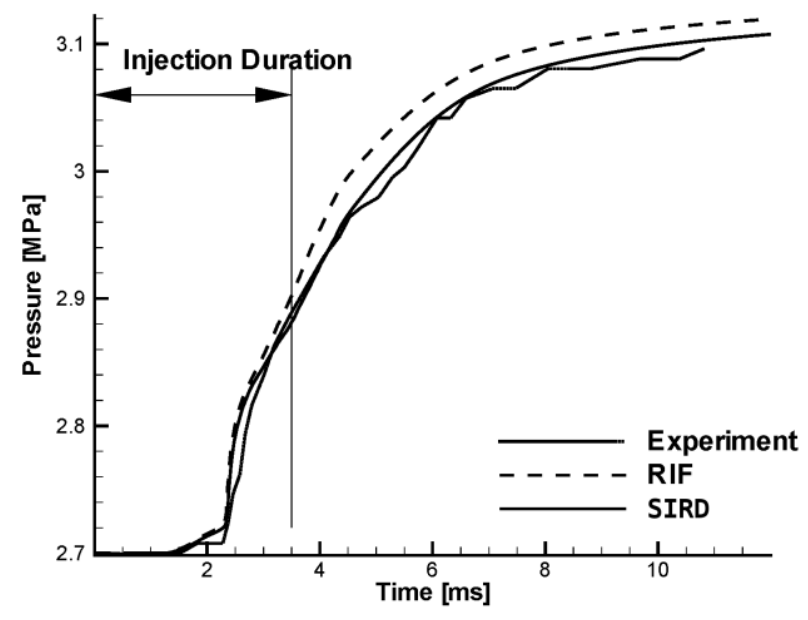

Figure 4 Pressure history comparison RCM experiment

From Figure 4, it is clear that the SIRD model is capable of accurately modeling the spray combustion. The SIRD model predicts lower rate of pressure rise than that of the RIF model. Such lower rate of pressure rise can be attributed to the consideration of evaporation and increased unreacted fuel amount in the reaction space. In the SIRD model, the evaporation effect will generally increase the amount of unreacted fuel content than the classic RIF model, which will be broken down into smaller molecules by endothermic reaction. From Figure 4, it is clear that the SIRD model result is in very good agreement with the experimental data. 


\section{Application to PPCI Combustion}

The main objective of this research is to investigate the effect of stratification on DI/PPCI as a possible combustion stabilization mechanism at low load operation of HCCI engine. As the SIRD model has been validated using the RCM machine experiment, the model was applied to model the DI/PPCI combustion. An experimental study of Dec [9] was chosen as a reference case for numerical experiments. In [9], the effect of different level of stratification on combustion was examined experimentally by changing the SOI (Start of Injection) timing. A schematic diagram of the engine used in the experiment is shown in Figure 5. Details of experimental setup can be found in [9].

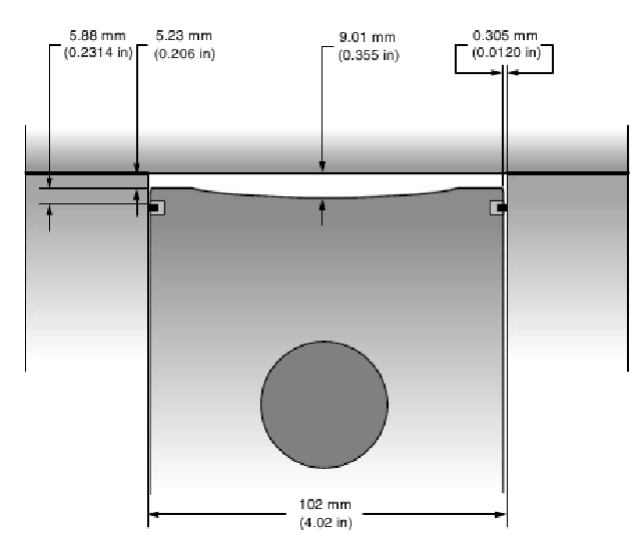

Figure 5 Engine schematic diagram used in experiment

In [9], different level of stratification was realized by controlling the SOI timing. Early injection was used to produce close-to-homogeneous mixture by allowing ample amount of time for the injected fuel and oxidizer to mix before the combustion event. Then, the SOI timing was retarded to increase the stratification level by effectively reducing the absolute amount of time for fuel and oxidizer to mix.

The KIVA3v CFD solver with the SIRD model is used to simulate the flow field and in-cylinder combustion. The fuel species used in the experiment was iso-octane, and an iso-octane reaction mechanism suggested by [10] was used in the numerical simulation to model chemistry. A 0.5 degree sectored mesh with bowl geometry and crevice volume is prepared and used in the numerical simulation, which is shown in Figure 6. The operating condition was 1500 RPM with equivalence of 0.1 , which was chosen as the low load condition in [9]. In the numerical study, SOI was varied from 240 CA to $310 \mathrm{CA}$ aTDC intake. The SOI range used in the numerical study was reduced from the experimental range due to the nature of sectored mesh applied to the current study. This reduced range was found to be adequate to examine the effect of stratification on combustion.

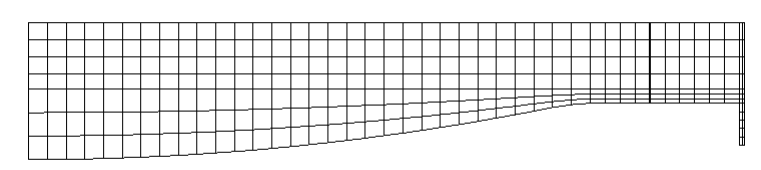

Figure 6 Computation mesh for DI/PPCI study 
In the numerical study, first the effect of different level of stratification on combustion is examined by two parameters, $\mathrm{CO}$ emission and the combustion efficiency. The result is compared to the experimental observation. Then spatial distribution of $\mathrm{CO}$ is examined to identify the source of $\mathrm{CO}$ at low load condition with different level of stratification.

\section{a. CO and combustion efficiency against stratification}

$\mathrm{CO}$ emission and the combustion efficiency against SOI are shown in Figure 7 and Figure 8, respectively. In both figures, experimental results are plotted in red, while numerical results are plotted in blue. In both figures, numerical results are in good agreement with the experimental observation in trends against SOI.

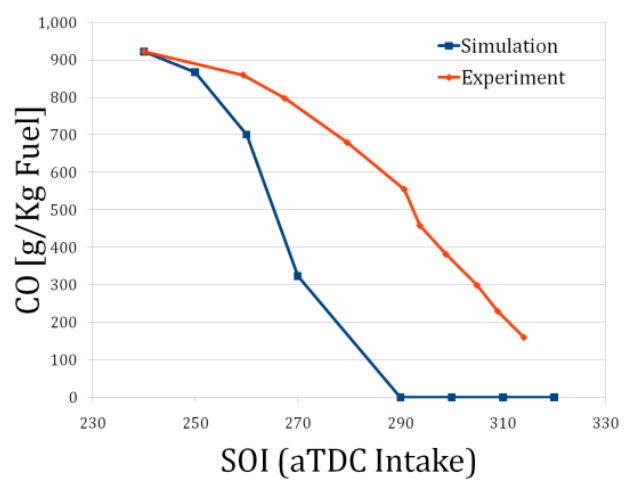

Figure $7 \mathrm{CO}$ trend against SOI

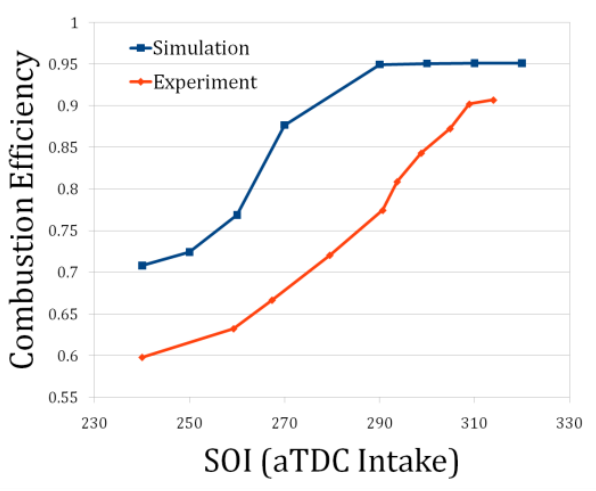

Figure 8 Fuel efficiency against SOI

In [9], it was found that the fuel efficiency increases with retarded injection, and it was understood that local richer regions created by poor mixing at later SOI allow stable ignition and combustion. Similar trend was found from numerical experiments. Numerical results will be analyzed further to identify the source of $\mathrm{CO}$ emissions against different levels of stratification.

\section{b. Source of $\mathrm{CO}$ for different level of stratification}

In [9], it was discussed that combustion at such low equivalence ratio suffers from incomplete combustion under HCCI operation. By retarding the injection timing, it is possible to create local higher equivalence ratio region, where combustion becomes more stable. As a result, reduction in $\mathrm{CO}$ with retarded SOI, or equivalently, higher level of stratification reduces the $\mathrm{CO}$ emission, as shown in Figure 7. It has been speculated in [9] that with early injection, $\mathrm{CO}$ is produced mainly from the bulk gas, which has low equivalence ratio due to ample mixing. On the other hand, with late injection, it was speculated that fuel is concentrated at certain regions in the cylinder due to poor mixing, where stable combustion leads to complete $\mathrm{CO}-\mathrm{CO}_{2}$ reaction. As a result, $\mathrm{CO}$ should be produced mainly at near-wall or squish region. The numerical simulation results are examined to identify the source of CO at different SOI's. Three different SOI's, SOI 240CA, 270CA, and 300CA are chosen for comparing fuel and CO distributions at TDC.

Spatial distributions of $\Phi$ and CO at TDC for SOI 240 CA case are shown in Figure 9(a) and Figure 9(b), respectively. It can be observed from Figure 9(a) that the equivalence ratio distribution is close to homogeneous with early injection. The standard deviation of $\Phi$ was found to be $\sigma_{\phi}=0.033$. Most of in-cylinder charge share similar $\Phi$ close to the overall equivalence of 0.1 , which is too lean to autoignite as reported in [9]. As a result, $\mathrm{CO}$ is produced widely over the 
bulk gas region, due to low temperature to complete the $\mathrm{CO}-\mathrm{CO}_{2}$ reaction at low equivalence ratio.

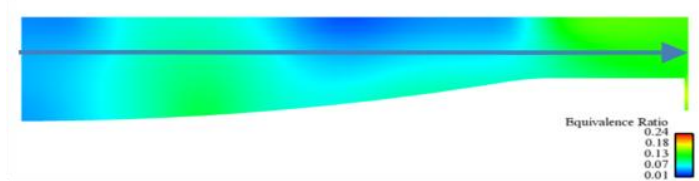

Figure 9(a) Spatial $\Phi$ distribution at TDC

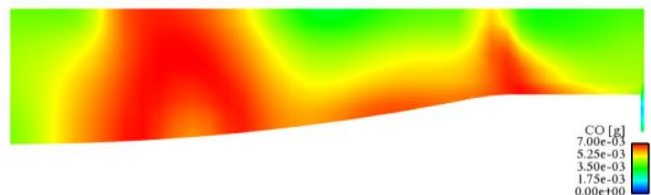

Figure 9(b) Spatial CO distribution at TDC

Figure 9 Spatial distribution of $\Phi$ and CO: SOI 240

Similar plots are prepared in Figure 10 for SOI 300 CA case. As the injection timing is retarded, it can be observed that higher equivalence region is created near the cylinder wall, as shown in Figure 10(a). The equivalence ratio at this region is high enough for stable combustion. Consequently, $\mathrm{CO}$ production near the wall has been decreased. However, the there are still wellmixed charge present near the cylinder axis, where $\mathrm{CO}$ level is found to be high.

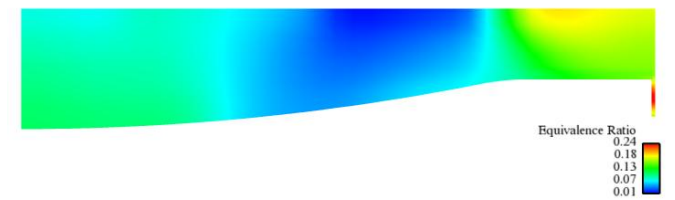

Figure 10 (a) Spatial $\Phi$ distribution at TDC

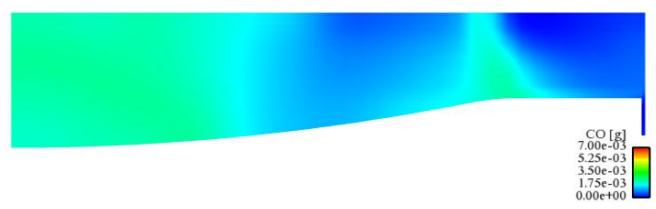

Figure 10 (b) Spatial CO distribution at TDC

Figure 10 Spatial distribution of $\Phi$ and CO: SOI 270

With late injection of SOI 320CA, the fuel distribution becomes very stratified, as shown in Figure 11(a). As a result, higher level of $\mathrm{CO}$ as previous cases is not to be observed in Figure 11(b).

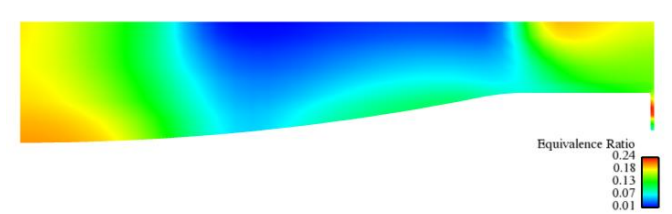

Figure 11(a) Spatial $\Phi$ distribution at TDC

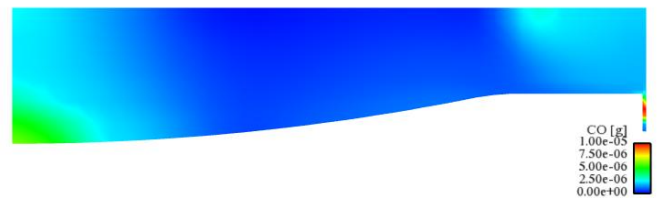

Figure 11 (b) Spatial CO distribution at TDC

Figure 11 Spatial distribution of $\Phi$ and CO: SOI 300

Equivalence ratio and $\mathrm{CO}$ distribution across the cylinder are shown in Figure 12 and Figure 13, respectively. Both equivalence ratio and $\mathrm{CO}$ distribution was sampled over a line which connects cylinder center to the cylinder wall, as shown in Figure 9(a). It is clear from Figure 12 that the stratification level increases with retarded injection. The overall equivalence ratio of 0.1 is plotted in a dashed line in Figure 12 for comparison. The earliest injection case of SOI 240CA, which is shown red, shows rather homogenous distribution of equivalence ratio over wide area. In this case, $\mathrm{CO}$ is produced over the bulk gas region as shown in Figure 13, with the red line. On the 
other hand, SOI 300CA case shown in blue in Figure 12 shows high level of stratification. In this case, $\mathrm{CO}$ is mainly produced near the wall region as shown in Figure 13.

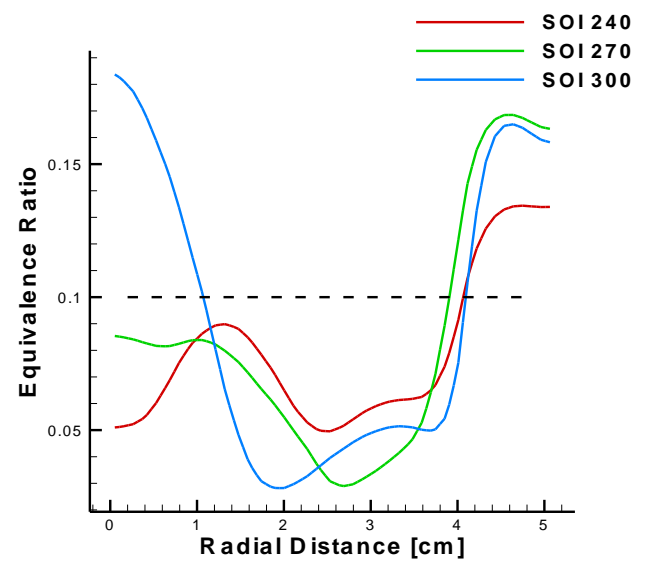

Figure 12 Equivalence ratio distribution

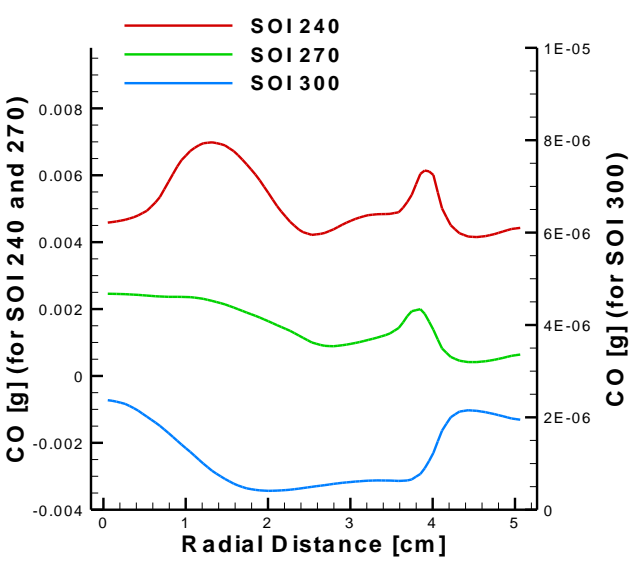

Figure $13 \mathrm{CO}$ distribution

\section{References:}

[1] Akiyama, H., Nishimura, H., Ibaraki, Y., \& Iida, N. 1998. Study of diesel spray combustion and ignition using high-pressure fuel injection and a micro-hole nozzle with a rapid compression machine: Improvement of combustion using low cetane number fuel. JSAE review, 19(4), 319 - 327.

[2] Tanaka, S., Ayala, F., \& Keck, J. C. 2003. A reduced chemical kinetic model for HCCI combustion of primary reference fuels in a rapid compression machine. Combustion and flame, 133(4), $467-481$.

[3] Babajimopoulos, A., Assanis, D. N., \& Fiveland, S. B. 2002. An approach for modeling the effects of gas exchange processes on HCCI combustion and its application in evaluating variable valve timing control strategies. SAE technical paper series 2002-01-2829.

[4] Babajimopoulos, A., Assanis, D.N., Flowers, D.L., Aceves, S.M., \& Hessel, R.P. 2005. A fully coupled computational fluid dynamics and multi-zone model with detailed chemical kinetics for the simulation of premixed charge compression ignition engines. International journal of engine research, 6(5), 497 - 512.

[5] Peters, N. 2000. Turbulent combustion. Cambridge University Press.

[6] Peters, N. 1984. Laminar diffusion flamelet models in non-premixed turbulent combustion. Progress in energy and combustion science, 10, 319-339.

[7] Patterson, M. A., Kong, S. C., Hampson, G.J., \& Reitz, R. D. 1994. Modeling the effects of fuel injection characteristics on diesel engine soot and nox emissions. SAE technical paper series 940523.

[8] Liu, S., Hewson, J. C., Chen, J. H., \&Pitsch, H. 2004. Effects of strain rate on high-pressure nonpremixed n-heptane autoignition in counterflow. Combustion and flame, 137(3), 320-39.

[9] Dec, J. E., \& Sjoberg, M. 2003. A parametric study of HCCI combustion the sources of emissions at low loads and the effects of GDI fuel injection. SAE paper 2003-01-0752.

[10] Chen, J.-Y., Chen, Yi-Hann, \& Choi, Young. 2008. Development and validation of isooctane skeletal mechanisms based on LLNL detailed mechanism. International journal of vehicle design, 46(1), 128 - 38. 


\section{Task 3: Engine control for extended HCCI operation (MIT)}

Objective: The original objective of Task 3 was to examine the physics behind the formulation of a rational control strategy for multiple engine parameters in order to maximize the fuel economy benefits within the emissions constraints for a turbocharged SI/HCCI engine with VVT and intake air/EGR temperature controls. Specifically, a single cylinder engine will be used to define statically and dynamically sustainable operating points from the point of view of control options for the engine system. Because of the severe knocking observed under boosted condition in our experiment, we had modified the objectives (sub-tasks 3.5 and 3.6) to assess the fundamental constraints to the high load limit of HCCI engines, and to devise methods to abate these constraints.

The task has been completed successfully. The accomplishments are:

- Formulating the scaling law relating the Maximum Pressure Rise Rate (MPRR) in a boosted engine to the Net Indicated Mean Effective Pressure (NIMEP) and heat release time scale. The relationship has been demonstrated using data from a boosted HCCI engine with electro-magnetic valve control.

- Establishing the dependence of MPRR on engine operating parameters: charge oxygen and fuel mole fractions, compression temperature and pressure.

- Clarifying the high load limit of boosted engine operation: the high load limit and the misfire limit occur at the same operating point (at the intersection of the constraining MPRR contour and the misfire limit contour)

- Establishing the dependence of the high load limit to EGR and boost.

The research results have been disseminated in the research literature (see later section for publication list.) Synopses of the results are given in the following. 


\section{On the Maximum Pressure Rise Rate in Boosted HCCI Operation}

While gasoline Homogeneous Charge Compression Ignition (HCCI) engines could offer substantial gain in fuel economy, the operating domain is rather limited compared to the drive train requirement $[1,2]$. There is, therefore, substantial interest in widening the range of operation. Boosting is one option to extend the high load limit [2-6]. Because of Noise-Vibration-and-Harshness (NVH) and engine durability concerns, however, the maximum pressure rise rate (MPRR) posts a severe limitation on the high load limit of HCCI engines. This constraint is especially pronounced under boosted operation because of the higher energy density of the charge and the increase of chemical reaction rate with fuel and air concentrations.

This project explores the combined effects of boosting, intake air temperature, trapped residual gas fraction, and dilution on MPRR in a single cylinder gasoline engine equipped with electromagnetically activated intake and exhaust valves so that trapped residual gas was controlled by negative valve overlap. Dilutions by both air and by cooled EGR were used. The boost was generated by a motor driven compressor; the exhaust was throttled so that the exhaust and intake pressure were approximately equal. The purpose of this work was not to design or calibrate an engine to reach the highest load, but rather, to assess the dependence of the MPRR on the various engine parameters.

\section{Engine Set Up}

The single cylinder engine with electromagnetic variable valve timing (EVVT) has been described previously [1]. The engine was based on a Ricardo Hydra Diesel crankcase and a Volkswagen TDI engine head (Model year 2001). A small racing car spark plug (NGK R847-11) was mounted in the original fuel injector hole and a Kistler 6125 pressure transducer was mounted in the original glow-plug hole. To accommodate the boosted operation, the compression ratio was lowered (by inserting a spacer between the head and the block) to 10.2 to avoid severe knocking in both the SI and HCCI modes under boosted operation. The engine specifications are listed in Table 1.

$\begin{array}{ll}\text { Table 1: EM Valve Engine } & \\ \text { Bore } & 80.26 \mathrm{~m} \\ \text { Stroke } & 88.9 \mathrm{~mm} \\ \text { Connecting rod } & 158 \mathrm{~mm} \\ \text { Displacement } & 449.8 \mathrm{cc} \\ \text { Compression ratio } & 10.2 \\ \text { Fuel } & \text { UTG91 } \\ \text { Octane \# } & \text { RON 91, MON83 } \\ \Delta p \text { for PFI } & 2.7 \mathrm{bar}\end{array}$

The fuel (a calibration gasoline, UTG91 from Chevron Philips, with RON =91, MON=83) was introduced by port fuel injection at an injection pressure differential of 2.7 bar.

Because it was difficult to obtain a production turbo-charger for a small single cylinder engine, and that substantial calibration would be needed for the matching of the turbo-charger and the engine characteristics, the boosted operation was simulated by using an externally driven compressor. The compressor was a production supercharger (the one used by the BMW MiniCooper vehicle for a $1.6 \mathrm{~L}$ engine) driven by an electric motor. The arrangement is shown in Fig. 1. The compressor discharge was water-cooled by a heat exchanger. Most of the discharge was by-passed back to the compressor in a loop; the flow to the engine was controlled by throttling this by-pass loop. 
The flow into the engine comprised a branch of the cooled compressor air flow as described above, and an external Exhaust Gas Recirculation (EGR) flow. To enable the latter, a close loop controlled exhaust throttle was used to maintain an exhaust pressure slightly higher (by 0.03 bar) than the Manifold Absolute Pressure (MAP). The EGR flow was controlled by a throttle valve.

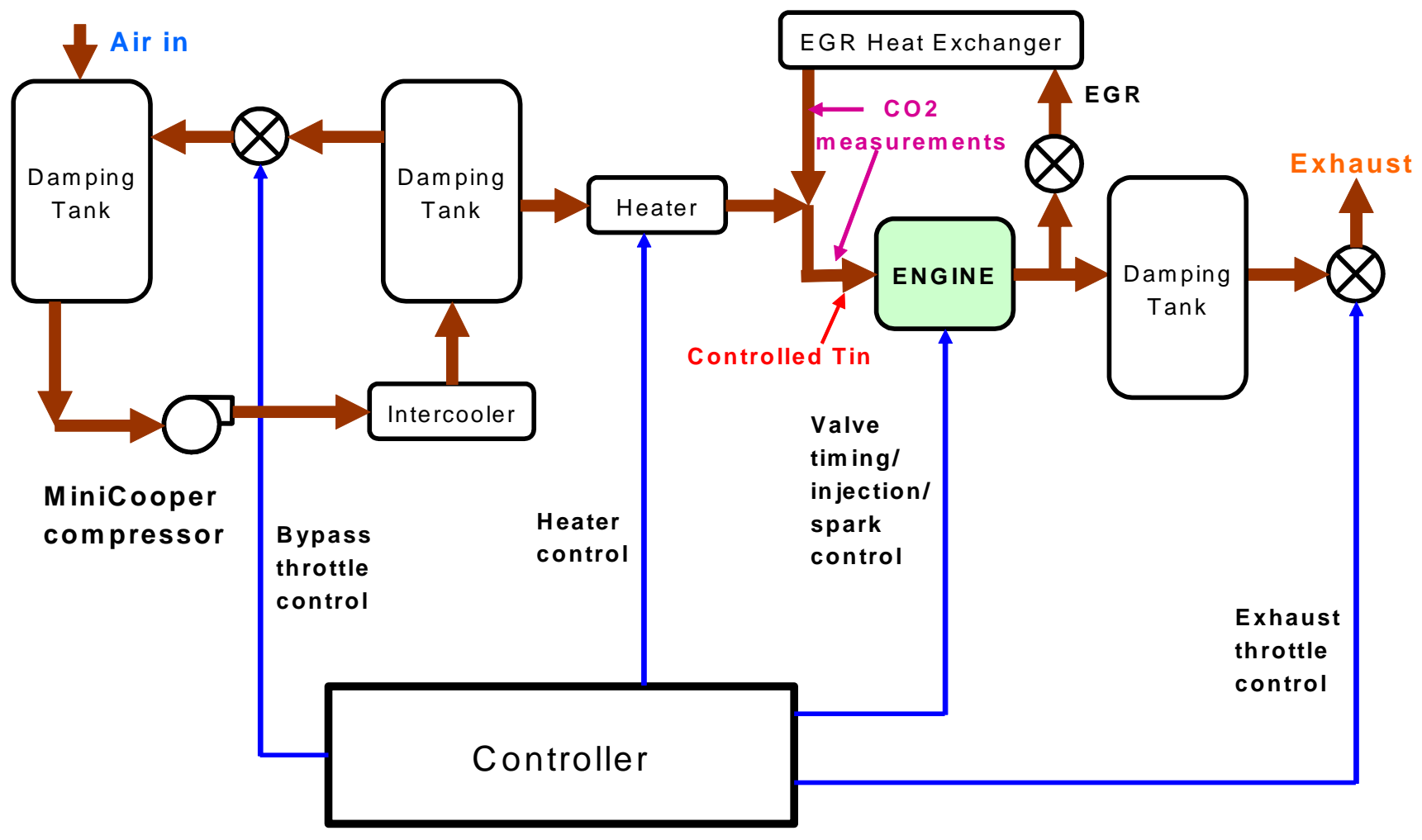

Fig.1 Engine set up for boosted operation with EGR.

The EGR flow was water cooled. Care was taken to ensure that the temperature was above the dew point to prevent water condensation. The cooled compressed air was reheated and mixed with the EGR flow. The heating power was controlled to maintain a targeted intake mixture temperature into the engine. 


\section{DIRECT MEASUREMENT OF TRAPPED BURNED GAS MOLE FRACTION}

An important parameter for assessing the engine operation is the amount of total trapped burned gas, which comprises the external EGR and the internal residual. The amount of EGR flow relative to the compressed air flow was determined by measuring the $\mathrm{CO}_{2}$ concentrations at the two points indicated in Fig. 1. The total burned gas mole fraction before combustion, $x_{\text {burn }}$, was determined by measuring the time resolved in-cylinder $\mathrm{CO}_{2}$ mole fraction with a fast-response $\mathrm{CO}_{2}$ analyzer (Cambustion Model NDIR 500).

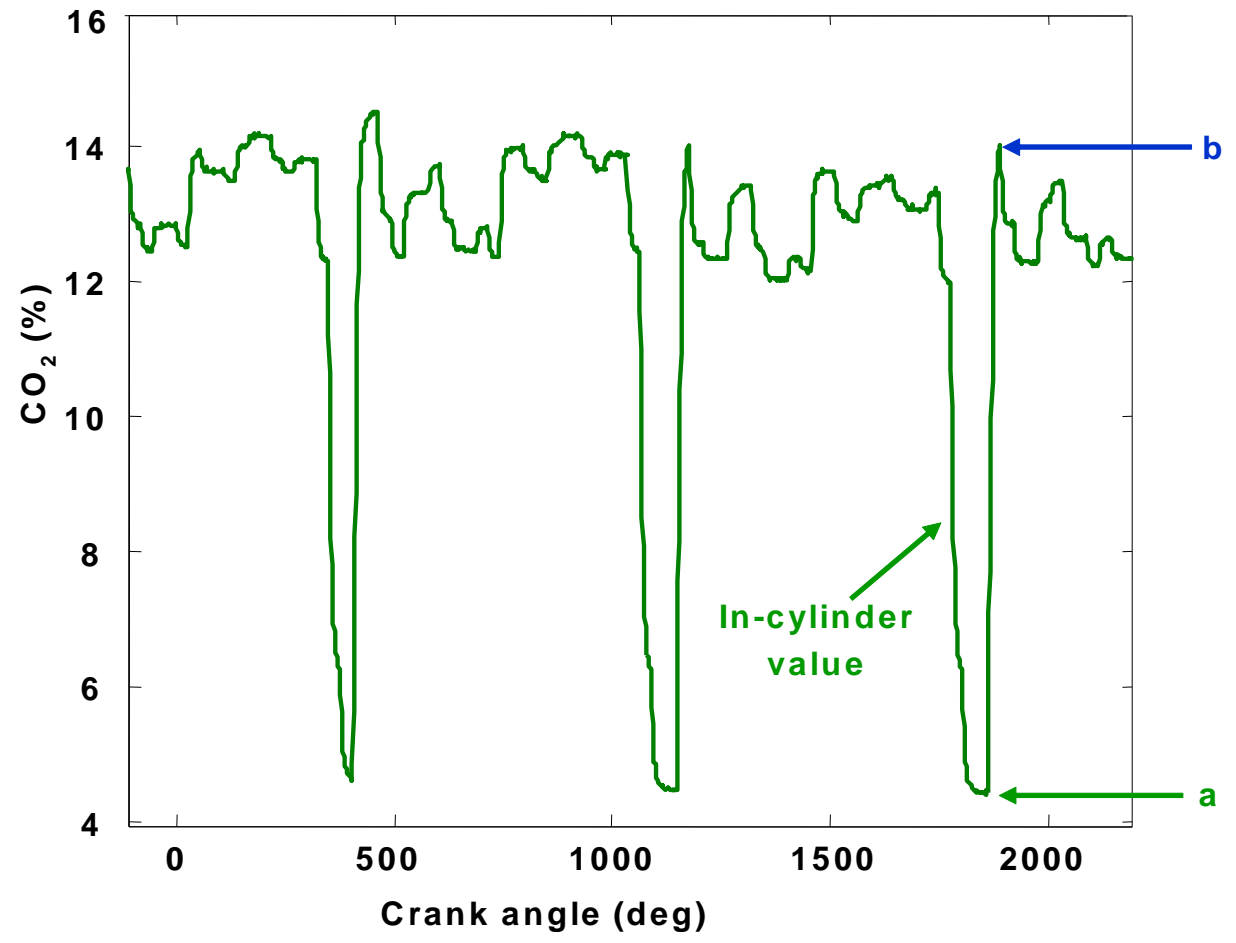

Fig.2 In-cylinder time-resolved $\mathrm{CO} 2$ measurement by fast-response $\mathrm{CO}_{2}$ analyzer.

Measurement of $x_{\text {burn }}$ is illustrated in Fig. 2. In the figure, the values a and $b$ are the $\mathrm{CO}_{2}$ mole fractions of the charge before and after combustion. Thus

$$
\begin{aligned}
& \mathrm{a}=\frac{\mathrm{N}_{\mathrm{EGR}} \mathrm{x}_{\mathrm{CO} \text { 2,burn }}+\mathrm{N}_{\text {residual }} \mathrm{x}_{\mathrm{CO} \text { 2,burn }}}{\mathrm{N}_{\text {air }}+\mathrm{N}_{\text {fuel }}+\mathrm{N}_{\mathrm{EGR}}+\mathrm{N}_{\text {residual }}} \\
& \mathrm{b}=\mathrm{x}_{\mathrm{CO} \text { 2,burn }}
\end{aligned}
$$

Here $\mathrm{N}$ denotes the number of moles of the subscripted quantities and $\mathrm{x}_{\mathrm{CO} 2 \text {, burn }}$ is the mole fraction of $\mathrm{CO}_{2}$ in the combustion product. Combining Eqs. (1) and (2):

$$
\mathrm{x}_{\text {burn }}=\frac{\mathrm{N}_{\text {EGR }}+\mathrm{N}_{\text {residual }}}{\mathrm{N}_{\text {air }}+\mathrm{N}_{\text {fuel }}+\mathrm{N}_{\text {EGR }}+N_{\text {residual }}}=\frac{\mathrm{a}}{\mathrm{b}}
$$




\section{INDIRECT DETERMINATION OF TRAPPED BURNED GAS MOLE FRACTION}

While the above method was a direct measurement of $\mathrm{x}_{\text {burn }}$, the implementation of such for every measurement was difficult (e.g. the in-cylinder probe would plug up from time to time). We therefore, sought an indirect determination of $\mathrm{x}_{\text {burn }}$ and verified these values with those from the direct method.

The mole of trapped residual may be calculated from the charge pressure and temperature at EVC.

$$
\mathrm{N}_{\text {residual }}=\left(\frac{\mathrm{PV}}{\mathrm{RT}}\right)_{\mathrm{EVC}}
$$

In practice, however, accurate in-cylinder pressure measurement at EVC was difficult because of transducer sensitivity, drift, and exhaust system pressure wave phenomenon. The charge temperature was difficult to measure directly. The exhaust pressure and temperature, however, were monitored. We therefore approximated Eq. (4) by the following:

$$
\mathrm{N}_{\text {residual }}=\left(\frac{\mathrm{P}_{\text {exh }} \mathrm{V}}{R T_{\text {exh }}}\right)_{\text {EVC }}
$$

Since the flows of air, fuel, and EGR were known (the latter obtained by the previously described external $\mathrm{CO} 2$ measurement), the values of $\mathrm{x}_{\text {residual }}$ and $\mathrm{x}_{\text {burn }}$ may be calculated from Eqs. (5) and (3).

Comparisons of the $\mathrm{x}_{\text {residual }}$ values obtained by the direct and indirect methods are shown in Fig. 3 . There was very good agreement $-\mathrm{T}_{\text {exh }}$ probably under estimated the trapped residual gas temperature; the $\mathrm{P}_{\text {exh }}$ probably under estimated the trapped residual pressure; the two errors compensated for each other.

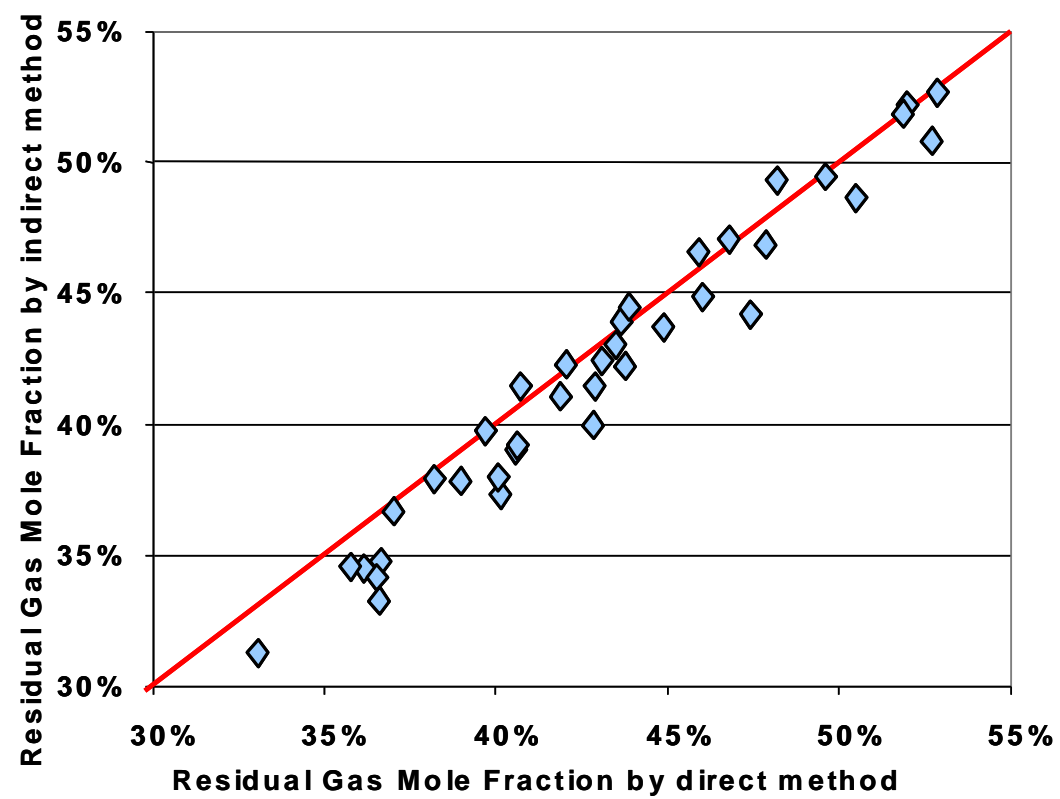

Fig.3 Comparison of the trapped residual fraction ( $\left.\mathrm{x}_{\text {residual }}\right)$ obtained by the indirect (Eq.5) and direct (Eq. 3) methods. Data encompass operation at MAP $=1.1$ and 1.3 bar. Extent of NVO was used to vary residual trapping. 


\section{NO $_{\mathrm{X}}$ CONSIDERATION}

To investigate whether the HCCI engine would be able to meet the NOx emission requirement without a 3way catalyst, and therefore, be permissible for lean operation, the effect of dilution on NOx emission under boosted condition was examined by using an engine simulation at $1500 \mathrm{rpm}$ and at various loads. Homogeneous combustion with a specified heat release profile typical of the HCCI combustion was used. The combustion phasing was at MBT timing.

Stoichiometric burned gas (i.e. operating at $\lambda=1$ ) was employed as the diluent to build the most optimistic case. (If air were used as the diluent in the simulation, there would be more NOx emission because the charge would be hotter due to the higher specific heat ratio and that more oxygen would be available for NO formation). The PZEV requirement of $0.02 \mathrm{~g} / \mathrm{mile}$ of NOx was used as the threshold. At the current CAFE level of $27.5 \mathrm{mpg}$, the corresponding NOx specific emission is $0.19 \mathrm{~g} / \mathrm{kg}$-fuel.

The engine-out NOx as a function of the diluent mole fraction is shown in Fig. 4 [7]. The specific NOx emission as a function of the diluent fraction was approximately independent of the level of boosting. To satisfy the PZEV requirement, more than $70 \%$ of diluent is required. At this high level of dilution, the combustion would not be stable, and even if good combustion could be achieved, the dilution would have substantially displaced the air so that NIMEP would be severely limited; see Fig. 5.

It is therefore concluded that to have reasonable NIMEP levels for HCCI high load operation, it is imperative that a 3-way catalyst be used. Thus the mixture must be at stoichiometric $(\lambda=1)$.

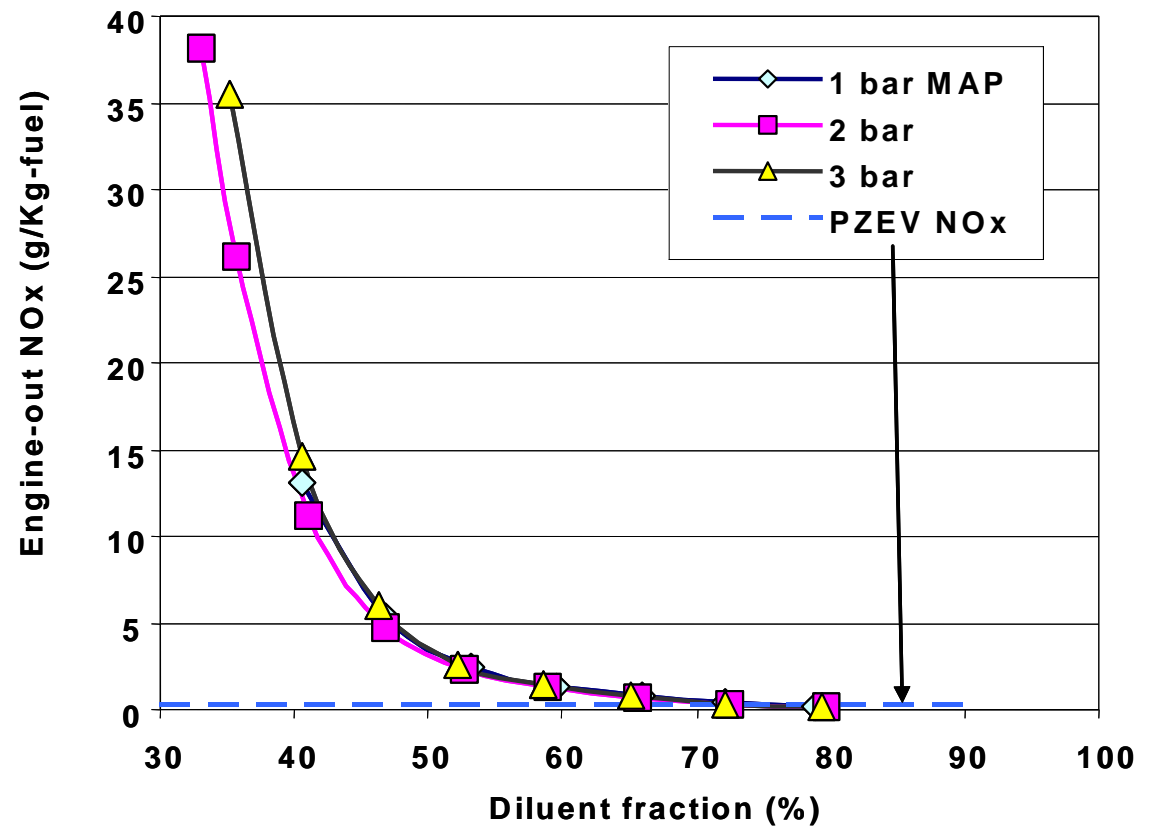

Fig. 4 Specific NOx emission as a function of diluent mole fraction; from HCCI engine simulation at 1500 rpm with NVO; $\lambda=1$; from Ref. [7] 
Most of our data were obtained at $\lambda=1$; however, to assess the effect of dilution by air on combustion, we also ran experiments at $\lambda>1$.

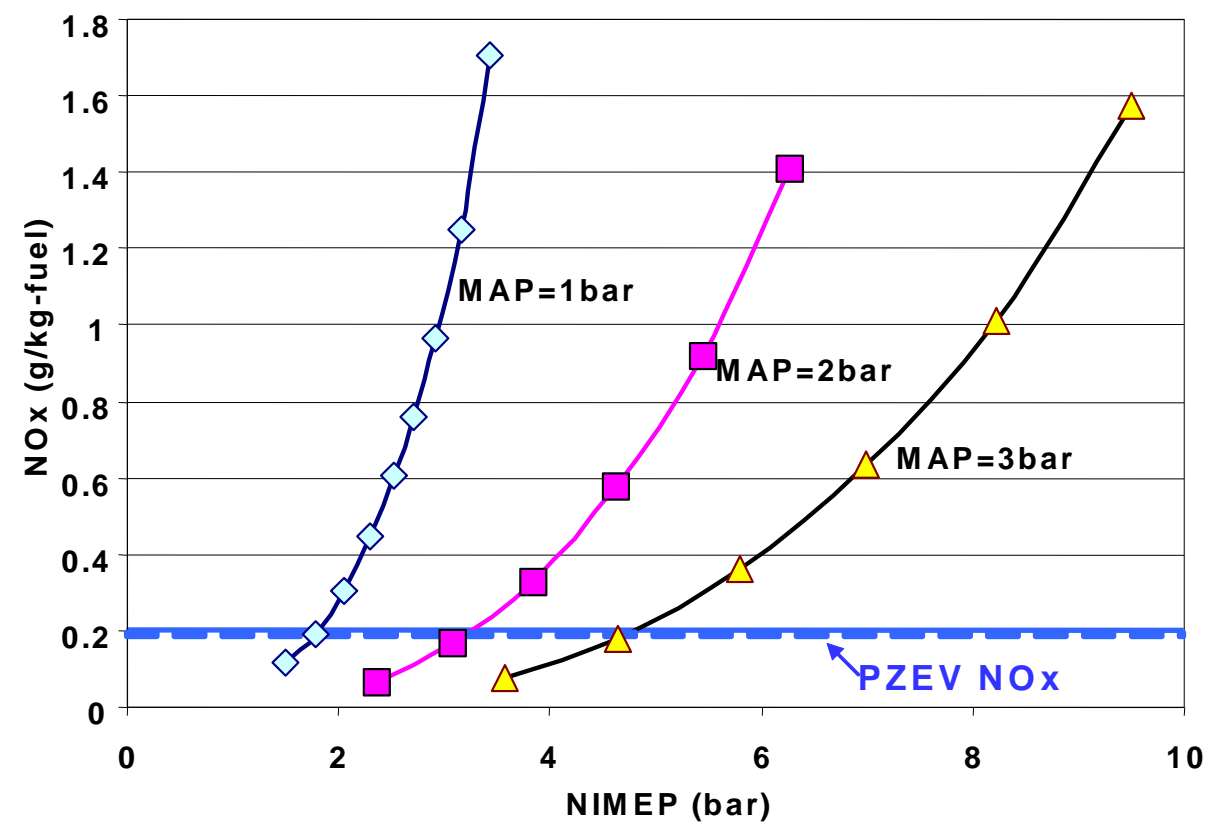

Fig. 5 Same plot as Fig. 4, except $x$-axis is replaced by the NIMEP values. To satisfy the PZEV requirement without catalyst, the range of NIMEP permissible is very limited; from Ref. [7] 


\section{NVH METRIC}

Several metrics used to measure the NVH from the combustion pressure oscillation are shown in Table 2. Also shown are the scaling of the metric with the pressure and its rise rate, and the scaling with MEP. The MPRR is most widely used because it is simple and easily obtainable from engine data. The criterion for onset of pressure oscillation [8] is deemed not appropriate for HCCI combustion in which pressure oscillations have often been observed without significant audible knock [10]. The ringing index (RI) is based on the acoustic energy flux produced by the oscillating charge pressure [9] $]^{1}$, and is increasingly being used in the literature.

Table 2: NVH Metric

\begin{tabular}{|c|c|c|c|}
\hline Basis & Metric & $\begin{array}{l}\dot{p} \text { and } p \\
\text { scaling }\end{array}$ & $\begin{array}{c}\text { Scaling } \\
\text { with } \\
\text { MEP }\end{array}$ \\
\hline $\begin{array}{l}\text { MPRR } \\
\text { (Widely } \\
\text { used) }\end{array}$ & $\dot{p}$ & $p$ & $\propto \mathrm{MEP}$ \\
\hline $\begin{array}{l}\text { Pressure } \\
\text { oscillation } \\
\text { onset [8] }\end{array}$ & $\begin{array}{l}{\left[\frac{\dot{p}}{\mathrm{p}} \frac{(\mathrm{r} / \mathrm{a})}{3 \gamma}\right]_{\text {local }} \text { where } \mathrm{r} \text { is }} \\
\text { the size of the fast } \\
\text { heat release region } \\
\text { and a the sonic } \\
\text { velocity }\end{array}$ & $\frac{\dot{p}}{p}$ & Neutral \\
\hline $\begin{array}{l}\text { Acoustic } \\
\text { energy } \\
\text { flux [9] }\end{array}$ & $\begin{array}{l}\text { Ringing index }(\mathrm{RI}) \\
==\frac{\sqrt{\gamma \mathrm{R}^{*} \mathrm{~T}_{\max }}}{2 \gamma \mathrm{P}_{\max }}\left[\beta(\dot{\mathrm{p}})_{\max }\right]^{2} \\
\text { where } \beta \approx 1 /(4 \mathrm{f}) \text { and } \mathrm{f} \\
\text { is the oscillation } \\
\text { frequency }\end{array}$ & $\frac{\dot{p}^{2}}{p}$ & $\propto \mathrm{MEP}$ \\
\hline
\end{tabular}

It should be noted that MPRR is proportional to $\dot{p}$ and RI is proportional to $\dot{p}{ }^{2} / p$; thus both values scale with MEP. We have chosen to use MPRR over RI as the metric because MPRR is readily available from the data while the maximum temperature required for the RI calculation needs to be estimated. For our data, there was a close correspondence between MPRR and RI so that the choice of the metric was almost immaterial; see Fig. 6. A reasonable MPRR limit of $5 \mathrm{MPa} / \mathrm{ms}$ [10] was used in this work. The value of MPRR was calculated as the average over many cycles of the individual cycle-value of $(\mathrm{dp} / \mathrm{dt})_{\max }$; see Ref.[10] for details.

\footnotetext{
${ }^{1}$ In Ref.[9], $\beta$ was set to $0.05 \mathrm{~ms}$, which corresponds to $f=5 \mathrm{KHz}$. In general the $\beta$ value should be adjusted according to $\mathrm{f}$.
} 


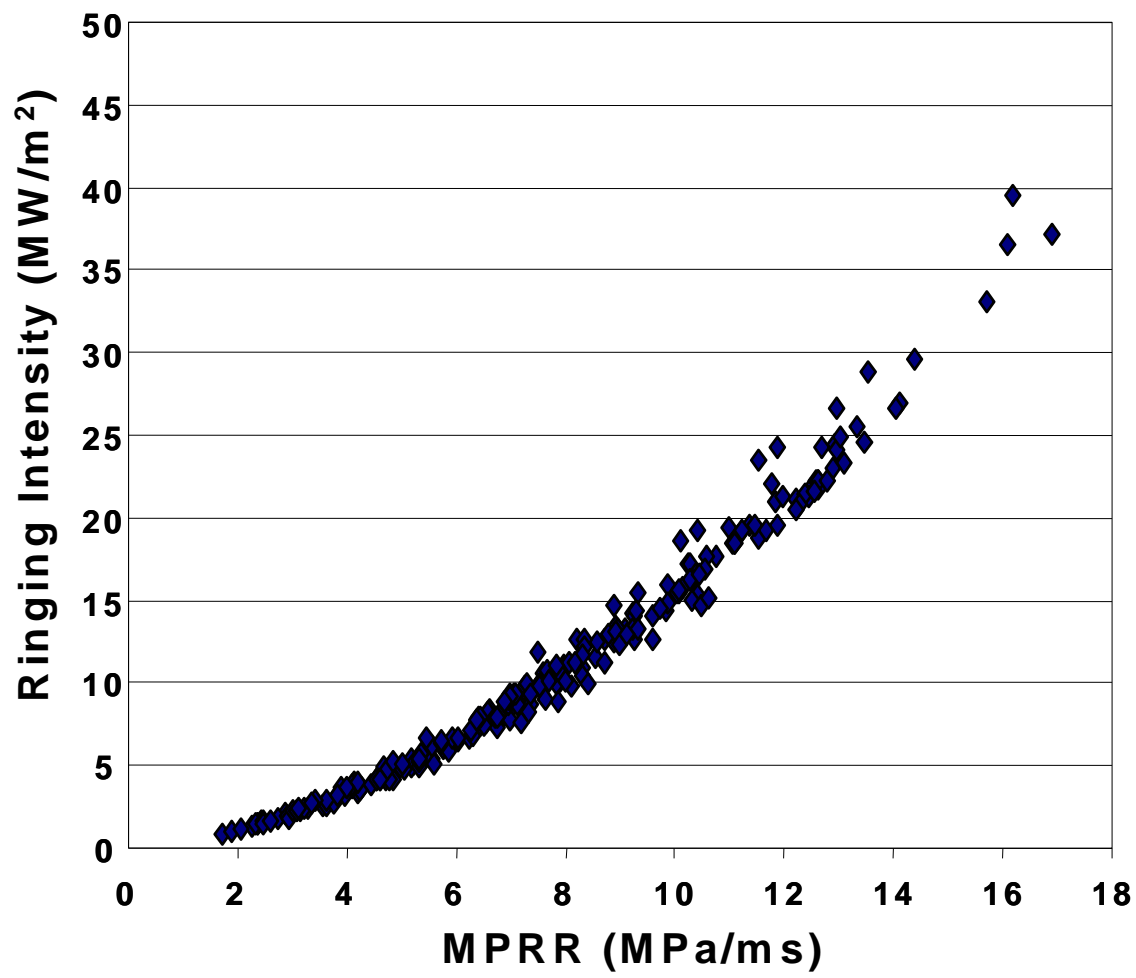

Fig. 6 Relationship between MPRR and ringing intensity. Data encompass MAP of 1 to 1.5 bar, various residual fractions; $1500 \mathrm{rpm}$. 


\section{TEST MATRIX}

All the data were taken at engine speed of $1500 \mathrm{rpm}$. The valve timing strategy is shown in Fig. 7. The NVO, of half angle $\theta_{0}$, is symmetric with respect to TDC-exhaust. The exhaust pressure was kept equal to $\mathrm{MAP}+0.03$ bar. The controlling parameters are MAP, intake mixture temperature $\mathrm{T}_{\mathrm{i}}$, and the NVO half angle $\theta_{0}$. All data were taken at $\lambda=1$ except when noted. Dilution with external EGR and with air (then $\lambda$ $>1$ ) were used.

The test matrix comprised temperature sweeps at MAP $=1.01,1.25$ and 1.5 bar with fixed $\theta_{0}=75^{\circ}$, sweeps of NVO and MAP (1 to 1.7 bar) at $\mathrm{T}_{\mathrm{i}}=30$ to $120^{\circ} \mathrm{C}$, and dilution UP TO 30 mole $\%$ with air and with EGR.

\section{GENERAL DATA TREND}

At fixed NVO, $\lambda=1$,.and with no EGR, the effects of intake temperature $\left(\mathrm{T}_{\mathrm{i}}\right)$ and MAP on NIMEP, MPRR, CA50 and 10-90\% burn duration are shown in Fig. 8. The NIMEP increased with MAP due to more fuel was burned; decreased with $T_{i}$ because of the lower volumetric efficiency. The MPRR increased with MAP because more energy was released and because of earlier combustion phasing (see CA50 data in the next plot); the latter also explains the MPRR increase with $\mathrm{T}_{\mathrm{i}}$.

The combustion phasing, as depicted by CA50 in Fig. 8, advanced with both MAP and $\mathrm{T}_{\mathrm{i}}$. This observation could be explained by the temperature and pressure dependence of the ignition delay.

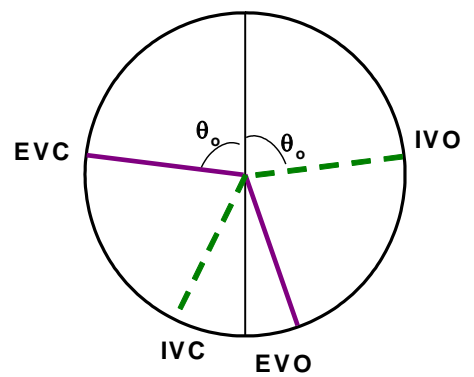

Fig.7 Valve timing strategy: IVC fixed at $29^{\circ} \mathrm{ABC}$-compression; EVO fixed at $15^{\circ} \mathrm{BBC}$-expansion; NVO symmetric about TDC exhaust; NVO half angle is $\theta_{0}$.

The 10-90\% burn duration also decreased with both MAP and $\mathrm{T}_{\mathrm{i}}$, although at the higher MAP values (1.25 and 1.5 bar), the burn duration did not change appreciably at $\mathrm{T}_{\mathrm{i}}>60^{\circ} \mathrm{C}$.

The NIMEP as a function of the fuel mass per cycle for all the data is shown in Fig. 9. The different operating temperatures were depicted by the symbol colors and the different intake temperatures by the symbol shapes. The data points with dilution by both air and EGR were included but not explicitly marked. The NIMEP was proportional to the fuel mass; the spread of the data was due to the different net indicated fuel conversion efficiency $\left(\eta_{\mathrm{f}, \mathrm{i}}\right)$ values, which were approximately in the range of 25 to $30 \%$. The lines of constant $\eta_{\mathrm{f}, \mathrm{I}}$ are also shown on Fig. 9. 

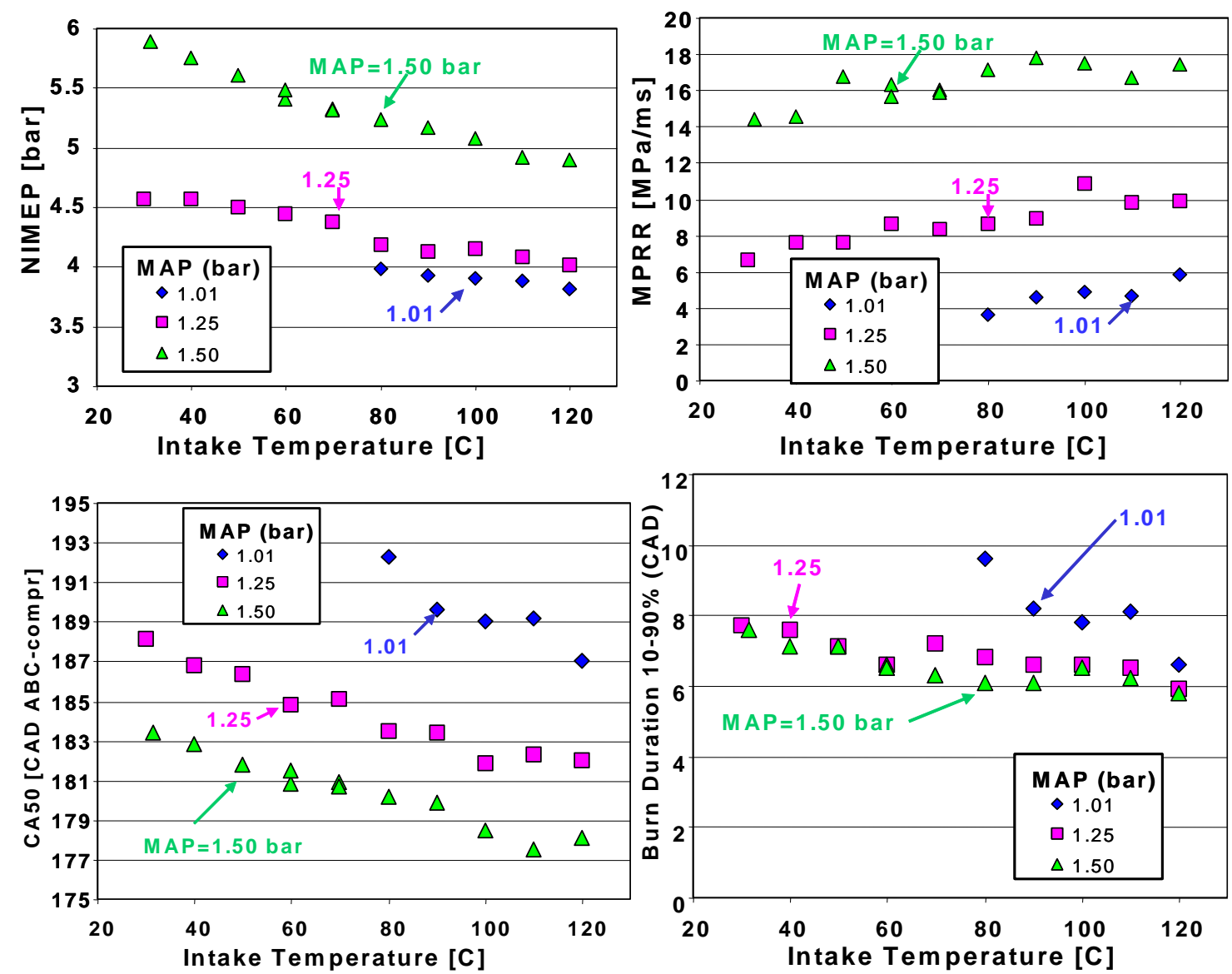

Fig. 8 General dependence of NIMEP, MPRR, CA50 and 10-90\% burn duration on MAP and $\mathrm{T}_{\mathrm{i}}$; $1500 \mathrm{rpm} ; \lambda=1$; no EGR; NVO half angle $\theta_{0}=75^{\circ}$.

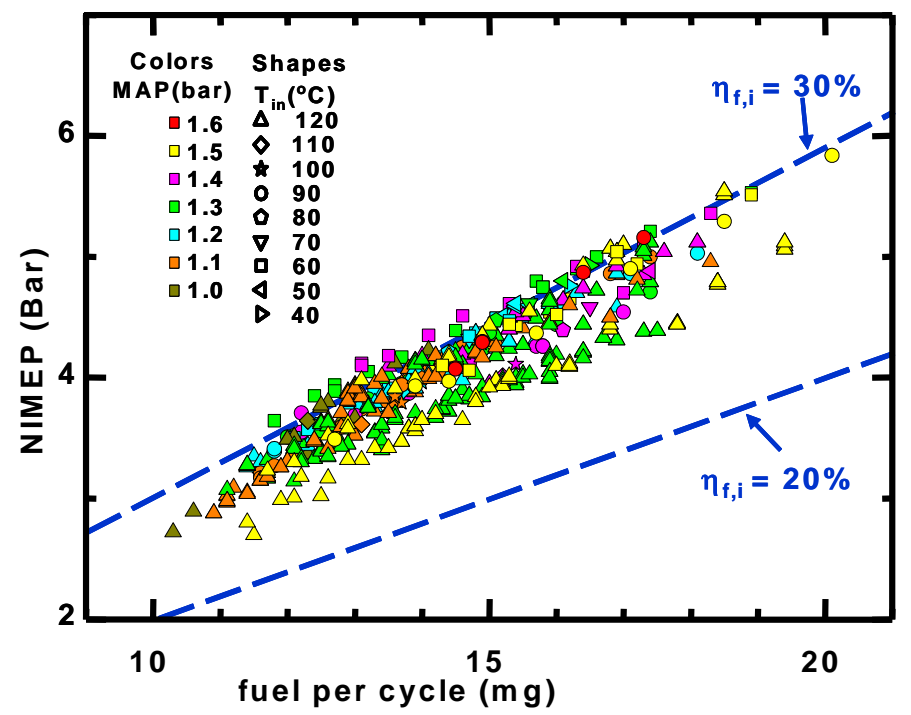

Fig. 9 NIMEP as a function of the fuel mass per cycle. The colors and symbols represent different operating conditions. The dilution data with both EGR and air were included but not explicitly marked. 
The MPRR values were plotted versus NIMEP for the same set of data points in Fig. 10. There is a substantial data scatter, although it could be argued that there is a trend that MPRR increased with NIMEP. This data will be further analyzed in a later section with a simple thermodynamic analysis to collapse the data. Note that the MPRR values for most of the data were higher than the threshold level of $5 \mathrm{MPa} / \mathrm{ms}$.

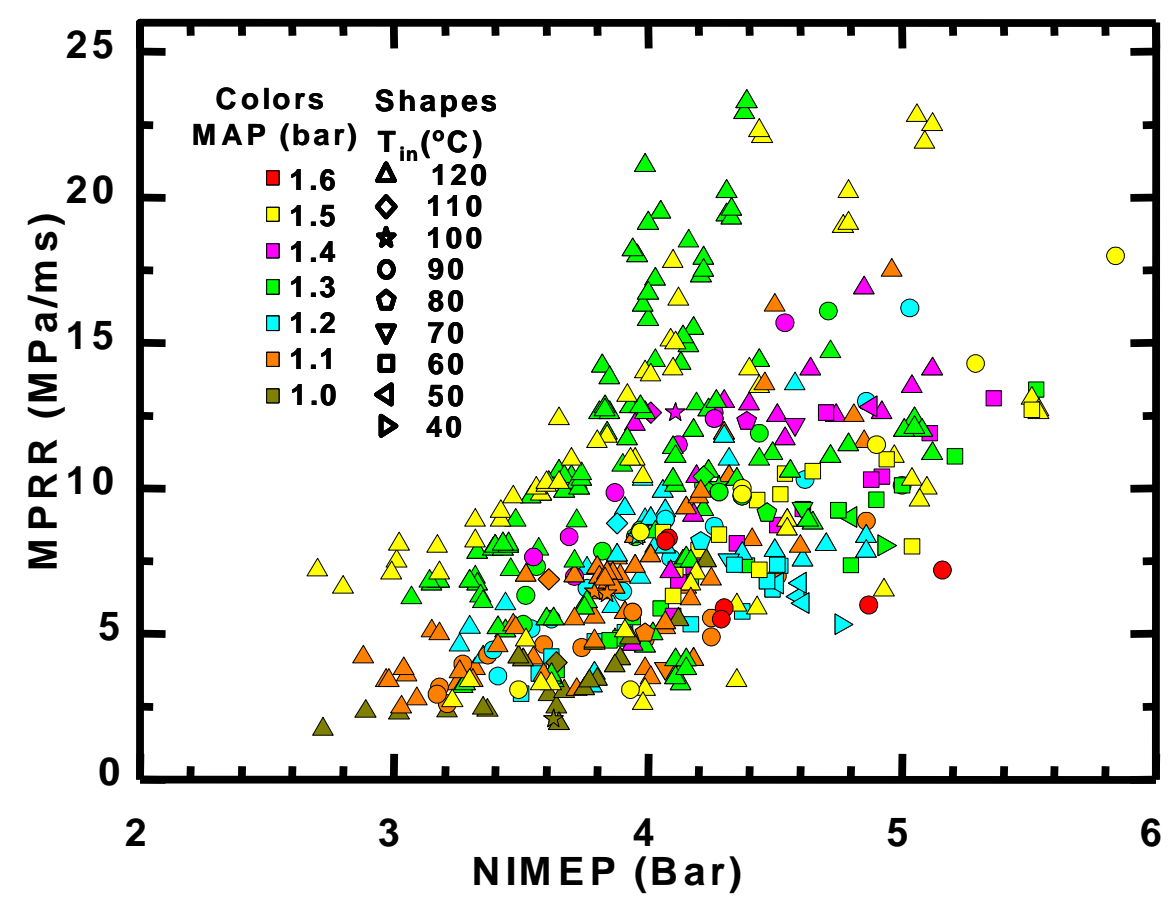

Fig. 10 MPRR versus NIMEP for the data points described in Fig. 9.

\section{DILUTION EFFECTS}

Dilution is often used as a means to mitigate MPRR. However, because dilution reduces the energy density of the charge, the NIMEP would decrease from that obtained with a stoichiometric charge without dilution. Therefore, we compared the operations at the same level of total dilution (as mole fractions), both with external EGR and with air as "displacement" of the residual; see Fig. 11. In all cases, the intake was heated so that the intake temperatures of the mixtures were maintained at the target temperatures. Thus, referring to Fig. 11 for the three cases (subscripts $0=$ no dilution, $1=$ EGR dilution, and $2=$ air dilution) at the same level of total dilution, the fuel amount were the same, whence the trapped burned gas temperatures were about the same. The diluent temperatures were both at $\mathrm{T}_{\mathrm{i}}$; thus the trapped charge temperatures of the EGR and air dilution were the same, while that of the no dilution case was higher because of the higher trapped enthalpy of the residual.

In the following, the case for dilution at $\mathrm{T}_{\mathrm{in}}=120^{\circ} \mathrm{C}, \mathrm{MAP}=1.3 \mathrm{bar}$, and $10 \%$ dilution (i.e., mole of EGR or excess air equaled to $10 \%$ of the mole of stoichiometric mixture) will be discussed. Data for other intake temperatures and MAP values behave similarly; see Appendix A. It should be noted that for the air dilution case, because of the presence of excess air in the residual gas, the averaged $\lambda$ in cylinder is higher than the metered $\lambda$ value. 


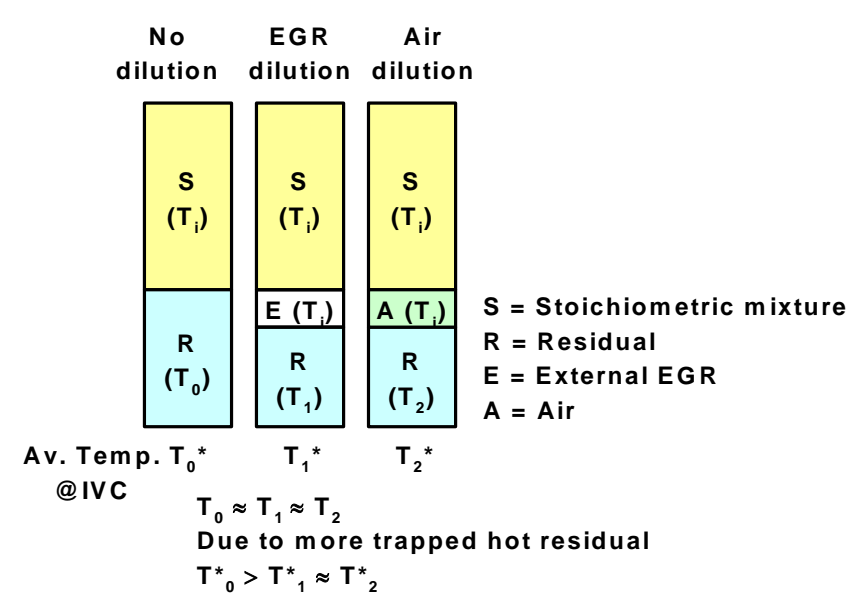

Fig. 11. Schematic of the dilution strategy at same level of dilution (all values in moles). A stoichiometric mixture was either diluted by EGR or by air; note that there was air in the residual for the latter case.

The NIMEP values decreased with the increase of total dilution; see Fig. 12. The differences between the no external dilution (the stoichiometric, no egr case), dilution with egr and with air were due to the differences in indicated fuel conversion efficiencies because of changes in combustion phasing and burn duration (these data will be discussed later).

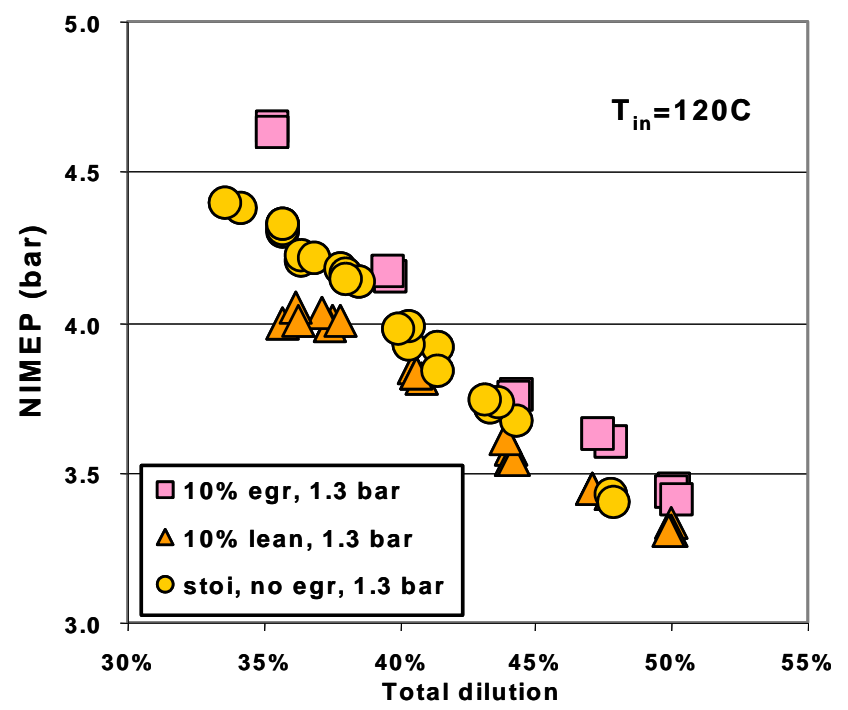

Fig. 12 Effect of total dilution on NIMEP. Engine at $1500 \mathrm{rpm} ; \mathrm{MAP}=1.3 \mathrm{bar} ; \mathrm{T}_{\mathrm{i}}=120^{\circ} \mathrm{C}$; $\lambda=1.0$ for $10 \%$ EGR case; $\lambda=1.1$ for $10 \%$ lean case.

With no EGR or air dilution, the MPRR values decreased with increase of total dilution because less fuel was burned; see Fig. 13. At the same total dilution, 10\% EGR substantially reduced the MPRR, although the effectiveness decreased with increase of total dilution. Dilution with $10 \%$ air, however, did not produce any change in the MPRR value.

The combustion phasing (as measured by CA50) and 10-90\% burn duration are shown in Fig. 14 and 15. At the same total dilution, CA 50 was substantially retarded and the burn duration lengthened by $10 \%$ external EGR. These two observations could explain the lower MPRR values obtained with EGR. 


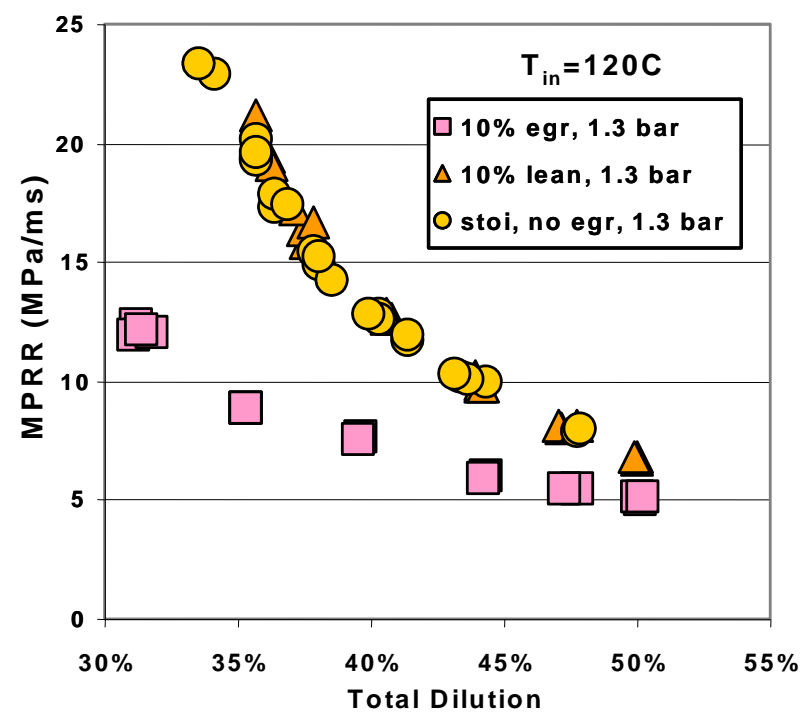

Fig. 13 Effect of total dilution on MPRR. See Fig. 12 caption for operating conditions.

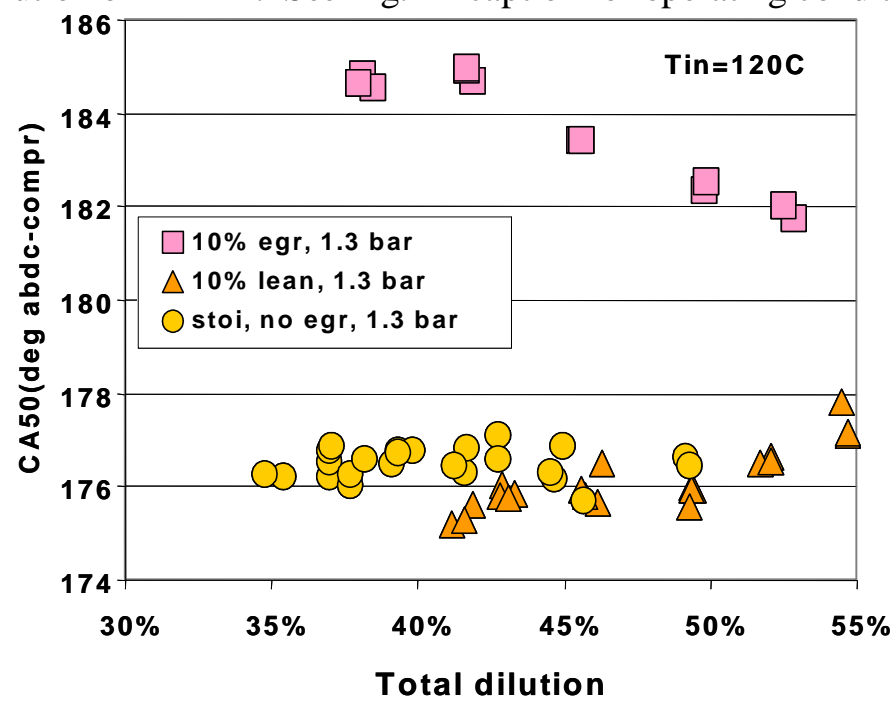

Fig. 14 Effect of total dilution on combustion phasing, as measured by CA50. See Fig. 12 caption for operating conditions.

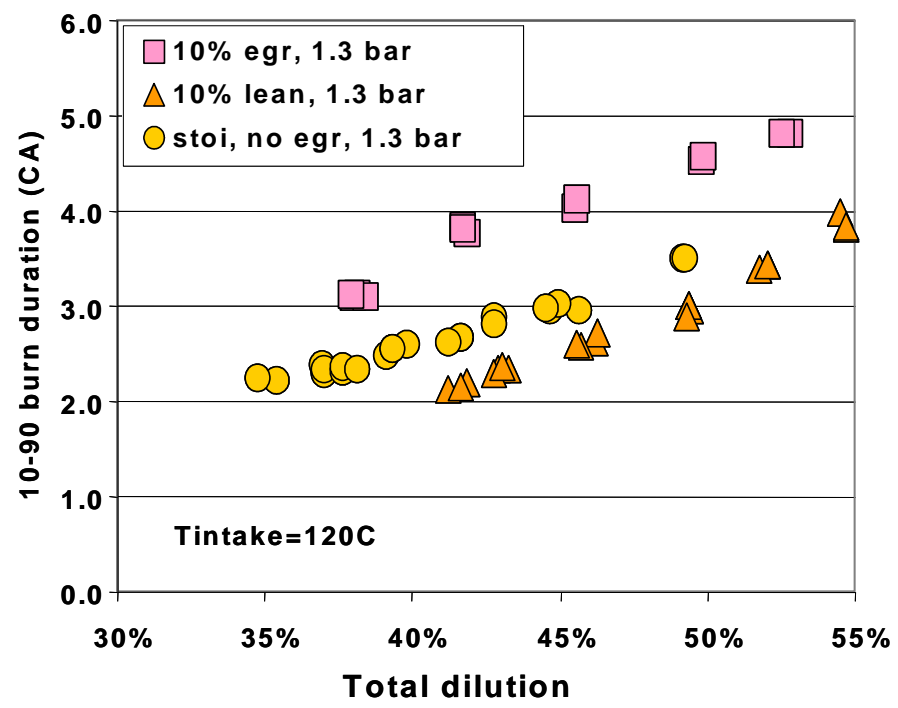

Fig. 15 Effect of total dilution on burn duration. See Fig. 12 caption for operating conditions. 
The dilution with air, however, did not produce substantial change in CA50 and burn duration compared to the no external dilution case. The CA50 values were actually slightly more advanced, and the burn duration slightly shortened.

Fig. 16 shows MPRR versus NIMEP for the three cases. At the same output NIMEP, dilution by EGR was very effective in reducing MPRR. Dilution by air, however, was detrimental - it would make the MPRR values higher.

The external dilutions by EGR and by air affected both the operating temperature. For the latter case, the charge composition also changed because of the presence of excess oxygen. The temperature effect was assessed by examining the compression temperature $T_{c}$ (as the charge temperature at $30^{\circ}$ BTCcompression, at which there was negligible heat release). This temperature was computed from the pressure data and the total charge moles with the residual moles obtained via Eq. (3) or Eq. (5).

The result is shown in Fig. 17. For the no external dilution case, $\mathrm{T}_{\mathrm{c}}$ first increased with increase of total dilution (comprised only of internal residual) because more burned gas was trapped; it then decreased

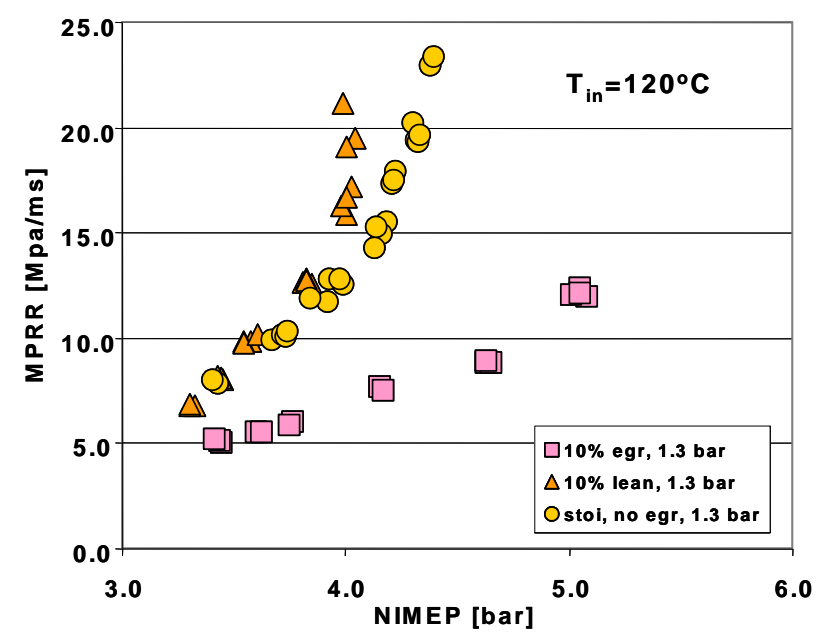

Fig. 16 MPRR versus NIMEP showing effect of dilution. See Fig. 12 caption for operating conditions.

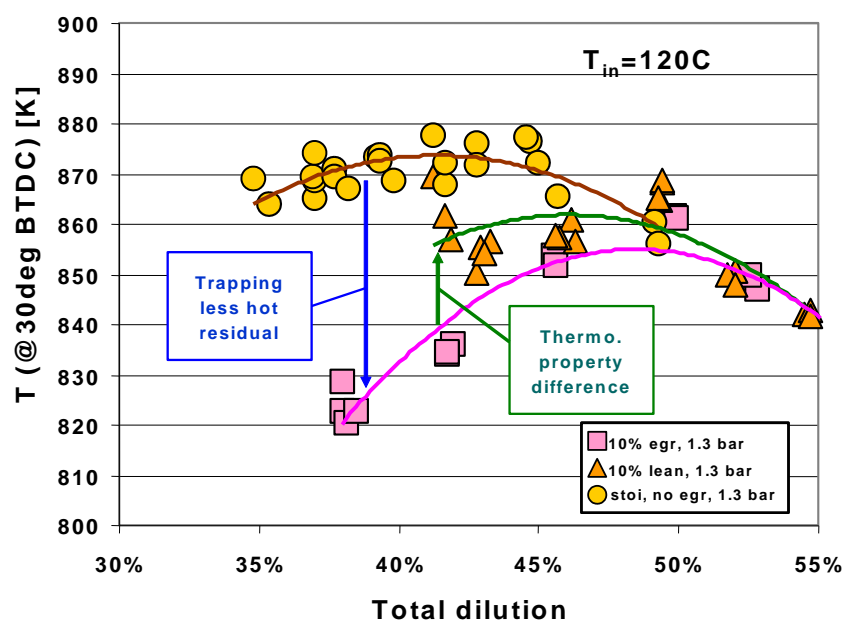

Fig. 17 Effect of dilution with EGR and with air on the pre-ignition compression temperature. See Fig. 11 caption for operating conditions. 
when the dilution was above approximately $42 \%$ because of the decrease in burned gas temperature.

With 10\% EGR, the trapped enthalpy decreased, and $\mathrm{T}_{\mathrm{c}}$ decreased correspondingly. This decrease in charge temperature, while the charge composition was approximately the same, was responsible for the retarded and slower combustion.

With $10 \%$ air dilution, $\mathrm{T}_{\mathrm{c}}$ was higher than that at 10\% EGR dilution due to the higher charge specific heat ratio. It is noted, however, that at the same dilution level, Tc was still lower than that obtained with no external dilution. Therefore the advance in combustion and decrease in burn rate depicted in Figures 14 and 15 could not be solely attributed to a temperature effect. These observations are thus attributed to the presence of excess oxygen in the mixture which overrode the effect of a lower temperature (compared to the no external dilution case) and shortened the both the ignition delay and burn duration

It could be concluded from the above discussion that to mitigate MPRR, operating with external EGR at stoichiometric condition should be the strategy. Lean operation would only increase the MPRR at the same NIMEP.

\section{THERMODYNAMIC ASSESSMENT OF MPRR}

To understand the factors contributing to MPRR, a simple thermodynamic model is used. From energy balance, the pressure rise rate is

$$
\dot{\mathrm{p}}=(\gamma-1)\left[\dot{\mathrm{q}}-\frac{\dot{Q_{L}}}{\mathrm{~V}}\right]-\left(\gamma \mathrm{P} \frac{\dot{\mathrm{V}}}{\mathrm{V}}\right)
$$

To assess the maximum pressure rise rate at the high load limit, the heat lost term $\dot{Q}_{L} / \mathrm{V}$ and the volumetric expansion term $\left(2^{\text {nd }}\right.$ term on the right-hand-side) are small compared to the volumetric heat release rate $\dot{q}$ term. Therefore,

$$
\dot{\mathrm{p}} \approx(\gamma-1) \dot{\mathrm{q}}
$$

The volumetric heat release rate at crank angle $\theta$ may be written as

$$
\dot{q}(\theta)=\frac{\operatorname{LHV}\left(\frac{m_{f}}{V(\theta)}\right)}{\tau_{\text {reaction }}}
$$

where $\mathrm{V}(\theta)$ is the cylinder volume and $\tau_{\text {reaction }}$ is the chemical reaction time scale. Thus

$$
\operatorname{MPRR}=(\gamma-1)\left[\frac{m_{f} \text { LHV }}{V(\theta) \tau_{\text {reaction }}}\right]_{\text {max }}
$$

To assess the validity of Eq. (9), we used the $10-90 \%$ burn duration as an estimate for $\tau_{\text {reaction }}$ and the volume at CA50 as estimate for the charge volume at the maximum pressure rise point. 
The plot of MPRR $\mathrm{V}_{\mathrm{CA50} 0} \tau_{10-90}$ versus the fuel mass, which, according to Eq. (9) should be a straight line, is shown in Fig. 18. This good correlation, which collapses the significantly scattered data in Fig. 10, supports the validity of the above simple thermodynamic model for MPRR. Thus Eq. (9) may be used to

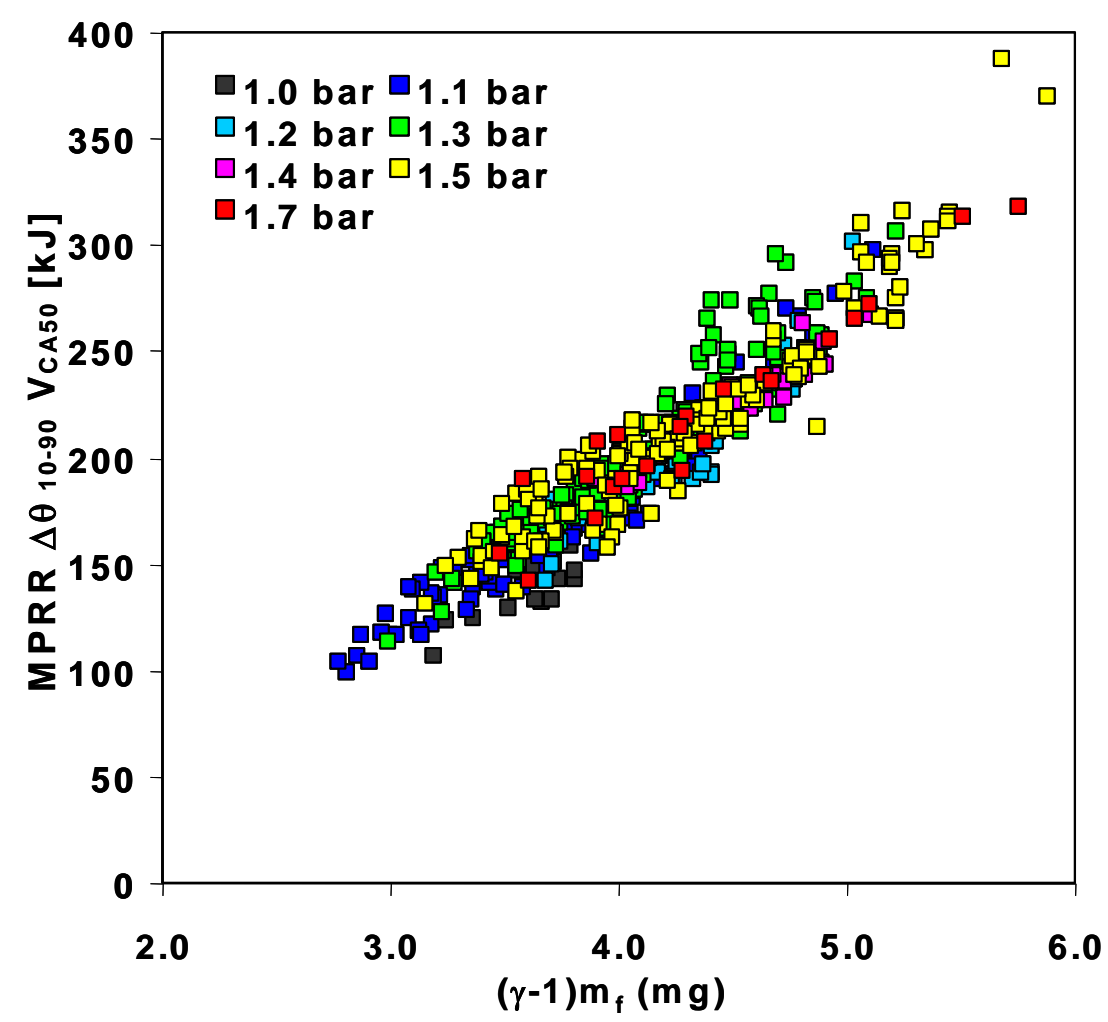

Fig. 18 Correlation plot of MPRR to engine combustion parameters.

interpret the relationship of MPRR and boosting.

Since

$$
m_{f} L H V=\frac{N I M E P V_{D}}{\eta_{f, i}}
$$

whence

$$
\operatorname{MPRR}=(\gamma-1)\left\lceil\frac{\operatorname{NIMEP}}{\eta_{f, i}} \frac{\mathrm{V}_{\mathrm{D}}}{\mathrm{V}\left(\theta^{*}\right)}\right\rceil \frac{1}{\tau_{\text {reaction }}}
$$

where $\mathrm{V}\left(\theta^{*}\right)$ is the cylinder volume at the MPRR point. With boosting to obtain a higher NIMEP, MPRR will increase proportionally if everything else remains the same. However, because ignition delay decreases with increase of charge density associated with boosting, the MPRR point will advance so that $\mathrm{V}\left(\theta^{*}\right)$ would be smaller; the efficiency $\eta_{\mathrm{f}, \mathrm{i}}$ will also be lower and thus increase the value of MPRR. (The above statement assumes that the nominal MPRR point is after TDC.) More significantly, if the charge is homogeneous and of fixed composition, reaction rate will increase (larger $1 / \tau_{\text {reaction }}$ ) with charge density. Then if the high load limit is constrained by MPRR, boosting will only make things worse. 
To get out of the above conundrum, the opportunity is to relax the homogeneous charge condition and to let the composition change via the use of EGR. Regarding the former, it has been reported in the literature the use of direct injection [6,11] and novel stratified EGR method [12] to produce charge stratification. Regarding the latter, the effect of EGR has been illustrated in Fig. 16. There is, however, the balance between suppression of MPRR and avoidance of misfiring in the trade off between EGR and boosting. That will be discussed in a later section.

To make Eq.(9) a useful formula for assessing MPRR, instead of using $\Delta \tau_{10-90}$, the value of $\tau_{\text {reaction }}$ was calculated directly from the data:

$$
\frac{1}{\tau_{\text {reaction }}}=\left[\frac{\text { MPRR V }(\text { CA 50) }}{(\gamma-1) m_{f} \text { LHV }}\right]_{\text {data }}
$$

This value was then regressed against the engine thermo-chemistry variables to produce the following correlation:

$$
\begin{aligned}
& \left(\frac{1}{\tau_{\text {reaction }}}\right)=3.32 \cdot \mathrm{x}_{\mathrm{O} 2}^{1.88} \cdot \mathrm{x}_{\text {fuel }}{ }^{0.35} \cdot \mathrm{P}_{10 \mathrm{BTC}}{ }^{1.92} \cdot \exp \left(\frac{-2560}{\mathrm{~T}_{10 \mathrm{BTC}}}\right) \\
& \left(\tau_{\text {reacton }} \text { in } \mathrm{ms} ; \mathrm{P} \text { in bar; } \mathrm{T} \text { in }{ }^{\circ} \mathrm{K}\right)
\end{aligned}
$$

The choice of $\mathrm{x}_{02}$ instead of the residual gas fraction as variable was to reflect the significant influence of oxygen concentration (see observation (c) above). The compression pressure and temperature at $10^{\circ}$ before-top-center were chosen as the thermodynamics variables because up to that point, there was no significant heat release, and the temperature and pressure there encompassed the effects of the trapped enthalpy of the residual, the intake air temperature, and the heat loss. The value of $\mathrm{T}_{10 \text { BTC }}$ was calculated from $\mathrm{P}_{10 \text { втс }}$ using the ideal gas law and the residual fraction value obtained from the exhaust temperature and pressure measurements [13].

The result of the regression is shown in Fig. 19. The agreement was satisfactory $\left(\mathrm{R}^{2}=0.71\right)$; the data scatter (bracketed by a factor of 0.5 to 1.5 ) may be attributed to the effect of stratification. 


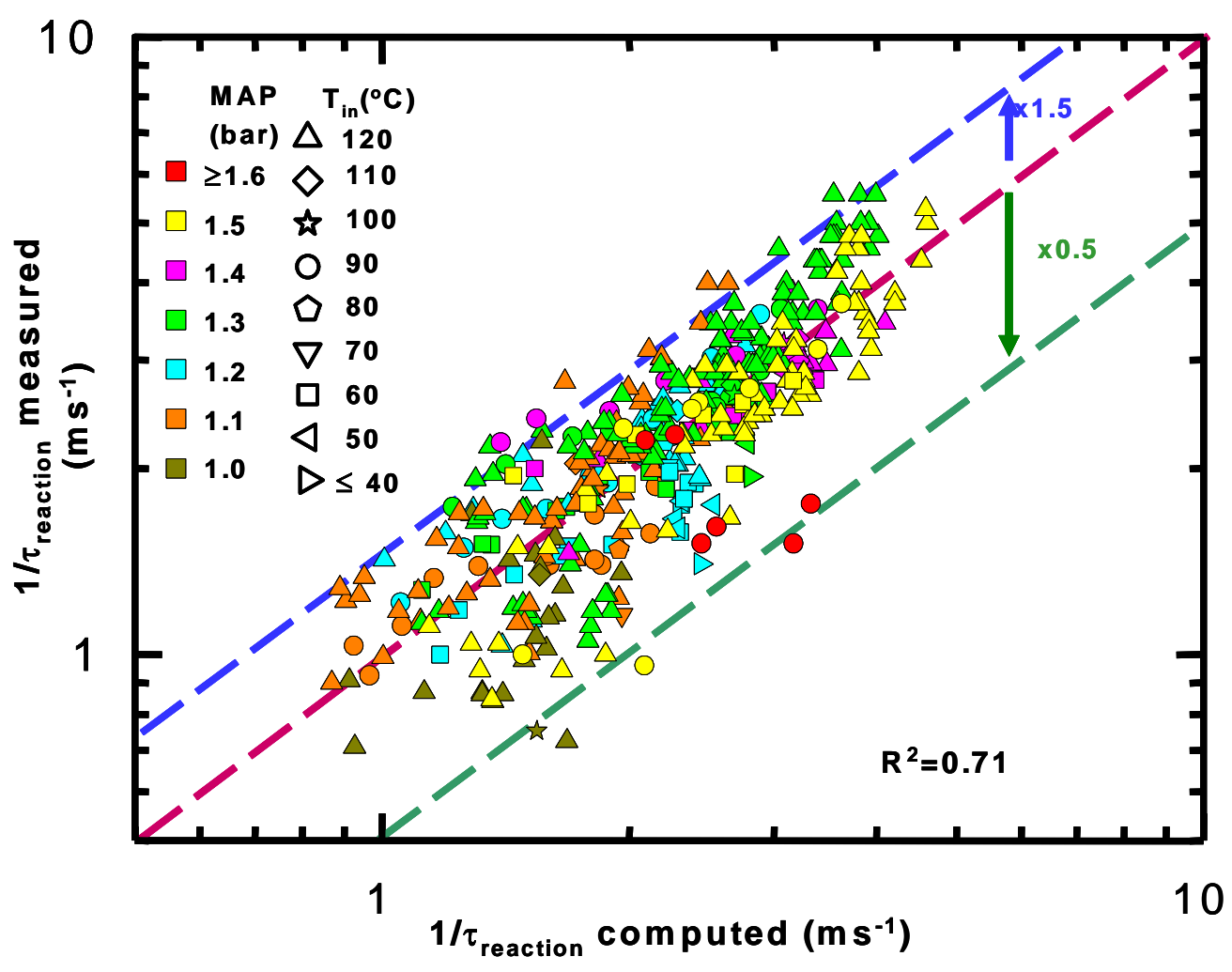

Fig. 19 Comparison between reaction rate obtained from data and from the correlation of Eq. (13).

To assess the stratification factors, it was noted that precise quantitative measures of stratification are difficult. Therefore, the following variables that addressed stratification were added to the regression:

(1) $\left(T_{\text {exh }}-T_{\text {in }}\right)$; to represent the temperature non-uniformity due to the mixing between the hot trapped residual and the relatively cool intake fluid.

(2) $\mathrm{x}_{\mathrm{r}}\left(1-\mathrm{x}_{\mathrm{r}}\right)$; to represent the concentration non-uniformity due to the mixing between the residual and the fresh charge.

(3) $\left(1-\mathrm{X}_{\mathrm{EGR}}\right.$; to represent the concentration non-uniformity due to the mixing between the recirculated exhaust gas and the fresh charge. (Strictly speaking, the expression should be $\mathrm{x}_{\mathrm{EGR}}\left(1-\mathrm{x}_{\mathrm{EGR}}\right)$. However, a significant part of our data set was obtained with $\mathrm{x}_{\mathrm{EGR}}=0$, then such an expression would not work.)

It is recognized that the above variables did not address the stratification profiles, nor did they address any correlation between temperature and concentration stratifications. Nevertheless, assessing the regression by inclusion of these variables would give an indication of the effects of stratification.

The following correlation was obtained when the above "stratification" variables were added to the regression. 


$$
\begin{aligned}
& \left(\frac{1}{\tau_{\text {reaction }}}\right)= \\
& \left(\mathrm{T}_{\text {exh }}-\mathrm{T}_{\text {in }}\right)^{-1.63}\left[\mathrm{x}_{\mathrm{r}}\left(1-\mathrm{x}_{\mathrm{r}}\right)\right]^{-3.73}\left(1-\mathrm{x}_{\mathrm{EGR}}\right)^{0.46} \cdot \mathrm{x}_{\text {fuel }}{ }^{1.38} \cdot \mathrm{P}_{10 \mathrm{BTC}}{ }^{2.55} \cdot \exp \left(\frac{-893}{\mathrm{~T}_{10 \mathrm{BTC}}}\right) \\
& \left(\tau_{\text {reacton }} \text { in } \mathrm{m} \mathrm{s} ; \mathrm{P} \text { in bar; } \mathrm{T} \text { in }{ }^{\circ} \mathrm{K}\right)
\end{aligned}
$$

The result of the regression with this expanded set of variables is shown in Fig. 20. Although the stratification variables were a very crude representation of stratification, the agreement improved significantly $\left(\mathrm{R}^{2}=0.87\right)$, thus giving support to the hypothesis that stratification did play a significant role in explaining the data scatter in Fig. 19.

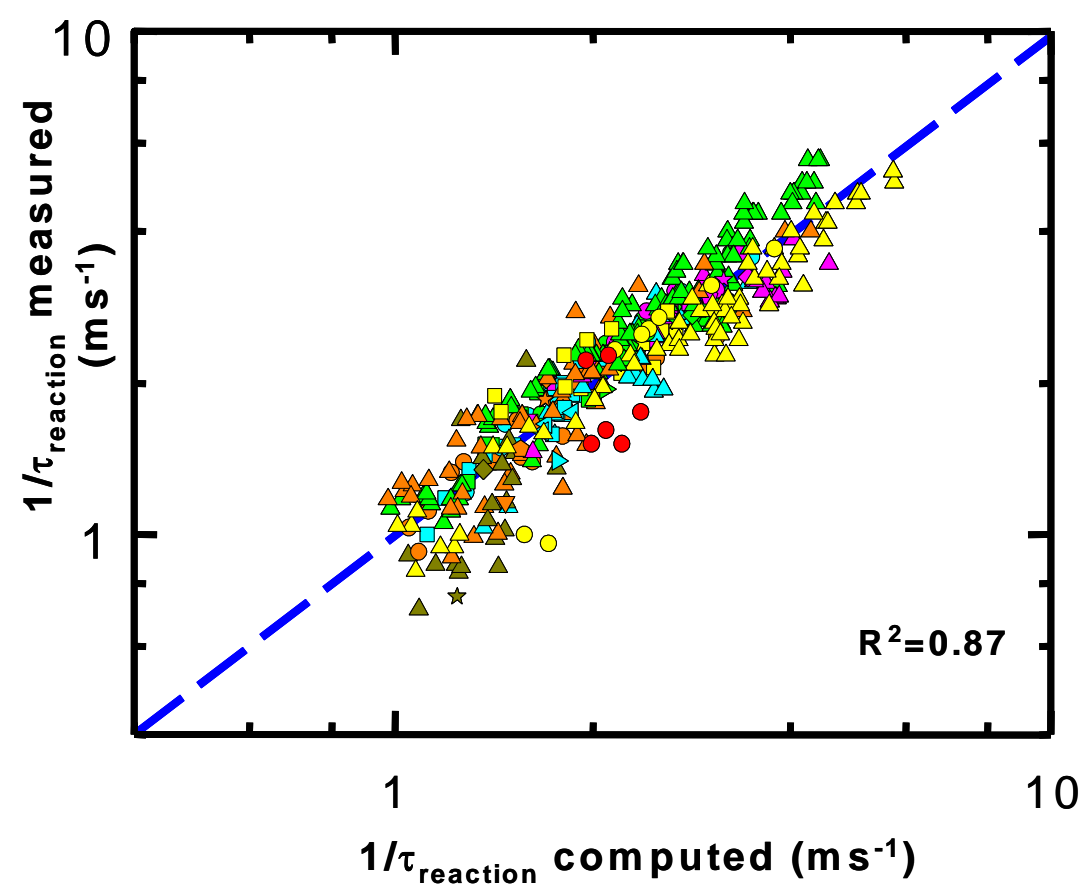

Fig. 20 Comparison between reaction rate obtained from data and from the correlation of Eq. (5)

In summary, a overall reaction rate $1 / \tau_{\text {reaction }}$ may be related to the thermodynamics and mole fraction variables by the correlation of Eq. (4). Then the MPRR value may be calculated from

$$
\operatorname{MPRR}=(\gamma-1)\left[\frac{\mathrm{m}_{\mathrm{f}} \mathrm{LHV}}{\mathrm{V} \tau_{\text {reaction }}}\right]
$$

Since the rapid pressure rise nominally occurs near TDC, the volume $\mathrm{V}$ at the maximum pressure rise rate point in Eq. (15) may be approximated by an average value, say $\mathrm{V}_{10}{ }^{\circ}$, the cylinder volume at $10^{\circ}$ after TDC. (For compression ratios of 10 to 15 , the change of cylinder volume respect to $\mathrm{V}_{10}{ }^{\circ}$ is less than $15 \%$ from TDC to $15^{\circ}$ after TDC.) The utility of Equations (13) and (15) is that they provide a reasonable assessment of the scaling of MPRR when the engine operating condition changes, notwithstanding the stratification effects. 


\section{IMPACT OF EGR ON HCCI ENGINE MISFIRE LIMIT AT HIGH LOAD}

Exhaust gas recirculation was found to be effective in suppressing MPRR. However, EGR displaces air so that for a given value of MAP and NVO setting, the load will decrease. If the NVO is adjusted so that the amount of burned gas (residual plus EGR) is kept constant, the temperature of the trapped charge will decrease as EGR increases. At some point, the charge temperature will be insufficient to sustain HCCI operation and the engine will misfire.

To assess the interactions between MPRR, NIMEP, and misfire in a HCCI engine near the high load limit, the engine behavior was mapped extensively at selected values of MAP and intake fluid temperature. The air/fuel ratio was at stoichiometric. In this process, the EGR valve was set at various positions (see Fig. 1), and then NVO was varied with the electromagnetic valves until the engine misfired. The misfired points were defined as where the engine would still run stably, but a one degree crank angle change in NVO would lead to unstable operation. (At the latter setting, the engine could run for a short time and then became erratic with very large cycle-to-cycle fluctuations and then died.) The values of EGR and residual fraction were not explicitly controlled; these values were calculated from the intake port $\mathrm{CO}_{2}$ measurement and the exhaust pressure and temperature (see experimental section).

A typical map of MPRR and misfire limit is shown in Fig. 21. The horizontal axis of the contours is the total burned gas fraction, $x_{\text {burn }}$, in the unburned charge $\left(x_{\text {burn }}=x_{\mathrm{r}}+x_{E G R}\right)$. The value was varied by the combination of EGR valve and NVO settings. The vertical axis is the fraction of EGR in the burned gas. The MPRR values decreased with both increase of $\mathrm{x}_{\text {burn }}$ and of the EGR fraction in the burned gas.

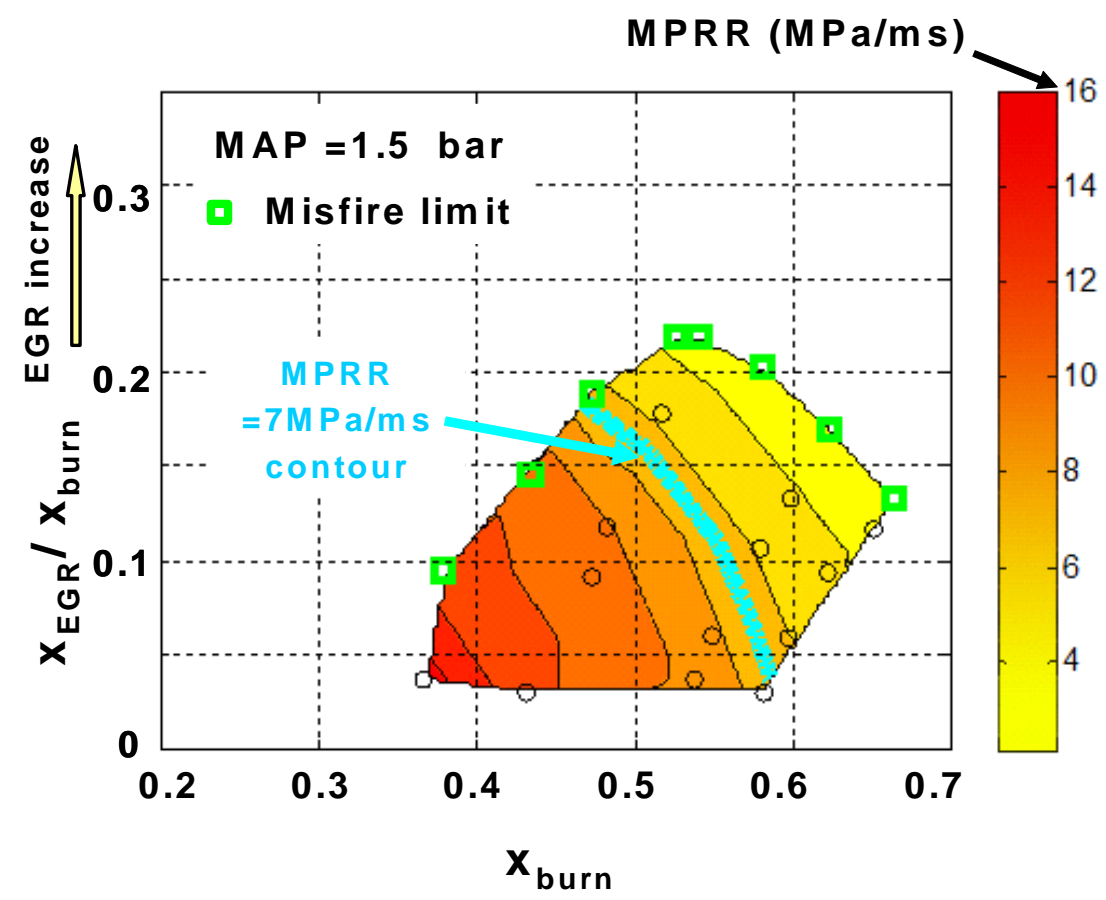

Figure 21 Map of MPRR and misfire limit at MAP $=1.5$ bar; $\lambda=1$. The markers are the mapped points, the data from which the contour map was constructed.

The corresponding map of NIMEP and misfire limit is shown in Fig. 22. The NIMEP values were mainly a function of $\mathrm{x}_{\text {burn }}$ (NIMEP increase with decrease of $\mathrm{x}_{\text {burn }}$ ) and not sensitive to the EGR fraction. The slight dependence of the latter was due to the variation of fuel conversion efficiency. 


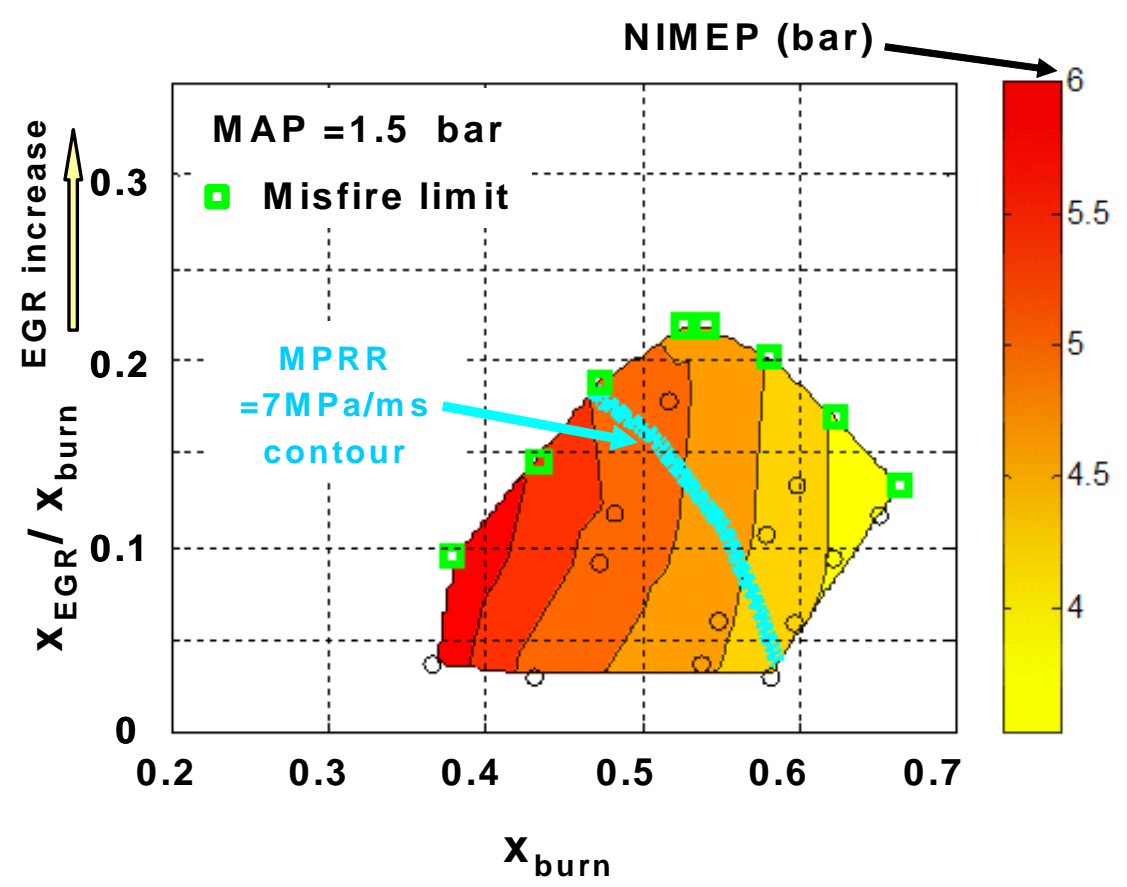

Fig. 22 Map of NIMEP and misfire limit at MAP $=1.5$ bar; $\lambda=1$. The markers are the mapped points, the data from which the contour map was constructed. The $7 \mathrm{MPa} / \mathrm{ms}$ MPRR contour is also displayed.

It is observed in Fig.22 and 23 that as $\mathrm{x}_{\text {burn }}$ increased, the EGR fraction in the burned gas at the misfire limit first increased (more tolerant to EGR) and then decreased (less tolerant to EGR). This observation was due to the fact that the charge temperature, which enables HCCI initiation, is a function of the trapped enthalpy of the charge. For the same EGR fraction, as $\mathrm{x}_{\text {burn }}$ increases, the charge temperature increases first because more hot residual is trapped. Beyond a certain value of $\mathrm{x}_{\text {burn }}$, however, the burned gas temperature decreases because of charge dilution and. Thus the tolerance to EGR first increases with $\mathrm{x}_{\text {burn }}$ and then decreases.

The relationship between the engine variables at the misfire limit was sought. The range of data encompassed MAP from 1.1 to $1.7 \mathrm{bar}$, and intake fluid temperature from 60 to $150^{\circ} \mathrm{C}$. The regressed variables were $\mathrm{x}_{\mathrm{O} 2}, \mathrm{x}_{\mathrm{r}}$, Tin, and MAP. The following correlation was obtained.

$$
\mathrm{x}_{\mathrm{O}_{2}}=3.036 \mathrm{x}_{\mathrm{r}}^{-0.978} \mathrm{~T}_{\mathrm{in}}{ }^{-0.693} \mathrm{MAP}^{-0.428}
$$

The result of the regression is shown in Fig. 23. The agreement was excellent $\left(R^{2}=0.997\right)$. The very tight correlation indicates that, unlike the overall reaction rate $\left(1 / \tau_{\text {reaction }}\right.$ in Eq. (13), which determines MPRR), the misfire limit was predominately determined by the overall thermodynamics variables and the residual gas fraction; it was not sensitive to stratification. 


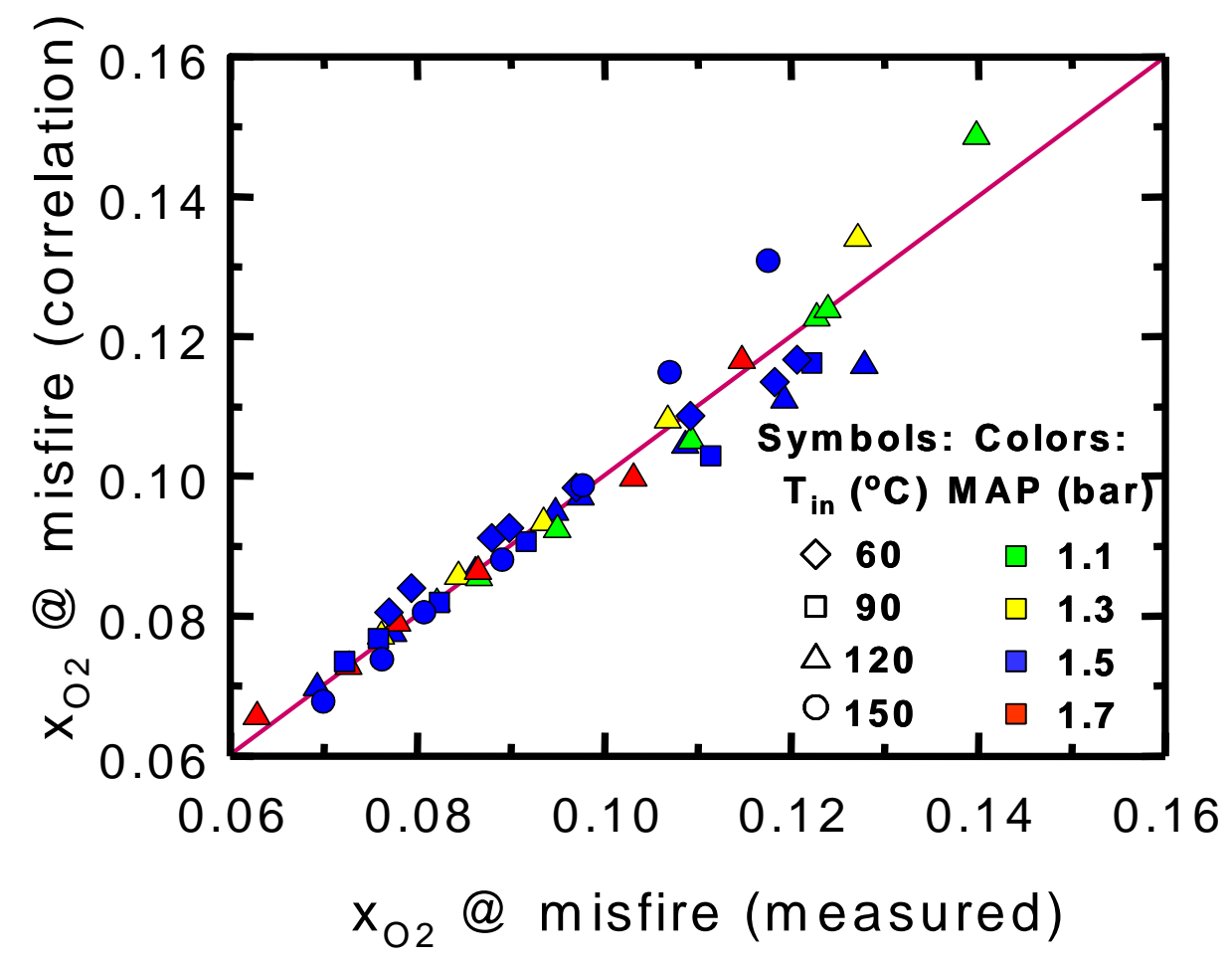

Fig. 23 Comparison between measured $\mathrm{x}_{\mathrm{O} 2}$ at misfire limit and computed value according to Eq. (16)

\section{HIGH LOAD LIMIT, MISFIRE LIMIT, AND INFLUENCE OF EGR}

To understand the relationship between NIMEP and MPRR under different engine setting of MAP, residual gas fraction and EGR, the topology of the NIMEP and MPRR contours are examined as a function of the mole fraction of unburned charge oxygen $\mathrm{x}_{\mathrm{O} 2}$ and MAP. The use of $\mathrm{x}_{\mathrm{O} 2}$ as a governing parameter is because of its significant influence on MPRR (see discussion immediately after Eq. (13)). The value of $\mathrm{xO} 2$ can easily be calculated from the mole fractions of residual $\left(\mathrm{x}_{\mathrm{r}}\right)$ and EGR $\left(\mathrm{x}_{\mathrm{EGR}}\right)$; see Appendix A.

For the case of no EGR, a typical contour map in the $\mathrm{x}_{\mathrm{O} 2}$-MAP diagram is shown in Fig. 24 with the misfire boundary. The NIMEP increased with both MAP and $\mathrm{x}_{\mathrm{O} 2}$; the constant NIMEP contours were therefore lines of negative slopes. The MPRR also increased with both MAP and $\mathrm{x}_{\mathrm{O} 2}$; thus the MPRR contours were also lines of negative slopes. It is shown in Appendix B that the MPRR contour lines are always steeper (more negative) than the NIMEP contour lines. This observation has a significant implication on the high load operating limit. 


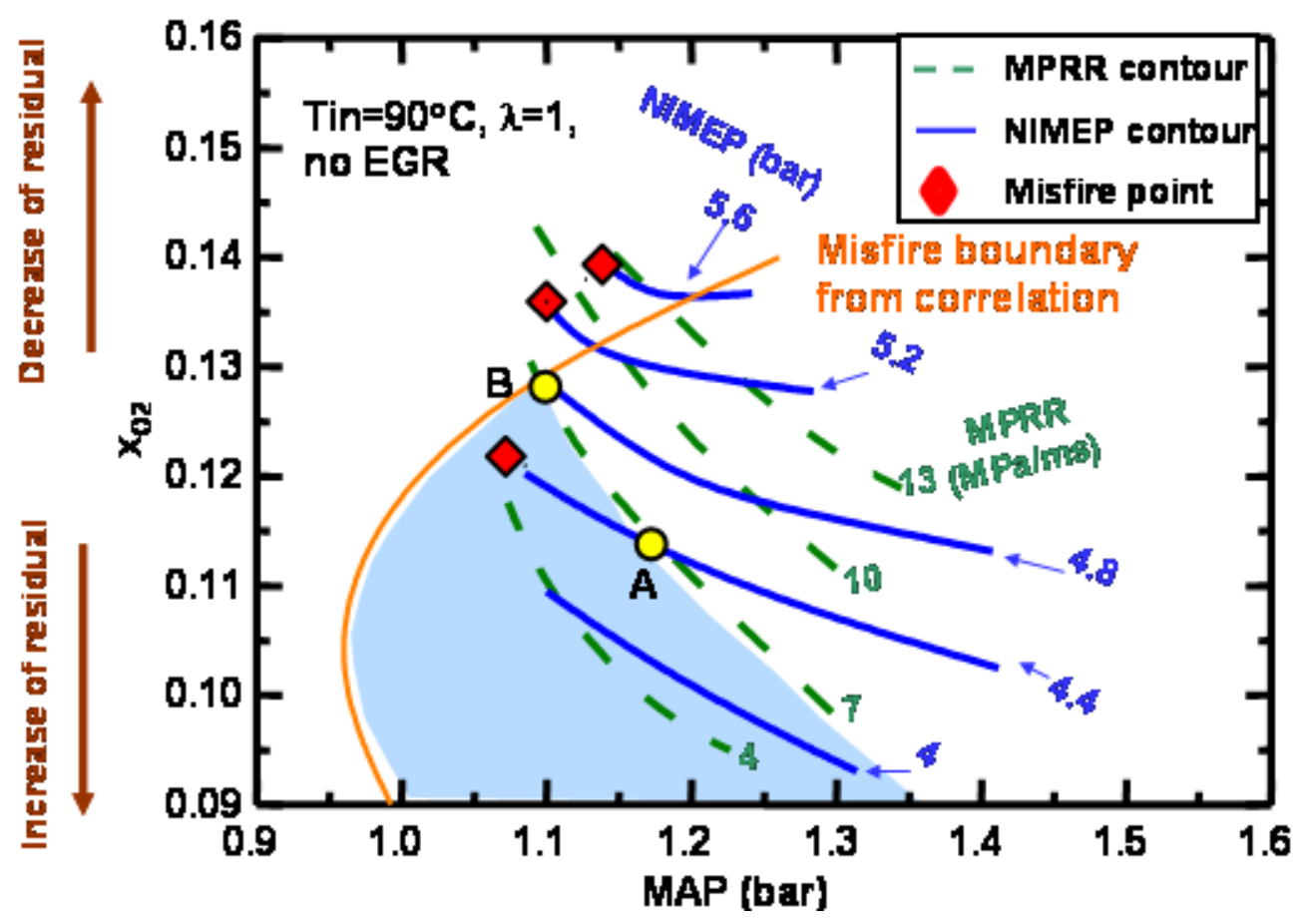

Fig. 24 MPRR/ NIMEP contours and misfire boundary on the $\mathrm{x}_{\mathrm{O} 2}-\mathrm{MAP}$ diagram; $\mathrm{T}_{\text {in }}=90^{\circ} \mathrm{C}, \lambda=1$, no EGR. Both the actual misfiring point and the misfire boundary according to the correlation of Eq. (16) are shown. Shaded area is the permitted region of operation under MPRR constraint of $7 \mathrm{MPa} / \mathrm{ms}$.

For illustrative purpose, assume that the MPRR value is constrained at $7 \mathrm{MPa} / \mathrm{ms}$. Then the MPRR constraint and preventing the engine from misfiring will limit the operating domain to be in the shaded area in Fig. 24. If, for example, the operating point is at A (4.4 bar NIMEP), then because that the MPRR contours are steeper than the NIMEP contours, the NIMEP could always be increased by shifting the operating point to the left along the MPRR contour until the misfiring point is reached (point $\mathrm{B}$, at NIMEP of 4.8 bar). Thus for MPRR constrained operation, the maximum NIMEP occurs at the intersection between the MPRR constraint line and the misfire boundary. Hence the high load limit and the misfire limit coincide under the MPRR constraint.

If EGR is used, both the MPRR contour and the misfire boundary will move. The NIMEP contours will mainly depend on the amount of fuel burned (with modification due to change in fuel conversion efficiency), and thus do not change much on the $\mathrm{x}_{\mathrm{O} 2}$-MAP diagram. The typical situation is shown in Fig. 25. 


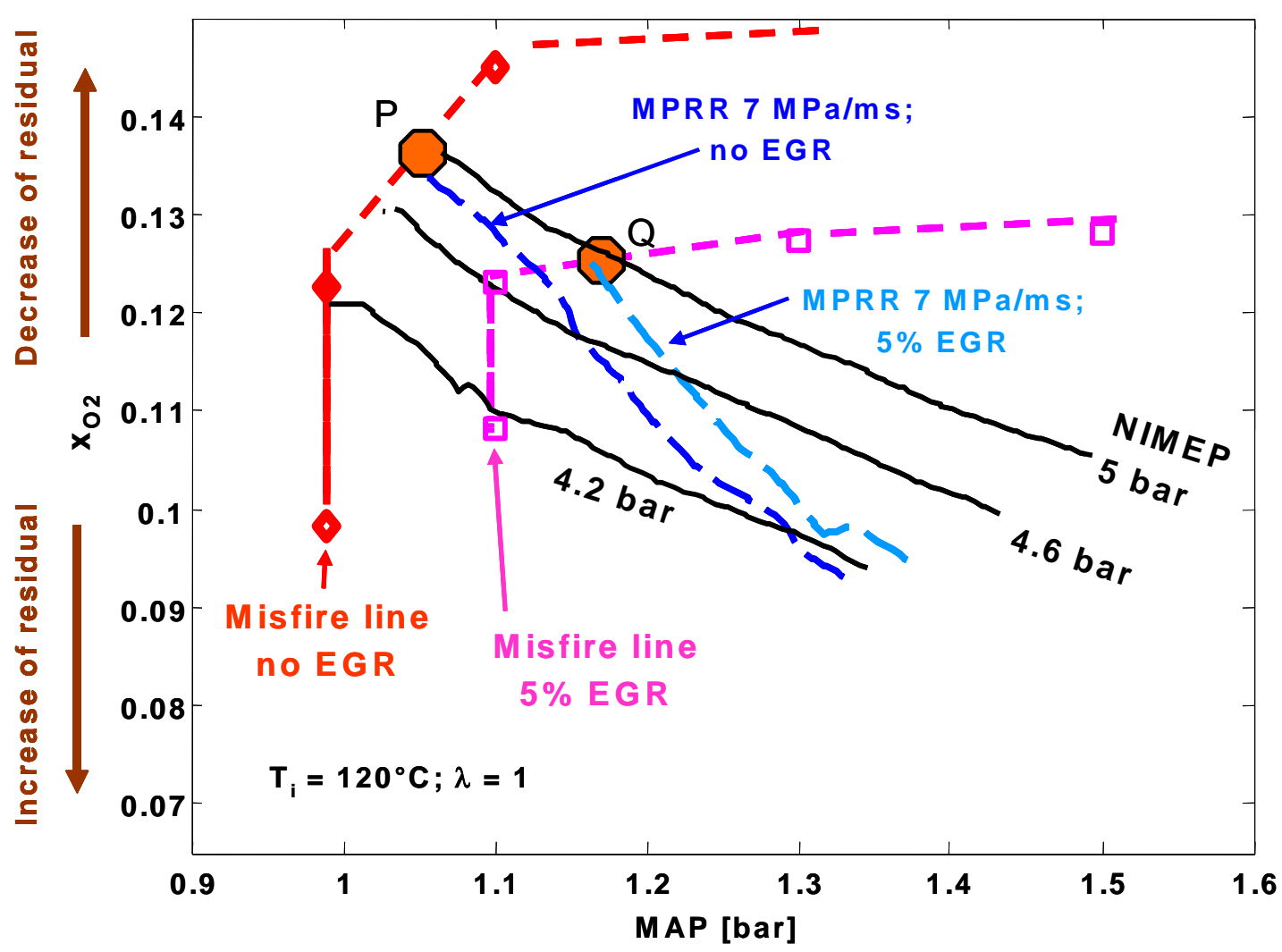

Fig. 25. MPRR, NIMEP contours and misfire boundary on the $\mathrm{x}_{\mathrm{O} 2}$-MAP diagram, showing effect of EGR; $\mathrm{T}_{\mathrm{in}}=120^{\circ} \mathrm{C}, \lambda=1$.

The effects of increasing EGR from 0 to $5 \%$ (operating at $\lambda=1$ ) on the MPRR/ NIMEP contours and misfire boundary are shown in Fig. 25. The NIMEP contours did not change materially. The MPRR contours shifted up and to the right; thus at the same burned gas fraction in the unburned mixture (same $\mathrm{x}_{\mathrm{O} 2}$ ), the engine could be operated at a higher MAP with the same MPRR. The misfire boundary, however, shifted down and to the right. The net effect on maximum NIMEP may be illustrated with the example of using the constraint of MPRR $=7 \mathrm{MPa} / \mathrm{ms}$. Then the high load limit is at point $\mathrm{P}$ (intersection of the $\mathrm{MPRR}=7 \mathrm{MPa} / \mathrm{ms}$ contour and the misfire boundary) for $0 \% \mathrm{EGR}$, and at point $\mathrm{Q}$ for $5 \%$ EGR. These two points have approximately the same NIMEP even though they are operating at different MAP.

The change in maximum load under the MPRR constraint of $7 \mathrm{MPa} / \mathrm{ms}$ as a function of EGR is shown in Fig. 26. For EGR increase from 2.5 to $21 \%$, the maximum NIMEP only changed modestly (from 5.1 bar to 5.7 bar), although the MAP had increased from 1.1 to 1.7 bar. Thus the MPRR constrained maximum load is roughly neutral to the amount of EGR. 


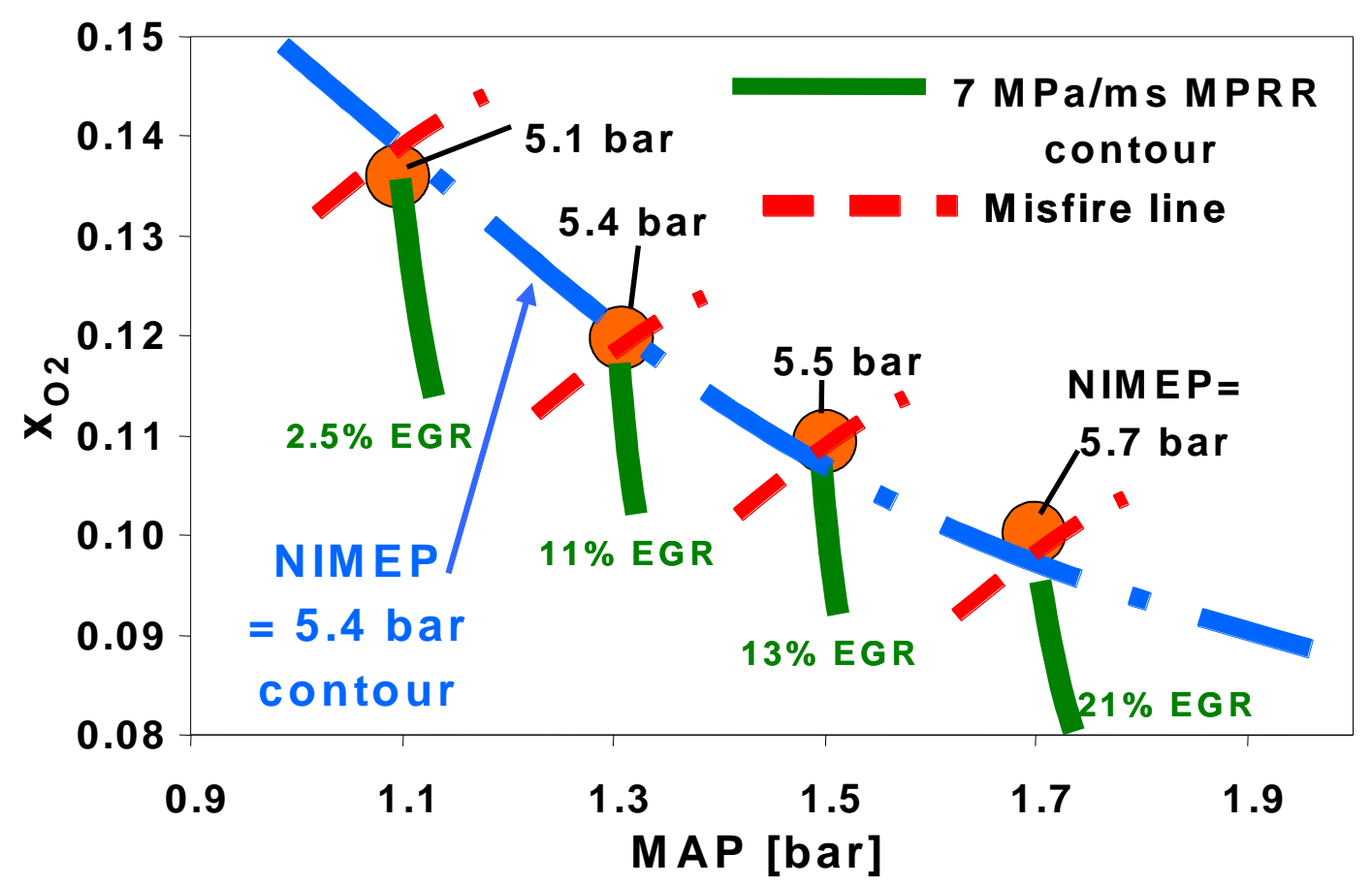

Fig. 26. High load limit points at different level of EGR; $\mathrm{T}_{\text {in }}=90^{\circ} \mathrm{C} ; \lambda=1$.

\section{SUMMARY/CONCLUSIONS}

The behavior of a boosted gasoline HCCI engine using Negative-Valve-Overlap at the high load limit was investigated. The maximum pressure rise rate (MPRR), which constrains the engine high load limit, is interpreted as proportional to the fuel energy density of the charge multiplied by an overall reaction rate $\left(1 / \tau_{\text {reaction }}\right)$. The effects of engine operating condition: manifold absolute pressure, EGR and amount of residual on $1 / \tau_{\text {reaction }}$ were regressed in terms of the thermo-chemistry variables; See Eq. (13). The data scatter from this correlation (with $\mathrm{R}^{2}=0.71$ ) was attributed to the effects of temperature and species concentration stratification. Notwithstanding the stratification effects, the correlation is useful for scaling the MPRR values due to change of engine operating condition since it reflects the gross change of the thermo-chemistry variables.

The misfire limit at high load under different boost, intake temperature, and EGR was found to be tightly correlated to the thermo-chemistry variables; see Eq. (16). The tightness of the correlation $\left(\mathrm{R}^{2}=0.997\right)$ suggests that the misfire limit is not sensitive to the stratification details of the engine operation.

The amount of boost, EGR, and residual gas need to be chosen to maximize the load (in terms of NIMEP) of a HCCI engine under MPRR constraint. It was found that under such constraint, the maximum load always occurs at the intersection between the constraining MPRR line of operation and the misfire boundary. The use of EGR shifts both the constant MPRR line and the misfire boundary so that the intersection is at a different operating point (in terms of the amount of boost and burned gas fraction in the unburned charge). However, the NIMEP does not change substantially between these points; thus under MPRR constraint, the high load limit is approximately neutral to EGR. 


\section{REFERENCES}

1. H. Santoso, J. Matthews and W. K. Cheng, "Managing SI/HCCI Dual-Mode Engine Operation," SAE Paper 2005-01-0162, 2005.

2. Y. Urata, M. Awasaka, J. Takanashi, T. Kakinuma, T. Hakozaki and A. Umemoto, "A Study of Gasoline-Fuelled HCCI Engine Equipped with an Electromagnetic Valve Train," 2004-01-1898.

3. J. Hyvönen, G. Haraldsson, B. Johansson, "Supercharging HCCI to Extend the Operating Range in a Multi-Cylinder VCR-HCCI Engine," SAE Paper 2003-01-3214, 2003.

4. D. Yap, M.L. Wyszynski, A. Megaritis, H. Xu, "Applying boosting to gasoline HCCI operation with residual gas trapping," SAE Paper 2005-01-2121, 2005

5. M. Sjöberg, J. E. Dec, "EGR and Intake Boost for Managing HCCI Low-Temperature Heat Release over Wide Ranges of Engine Speed," SAE Paper 2007-01-0051, 2007.

6. T. Johansson, B. Johansson, P. Tunestål, H. Aulin, "HCCI Operating Range in a Turbo-charged Multi Cylinder Engine with VVT and Spray-Guided DI," SAE Paper 2009-01-0494, 2009.

7. N. Anderson, "Examination of the High Load Limit of an HCCI Engine," MS thesis, Department of Mechanical Engineering, MIT, 2008.

8. P.E. Yelvington, W.H. Green, "Prediction of the Knock Limit and Viable Operating Range for a Homogeneous-Charge Compression-Ignition(HCCI) Engine," SAE Paper 2003-01-1092, 2003.

9. J. A. Eng, "Characterization of Pressure Wave Oscillation in HCCI Combustion," SAE Paper 2002-012859, 2002.

10. M.M. Andreae, W.K. Cheng, T.Kenney, J. Yang, “On HCCI Knock,” SAE Paper 2007-01-1858, 2007.

11. J. Kamio, T. Kurotani, K. Kuzuoka, Y. Kubo, H. Taniguchi, and K. Hashimoto, "Study on HCCI-SI Combustion Using Fuels Containing Ethanol," SAE Paper 2007-01-4051.

12. T.Kuboyama, Y. Moriyoshi, K. Hatamura, T. Yamada, J. Takanashi, "An Experimental Study of a Gasoline HCCI Engine Using the Blow-Down Super Charge System," SAE Paper 2009-01-0496, 2009.

13. C. Wildman, R.J. Scaringe, W. Cheng, "On the Maximum Pressure Rise Rte in Boosted HCCI Operation," SAE Paper 2009-01-2727, 2009.

\section{APPENDIX A: RELATING $\mathrm{x}_{\mathrm{r}}$ AND $\mathrm{x}_{\mathrm{EGR}}$ TO $\mathrm{x}_{\mathrm{O} 2}$}

Let the cylinder content be consisted of $\mathrm{N}_{\mathrm{r}}$ moles of residual, $\mathrm{N}_{\mathrm{EGR}}$ moles of recirculated exhaust gas, $\mathrm{N}_{\mathrm{a}}$ modes of air and $\mathrm{N}_{\mathrm{f}}$ modes of fuel. Then the number of moles of oxygen is:

$$
\mathrm{N}_{\mathrm{O}_{2}}=\mathrm{x}_{\mathrm{O}_{2}}^{\mathrm{b}}\left(\mathrm{N}_{\mathrm{r}}+\mathrm{N}_{\mathrm{EGR}}\right)+\mathrm{x}_{\mathrm{O}_{2}}^{\mathrm{a}} \mathrm{N}_{\mathrm{a}}
$$

where $\mathrm{x}_{\mathrm{O}_{2}}^{\mathrm{a}}$ and $\mathrm{x}_{\mathrm{O}_{2}}^{\mathrm{b}}$ are respectively the mole fractions of oxygen in air and in the burned gas. (The former is $1 / 3.773$; the latter is determined by the stoichiometry of combustion.) The total number of moles is:

$$
\mathrm{N}_{\text {total }}=\mathrm{N}_{\mathrm{a}}+\mathrm{N}_{\mathrm{f}}+\mathrm{N}_{\mathrm{r}}+\mathrm{N}_{\mathrm{EGR}}
$$

Therefore, the mole fraction of oxygen in the unburned charge is given by:

$$
x_{O_{2}}=x_{O_{2}}^{b}\left(x_{r}+x_{E G R}\right)+x_{O_{2}}^{a}\left(1-x_{r}-x_{E G R}\right) \frac{1}{1+\left(W_{a} / W_{f}\right) /(A / F)}
$$

where $\mathrm{W}_{\mathrm{a}}$ and $\mathrm{W}_{\mathrm{f}}$ are the air and fuel molecular weights and $\mathrm{A} / \mathrm{F}$ is the air-to-fuel mass ratio. 


\section{APPENDIX B: TOPOLOGY OF THE NIMEP AND MPRR CONTOUR LINES}

The topology of the NIMEP and MPRR contours plotted with $\mathrm{x}_{\mathrm{O} 2}$ and MAP as the vertical and horizontal axes may be examined as follows. The NIMEP may be expressed as:

$$
\text { NIMEP }=\frac{\text { MAP }}{R T_{\text {in }}} V_{D} \eta_{v, m} x_{02}\left(\frac{x_{f}}{x_{O 2}}\right)_{S} \frac{(\text { LHV })_{m}}{\lambda} \eta_{f, i} \frac{1}{V_{D}}
$$

where $R$ is the universal gas constant, $T_{\text {in }}$ the intake fluid temperature, $V_{D}$ the displacement volume, $\eta_{v, m}$ the volumetric efficiency based on the manifold condition, $\left(\mathrm{x}_{\mathrm{f}} / \mathrm{x}_{\mathrm{O} 2}\right)_{\mathrm{s}}$ the stoichiometric fuel to oxygen molar ratio, $\lambda$ the air equivalence ratio, $\eta_{\mathrm{f}, \mathrm{i}}$ the indicated net fuel conversion efficiency, and (LHV) $)_{\mathrm{m}}$ the fuel molar heating value. Thus the relationship between $\mathrm{x}_{\mathrm{O} 2}$ and MAP at constant NIMEP is given by:

$$
x_{\mathrm{O} 2}=\frac{\text { NIMEP }}{\operatorname{MAP}} \frac{\mathrm{RT}_{\mathrm{in}}}{\eta_{\mathrm{v}, \mathrm{m}} \eta_{\mathrm{f}, \mathrm{i}}\left(\frac{\mathrm{x}_{\mathrm{f}}}{\mathrm{x}_{\mathrm{O} 2}}\right)_{\mathrm{S}} \frac{(\text { LHV })_{\mathrm{m}}}{\lambda}}
$$

Since the $\eta$ values do not change substantially, at a given $T_{\text {in }}$ and $\lambda$, the NIMEP contours are approximately hyperbolas on the $\mathrm{x}_{02}$ versus MAP plot. The slope of the contour may be measured by the logarithmic derivative

$$
\left[\frac{\mathrm{d} \ell \mathrm{n}\left(\mathrm{x}_{\mathrm{O} 2}\right)}{\mathrm{d} \ell \mathrm{n}(\mathrm{MAP})}\right]_{\text {NIMEP }} \approx-1
$$

Thus along the constant NIMEP line, a $10 \%$ change in $\mathrm{x}_{\mathrm{O} 2}$ value would correspond to a $10 \%$ change in the MAP value; this assessment is consistent with the NIMEP contours depicted in Fig. 10.

The MPRR may be expressed via an overall reaction time $\tau_{\text {reaction, }}$, as:

$$
\operatorname{MPRR}=\frac{1}{\tau_{\text {reaction }}} \frac{(\gamma-1) \text { NIMEP } V_{D}}{\eta_{f, i} V_{C A 50}}
$$

where the cylinder volume at $50 \%$ burn, $\mathrm{V}_{\mathrm{CA5} 0}$, is used to estimate the cylinder volume at the maximum pressure rise point in the cycle. Using Eq. (B1) to express NIMEP in terms of $\mathrm{x}_{\mathrm{O} 2}$ and MAP, Eq. (B4) becomes

$$
\text { MPRR }=\frac{1}{\tau_{\text {reaction }}} \frac{(\gamma-1) V_{D}}{\eta_{f, i} V_{C A 50}}\left[\frac{M A P}{R T_{\text {in }}} V_{D} \eta_{V, m} x_{O 2}\left(\frac{x_{f}}{x_{O 2}}\right)_{s} \frac{(L H V)_{m}}{\lambda} \eta_{f, i} \frac{1}{V_{D}}\right]
$$

Thus the $\mathrm{x}_{\mathrm{O} 2}$, MAP relationship along a MPRR contour is given by:

$$
\mathrm{x}_{\mathrm{O} 2}=\frac{\mathrm{MPRR}}{\mathrm{MAP}} \tau_{\text {reaction }} \frac{\mathrm{RT}_{\text {in }}}{\eta_{\mathrm{v}, \mathrm{m}}\left(\frac{\mathrm{x}_{\mathrm{f}}}{\mathrm{x}_{\mathrm{O} 2}}\right)_{\mathrm{S}} \frac{\gamma-1}{\lambda}(\text { LHV })_{\mathrm{m}} \frac{\mathrm{V}_{\mathrm{D}}}{\mathrm{V}_{\text {CA } 50}}}
$$

Since $\eta_{v, m}$ and $V_{\text {CA50 }}$ do not significantly change, for a fixed $T_{\text {in }}$ and $\lambda$, the slope of the MPRR contour on the $\mathrm{x}_{02}$ versus MAP plot may be measured by:

$$
\left[\frac{\mathrm{d} \ell \mathrm{n}\left(\mathrm{x}_{\mathrm{O} 2}\right)}{\mathrm{d} \ell \mathrm{n}(\mathrm{MAP})}\right]_{\mathrm{MPRR}} \approx-1+\frac{\mathrm{d} \ell \mathrm{n}\left(\tau_{\text {reaction }}\right)}{\mathrm{d} \ell \mathrm{n}(\mathrm{MAP})}
$$

Because $\tau_{\text {reaction }}$ decreases with MAP, Eq. (B7), together with Eq. (B3), indicate that the MPRR contour would be steeper (more negative) than the constant NIMEP contour. 


\section{Task 4: Increased power density by turbo/supercharging and temperature control (UCB)}

Objective: Investigate supercharger and turbocharger use at moderate to high load operation on a multi-cylinder HCCI engine with heat exchangers and fast flow diverters as a means to limit knocking combustion at high loads.

\section{Accomplishments/Status:}

\section{Boosted HCCI Operation}

Our previous results with both gasoline and ethanol have shown that loads can be increased by boosting up to 1.7 bar MAP, with IMEP values up to 5.75 bar using higher fuel loads $(\Phi=0.36)$ at intake pressures of 1.42 bar.

The present experiments, which are conducted with commercial grade gasoline purchased in California (includes 6\% Ethanol), indicate that higher IMEP (above 6 bar) can be obtained by using delaying combustion timing, and increasing the boost pressure. Figure 14 demonstrates this result, and shows that maximum IMEP is limited by a ringing limited region, and the maximum combustion timing delay is limited by a misfire region. Our tests indicate that maximum IMEP can be achieved at target points near the intersection of these two limiting regions.

IMEP vs. CA50 for Various Intake Pressures

Phi $=0.40,1800$ RPM

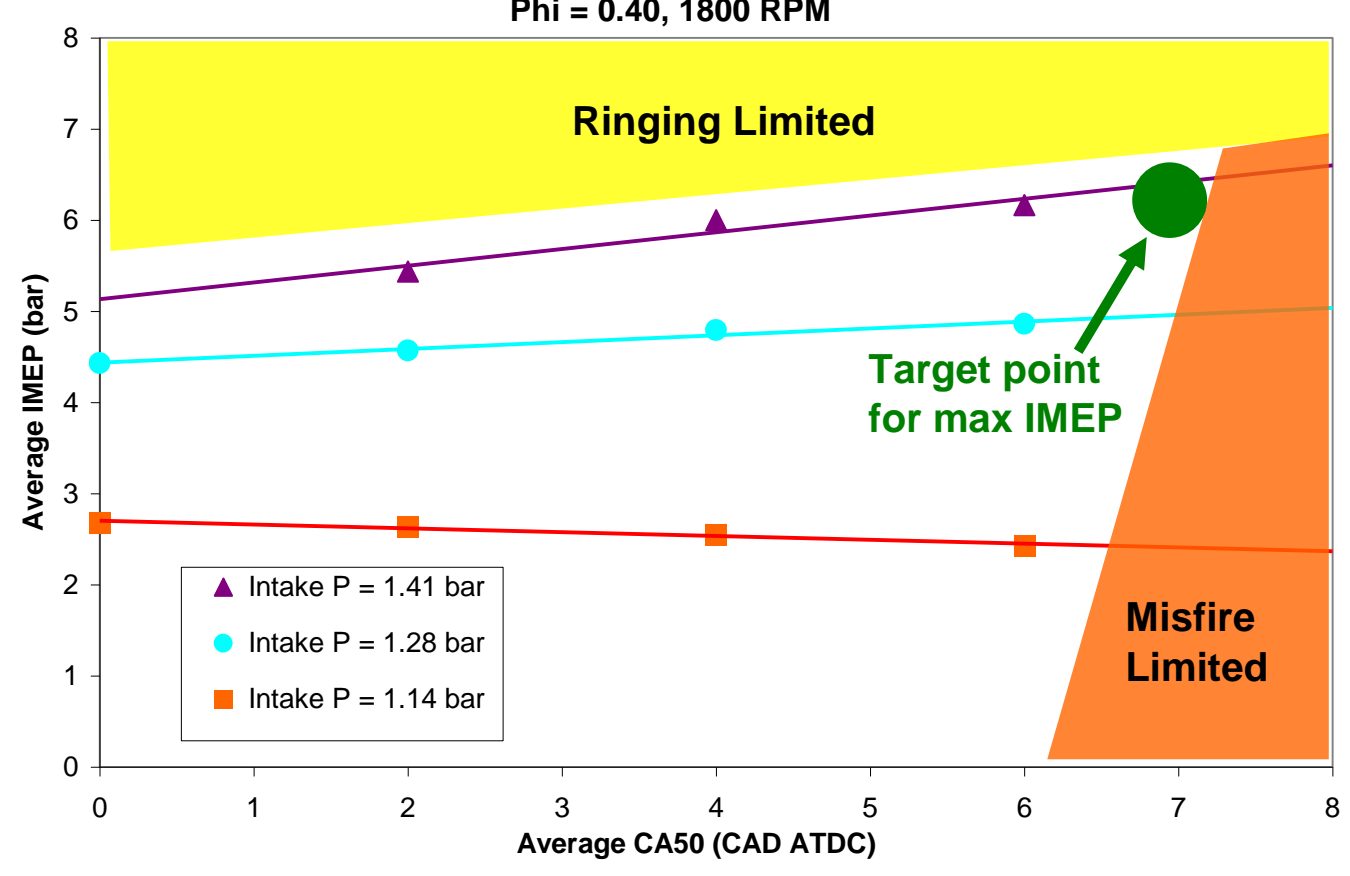

Figure 14 - Test results indicating existence of a maximum IMEP point

By comparing data points at several equivalence ratios, we found that the ringing limited region is encountered sooner (at lower IMEPs) when the equivalence ratio is higher. This dependence between ringing limits and equivalence ratio is illustrated in Figure 15: 


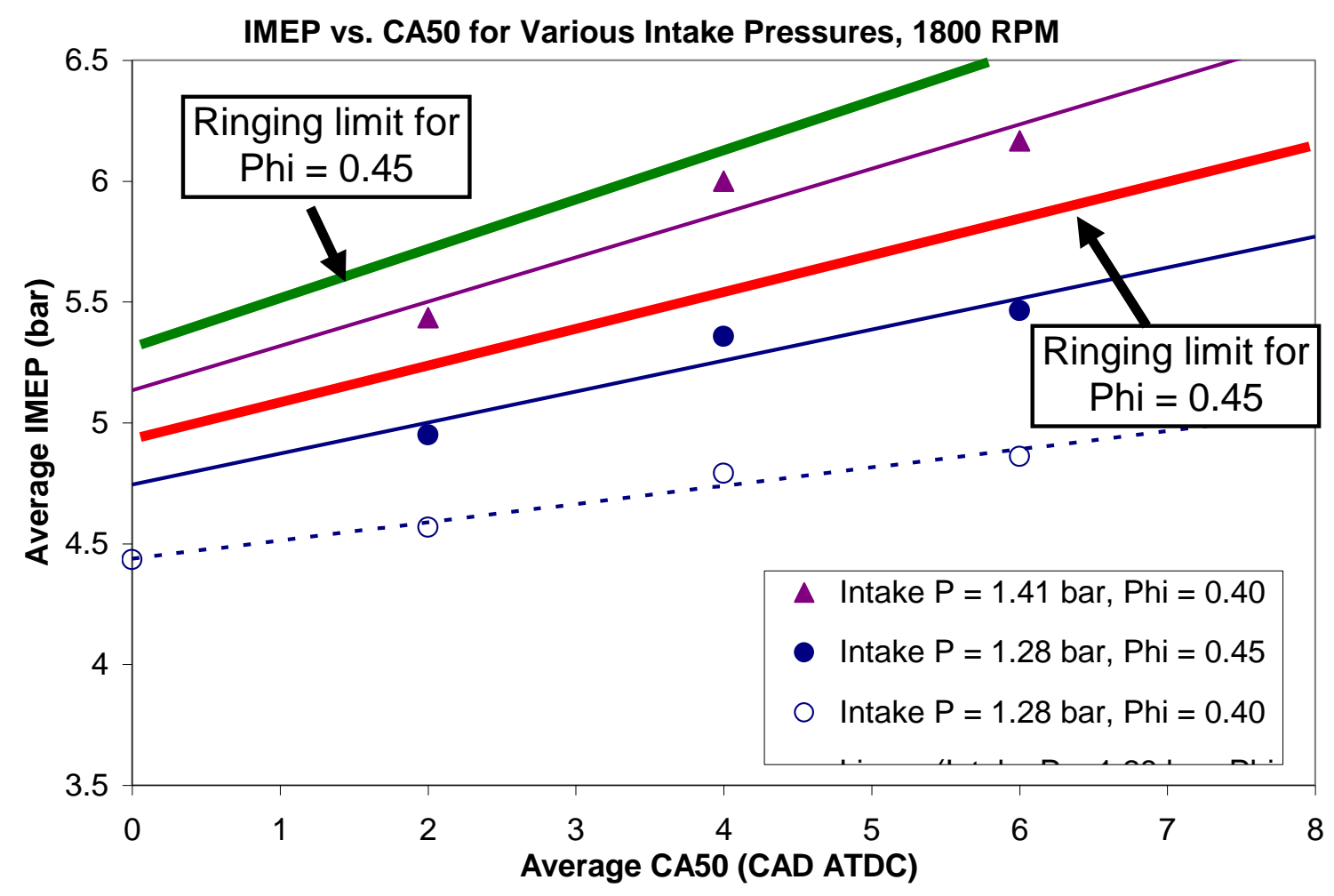

Figure 15 - Comparison of ringing limits for two equivalence ratios

By combining the results illustrated in Figure 14 and Figure 15, it is concluded that higher IMEPs can be achieved by using higher boost pressures, delayed combustion timings, and lower equivalence ratios. In the present tests, the maximum IMEP achieved was 6.17 bar using an intake pressure of 1.414 bar, equivalence ratio of 0.40 and a combustion time (CA50) of 6 CAD ATCD. Figure 16 plots all of the data points that were run in our test matrix. 
IMEP vs. Equivalence Ratio for Various Intake $P$ and CA50 VW 1.9L TDI Engine (CR=17:1), 1800 RPM

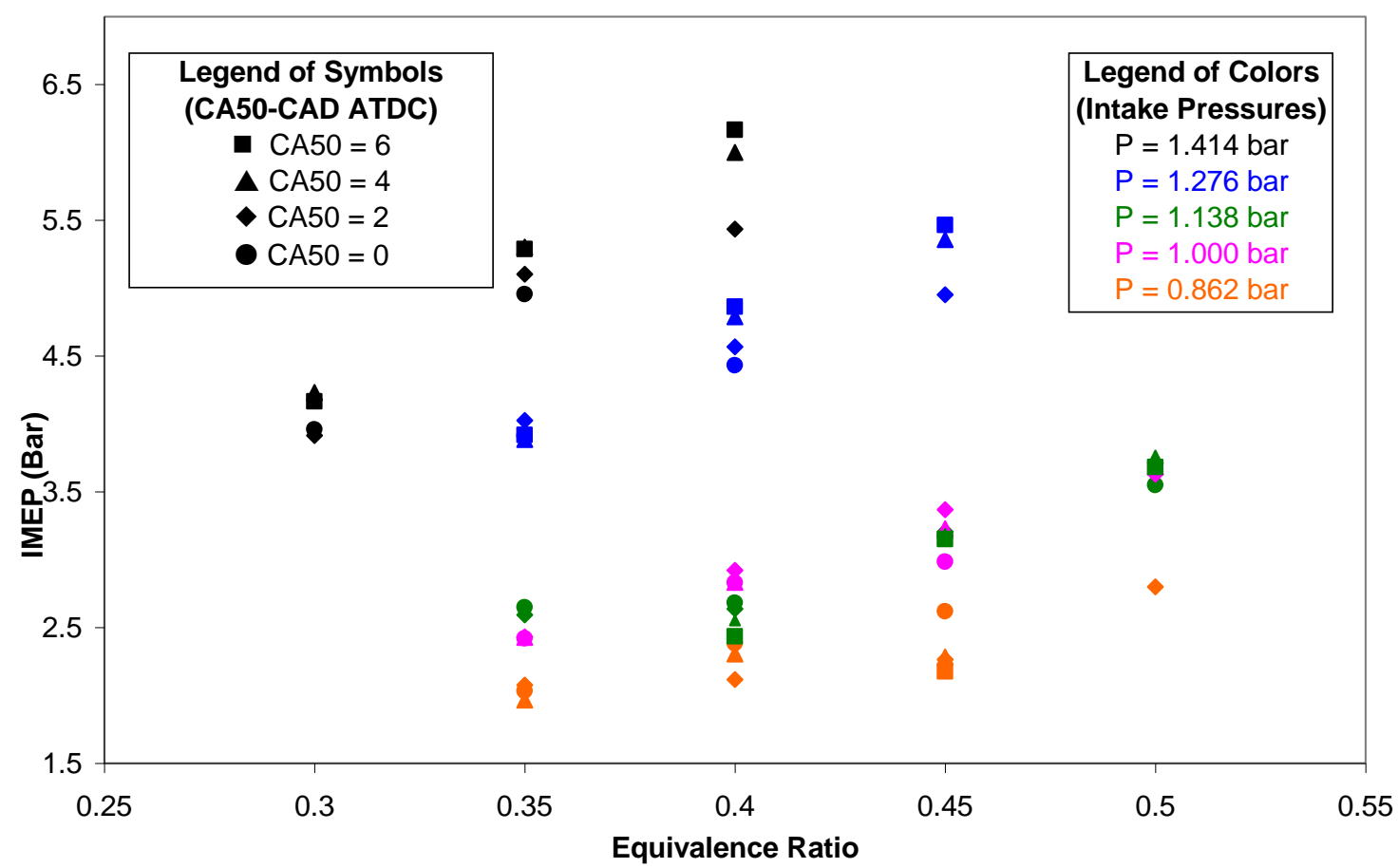

Figure 16 - Comparison of IMEP for all data points

Future work in maximizing IMEP will focus on the determination of the location of ringing and misfire limited regions. Experimental tests will be conducted to explore the true limits of ringing and misfire. Empirical relationships for ringing intensity will be utilized in classifying the severity of ringing and experimental tests will be extended for leaner equivalence ratios and higher boost pressures.

\section{Fast Thermal Management / Control}

Further refinements on the Fast Thermal Management (FTM) flow mixing system have also taken place. Aftermarket throttle valves have been integrated to function with the existing control software, and PID control gains have been optimized. The system is capable of controlling cylinder-to-cylinder variations within $1 \mathrm{CAD}$ of CA50 (shown in Figure 17), and also cycle-to-cycle variations within $1 \mathrm{CAD}$ of the CA50 set point (shown in Figure 18). The FTM system has been shown to provide precise control of CA50 for all of the test points listed in Figure 16, which includes intake pressures from 0.862 bar through 1.414 bar, equivalence ratios from 0.30 to 0.50 , and combustion times from TDC through 6 CAD ATDC. 


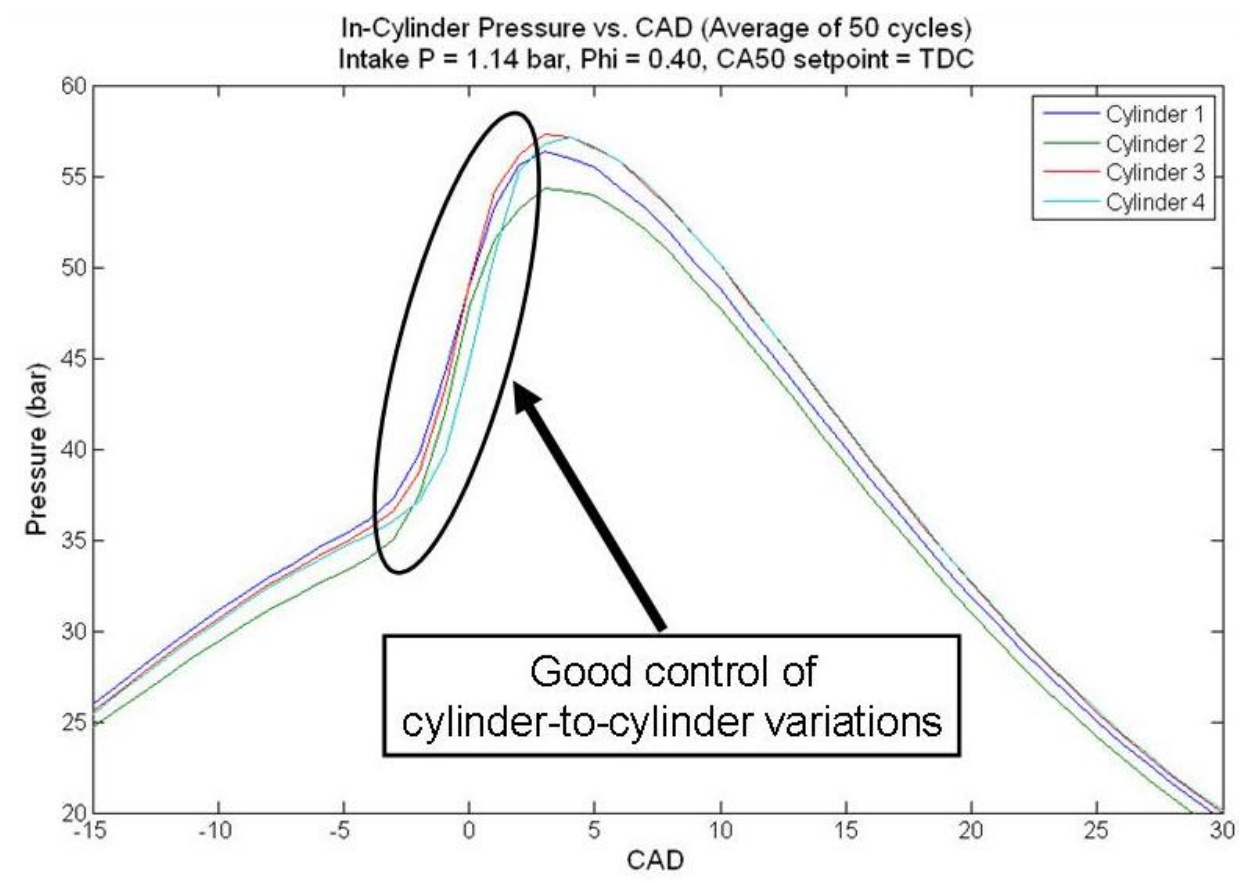

Figure 17 - FTM control of cylinder-to-cylinder variations

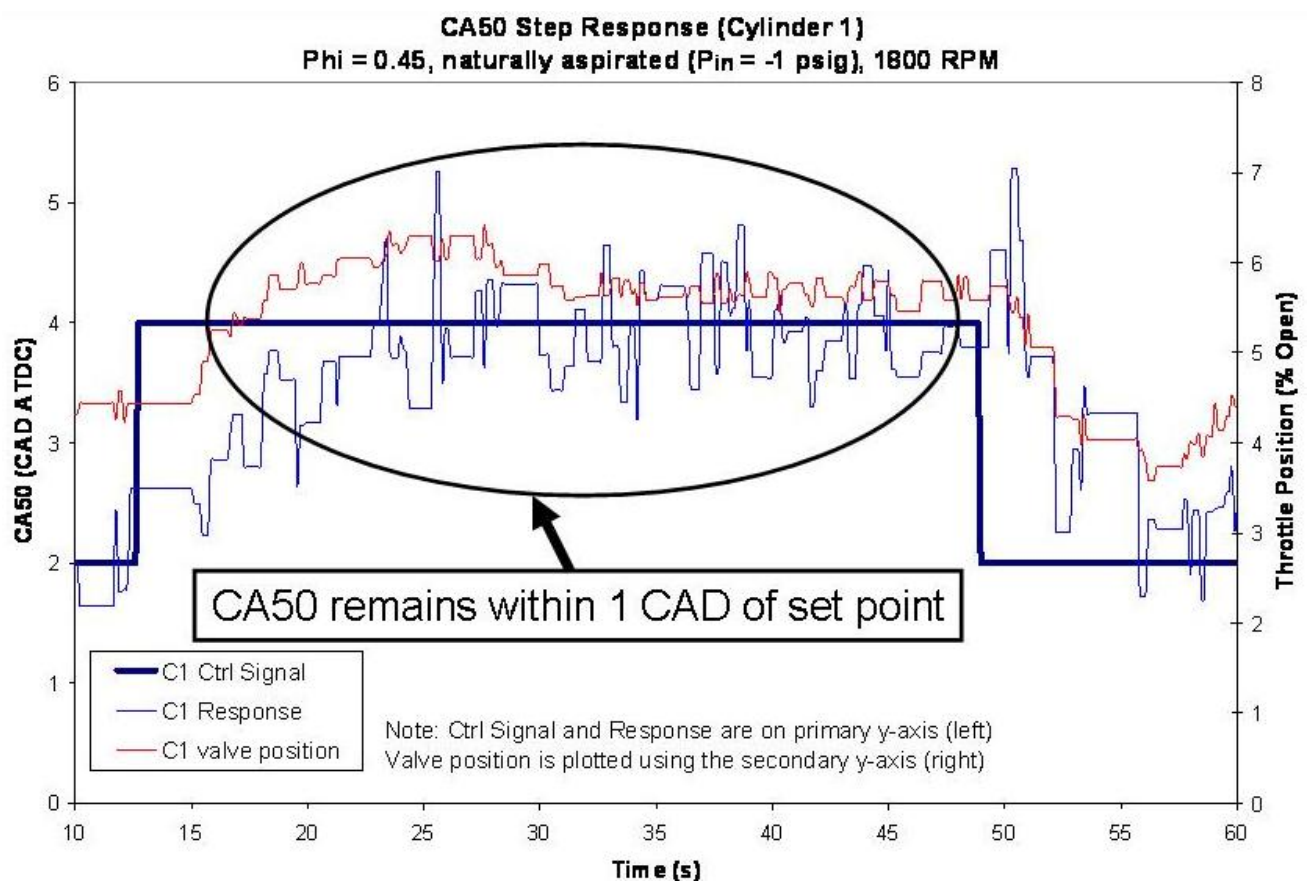

Figure 18 - FTM control of cycle-to-cycle variations

As shown in Figure 18, the current system has a response time of $\sim 6$ seconds. The reduction of this large response time represents the target of immediate work. Current strategies of minimizing this response time will focus on reducing control signal delays related to the data acquisition and control system, and reducing mechanical delays in the intake air system and the electronic mixing valves that are used. The 
target is to reduce system response time to within a few engine cycles while still maintaining stability during steady state conditions.

\section{Ion Sensing}

In parallel to the FTM improvements, we are setting up the engine controller to use the ion signal as the start of combustion (SOC) indicator for closed-loop feedback control. In-depth analysis of the ion signal in HCCI engines has led to new designs of circuitry, improved sensor design, and further understanding. Past experiments have shown that the spark plug ion sensors are able to detect several important parameters that traditionally rely on expensive in-cylinder pressure transducers. By simultaneously acquiring ion and pressure signals, we have shown that ion sensors can capture cycle-to-cycle variations. For example, Figure 19 shows the ion and pressure signals for 5 cycles. The ion signal was successfully able to capture the lower heat release in one of the cycles.

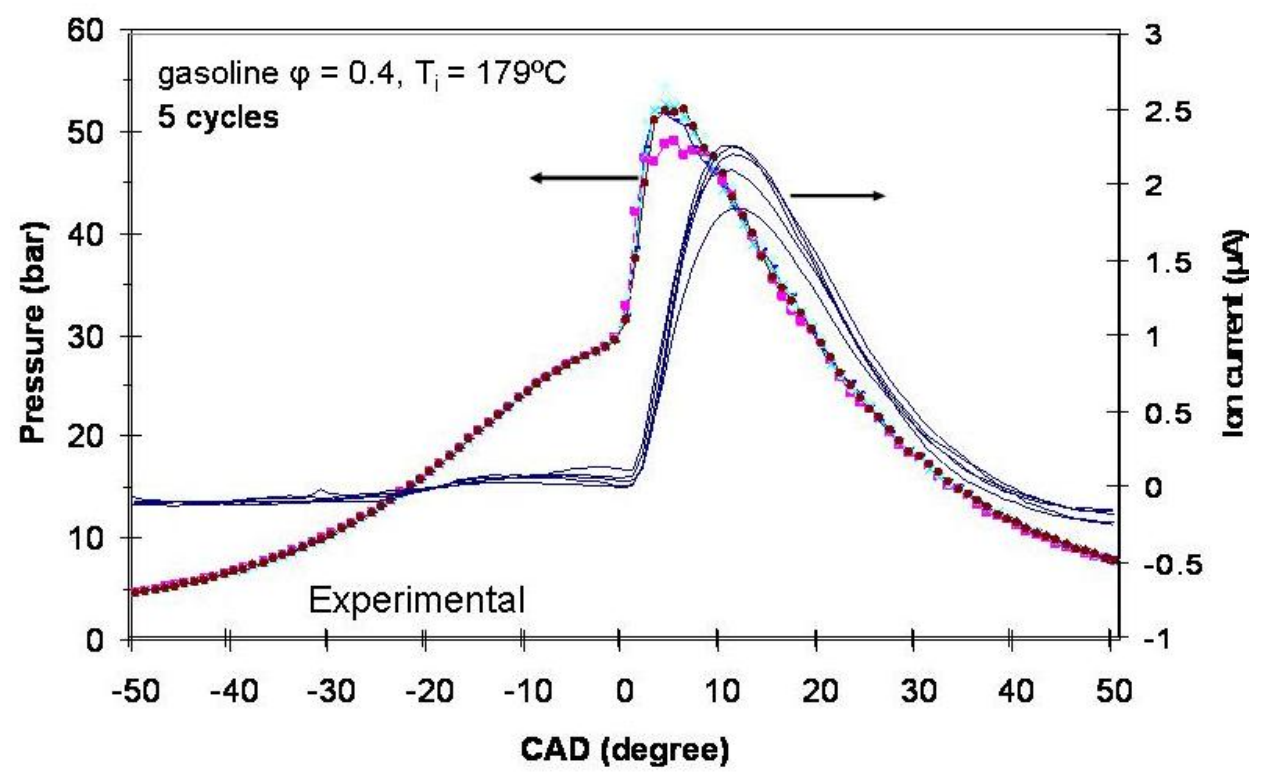

Figure 19 - Ion signal captures cycle-to-cycle variations

The main purpose of the ion sensor is to function as the SOC indicator. Figure $\mathbf{2 0}$ simultaneously plots pressure and ion signals for a single cylinder. The results show that the ion sensor is able to detect changes in the timing of start of combustion. 


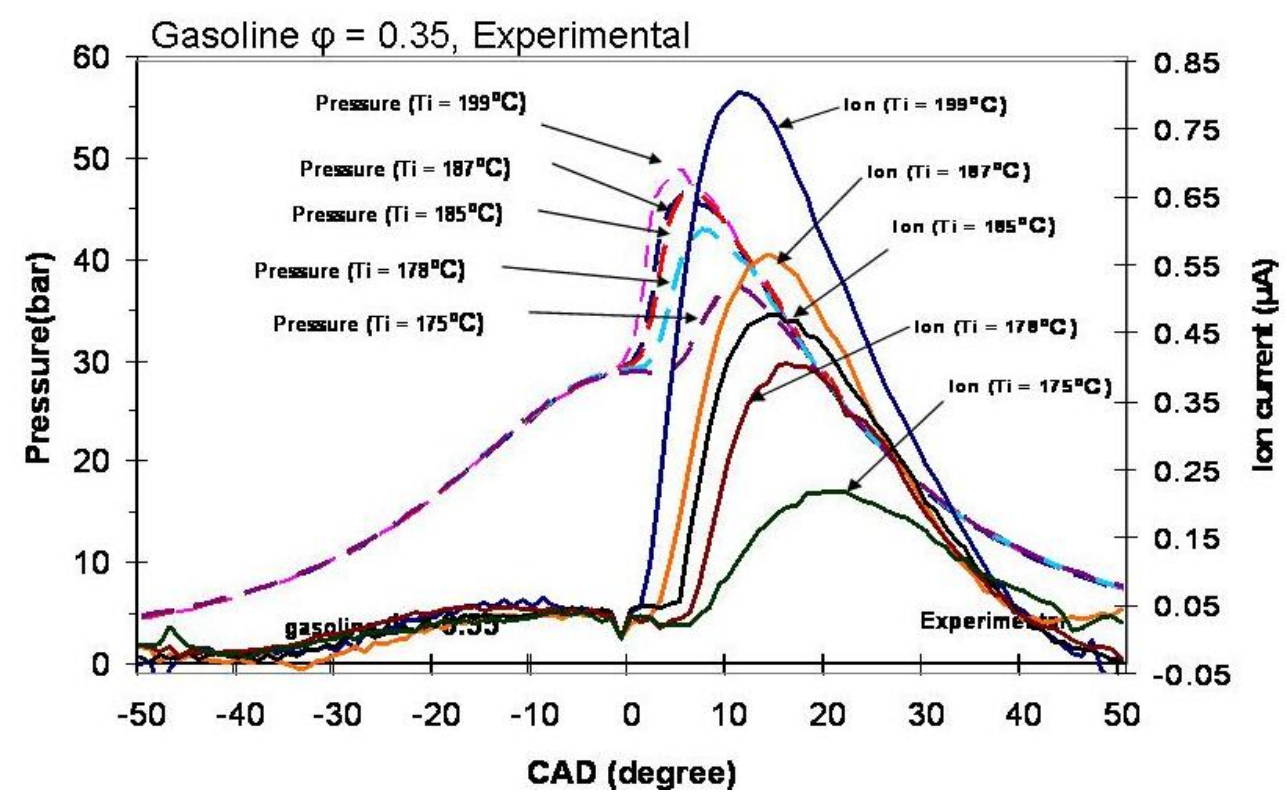

Figure 20 - Ion sensor able to detect changes in SOC timing

In a multi-cylinder HCCI engine, several spark plug ion sensors can be used simultaneously to provide SOC feedback to control individual cylinders. In order to properly balance the engine, the ion sensor should be able to sense cylinder-to-cylinder variations. Figure 21 shows pressure and ion signals for two cylinders. The pressure signal indicates that start of combustion occurs sooner in cylinder 1 , and the corresponding ion signal shows the same result.

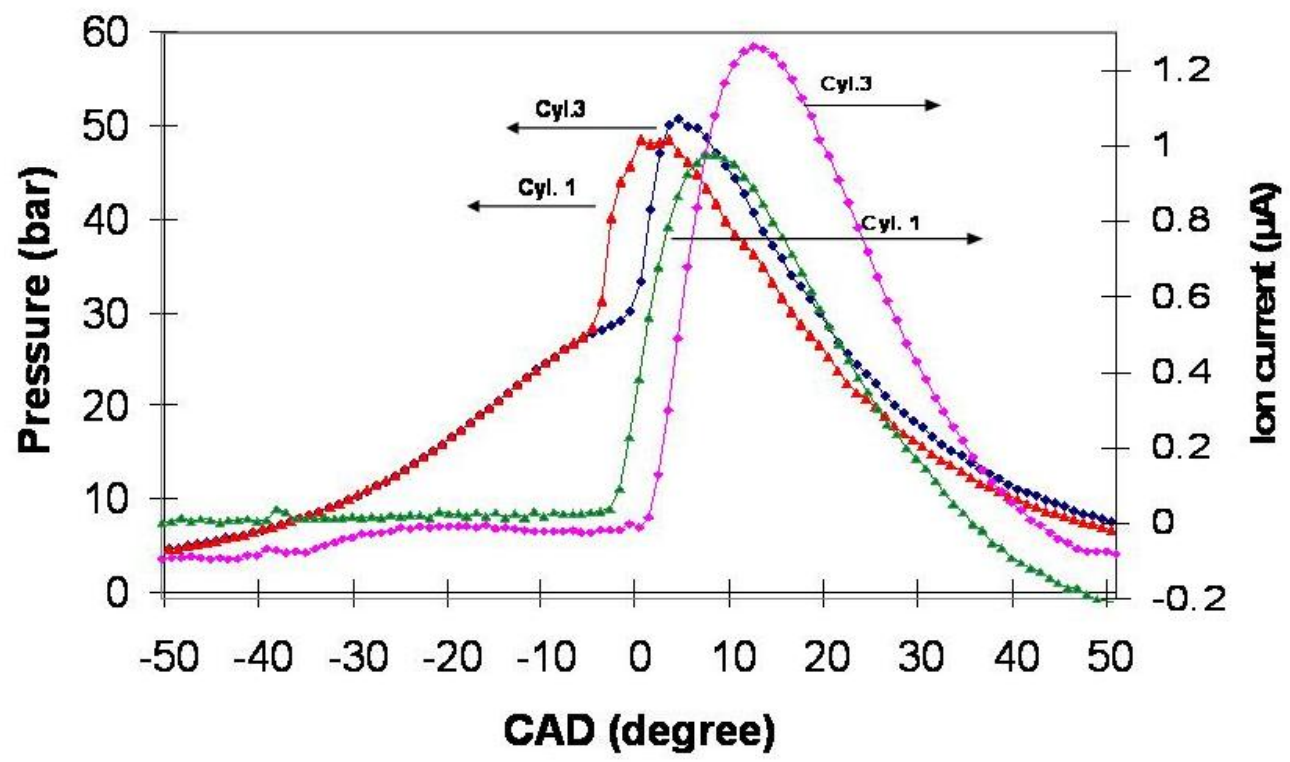

Figure 21 - Ion sensor detects cylinder-to-cylinder variations

In addition to experimentally proving the feasibility of spark plug ion sensors for feedback control in HCCI engines, we have done significant experimental and numerical work to determine the factors that affect the ion signal. Our results show the following dependencies: 
- Greater ion currents are detected for higher fuel equivalence ratios

- Ion signals decrease with increased intake pressure

- Ion signals increase with higher bias voltages applied to the spark plug electrodes, however there is an asymptotic limit to the maximum ion current

- Ion signals can be maximized by increasing the surface area of the spark plug's center electrode

In addition to characterizing the suitability of ion sensors, and the factors affecting their performance, we also performed experimental work to evaluate the compatibility of ion sensors with different fuels. Our tests show that ion signals for gasoline and ethanol exhibit similar behaviors, and thus ion signals can be used for feedback control while using blended gasoline-ethanol fuels. The results also show a decreased ion signal for n-heptane, however this may be remedied by an increase in bias voltage.

The next step is the implementation of ion signals as the feedback signal for the FTM controller. Experiments will be conducted to test the ability of the FTM system to maintain steady state conditions using an ion signal, and system response time to step changes will also be quantified.

\section{Numerical Modeling / Reduced Mechanisms}

Work is continuing on the two-zone well-mixed reactor model which is being developed for simulations of multi-cycle including flow exchanges and crevices; one for the fluids in the main cylinder and the other one for the crevices. We have used this updated model to study the effects of crevice and residual gas on the autoignition for isooctane and primary reference fuel (PRF80). For both cases, the residual gases tend to retard the ignition as the heat capacity of the residual gases is larger than fresh mixture. However, for PRF80, the chemical effect of residual gases starts to become noticeable at higher equivalence ratios due to low temperature combustion. These results have provided an estimate of the uncertainties in predictions start of combustion using the well-mixed reactor model when compared to the engine data.

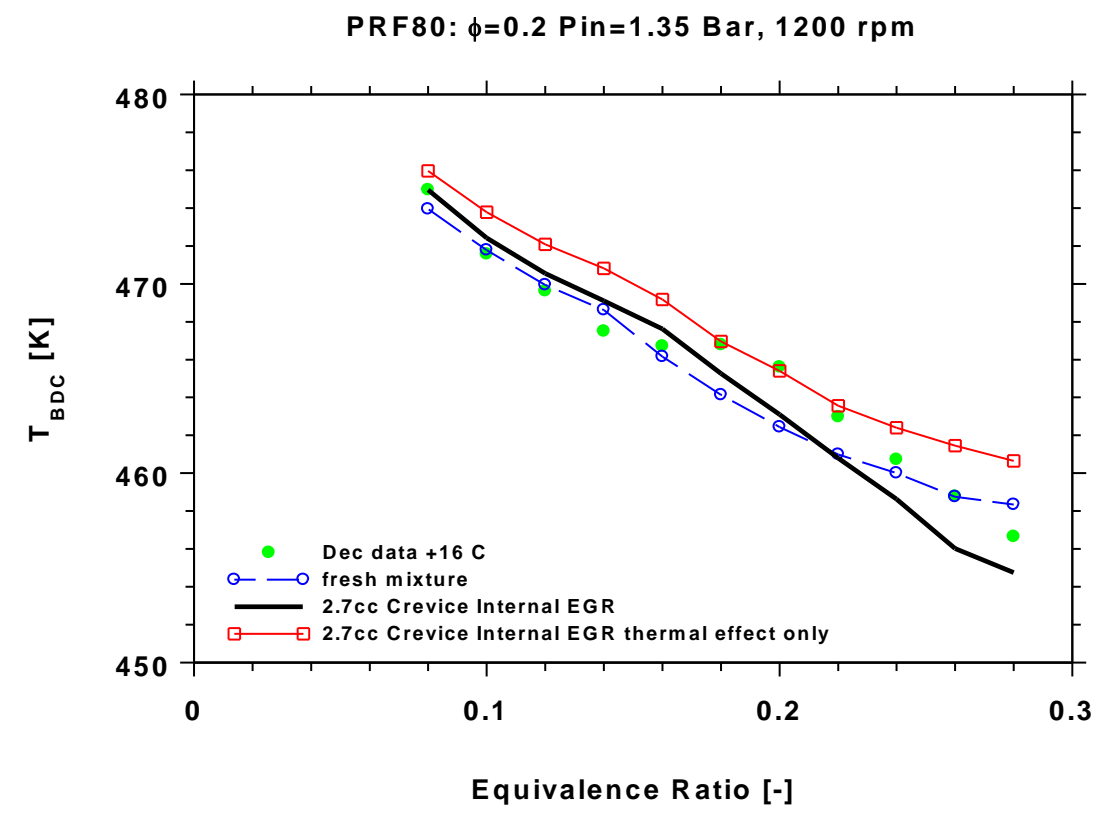

Figure 9 - Predicted effects of residual gases from crevices on the required temperature at bottom dead center to reach autoignition with CA50 at top dead center. 
Development of both skeletal and reduced chemistry with addition of two alcohol fuels, methanol and ethanol, has been carried out with primary reference fuel skeletal mechanism developed previously. Figure 10 compares the predicted autoignition from predictions from a 105-species reduced chemistry against those from a 361-species skeletal mechanism. The results show overall good agreement between the reduced chemistry and the skeletal mechanism over a wide range of pressure and temperature.

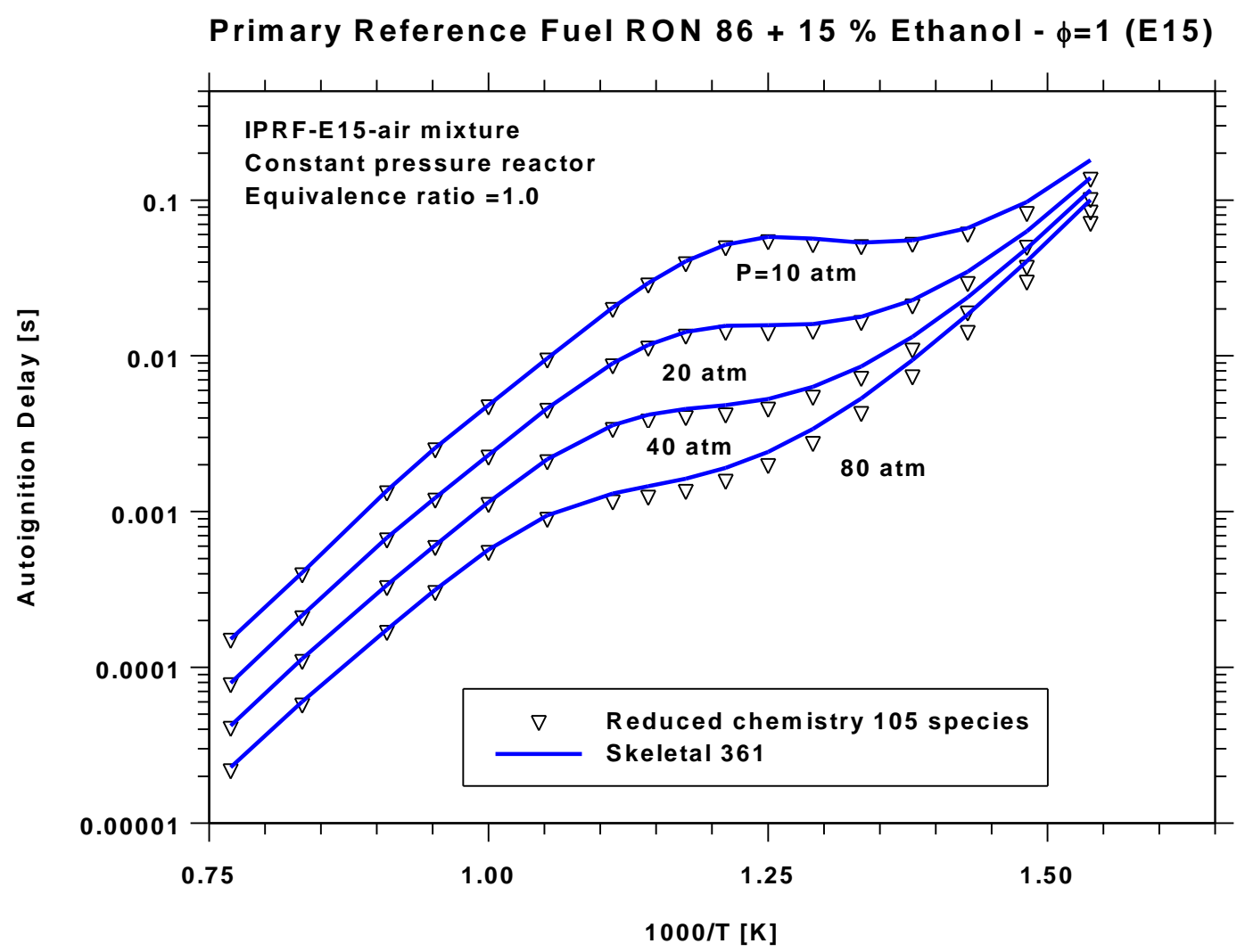

Figure 10 - Comparison of predicted autoignition delays between a 361 skeletal mechanism and a 105-species reduced chemistry. 


\section{Task 5: Direct injection to increase load limits and efficiency for HCCI engines (SU)}

Objective: The aim of this task is to extend the load range of HCCI, increase engine efficiency, and demonstrate the capabilities of advanced combustion control by use of Direct Injection (DI) strategies. Flexible fuel injection techniques will enable low, medium and high load regimes to be initiated in a single-cylinder engine with fully variable electro-hydraulic valve actuation (VVA). Unique in this work will be multiple metered and timed injections in combination with exhaust retention and re-induction to shape the energy release conditions in the engine.

\section{Accomplishments:}

Over the last three years, in-cylinder pre-processing (or recompression reaction) of direct-injected fuel during negative valve overlap (NVO) has been investigated for low-load-limit extension of retention-mode HCCI, both experimentally and computationally. Injecting fuel during NVO can induce fuel pyrolysis, reforming reactions, exothermic reactions, or charge cooling (overall called recompression reaction), depending on in-cylinder conditions. Isooctane and n-heptane were chosen as model fuels both because of the extensive work that has been undertaken to develop their chemical kinetic mechanisms (thus enabling modeling study) and because these fuels span the range of ignitability that is likely to be of interest for HCCI engines.

\section{Demonstration of low-load-limit extension using recompression reaction}

Figure 1 shows the valve and fuel injection timings used in the experiments. Both diagrams (Figs. 1a and 1b) show symmetric negative valve overlap. To understand the consequence of recompression reaction, two different injection strategies were compared. Figure 1a shows a pilot injection strategy in which all the fuel is injected during the recompression stage. Figure $1 \mathrm{~b}$ shows a main injection strategy in which the injection occurs after the intake valve opens (and there is no possibility of recompression reaction). The base compression ratio was fixed at 13:1 and 18:1 for n-heptane and isooctane, respectively. It is noted that the results from these fuels show essentially the same load-extension behavior when operated under comparable conditions, and thus we include only the n-heptane results in this report. For isooctane results, refer to Ref [1].

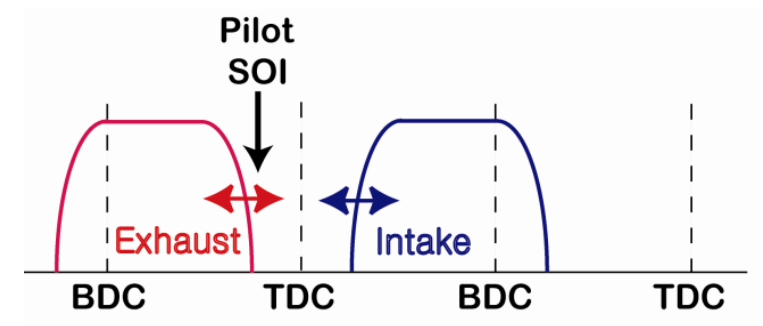

(a) Pilot injection strategy

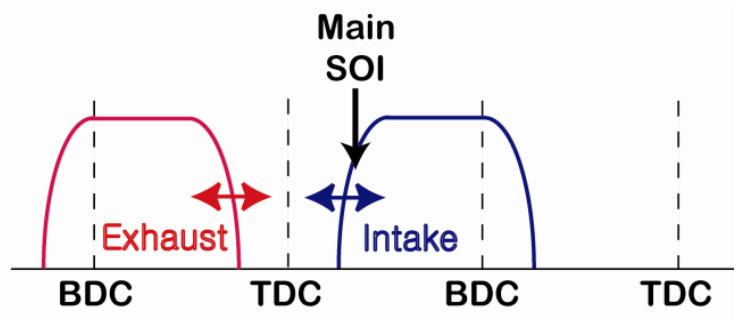

(b) Main injection strategy

Figure 1: Valve and fuel injection timing diagram. Both strategies are used in conjunction with negative valve overlap. Two different injection strategies are depicted: (a) pilot injection and (b) main injection.

Figure 2a shows net indicated mean effective pressure (NMEP) as a function of residual fraction at various equivalence ratios. As listed in the legend, four equivalence ratio conditions for pilot injection $(p)$ and two conditions for main injection $(m)$ are depicted. NMEP decreases as residual fraction increases due to the increased amount of EGR and reduced proportion of fresh charge. For each case there exists a distinct maximum residual limit (the low-load-limit), beyond which operation is no longer sustainable. In contrast, the lower bounds of residual used in these tests were chosen arbitrarily around 0.50 , since the current focus is on low-load operation. The data in Fig. 2a show that pilot injection with lean equivalence ratios extends the low-load-limit to as low as 1 bar, whereas the limit for main injection was around 3 bar. Pilot injection 
with an equivalence ratio of unity shows almost no load extension and equivalence ratio 0.95 shows only a moderate extension at the highest residual fraction (down to 2 bar).
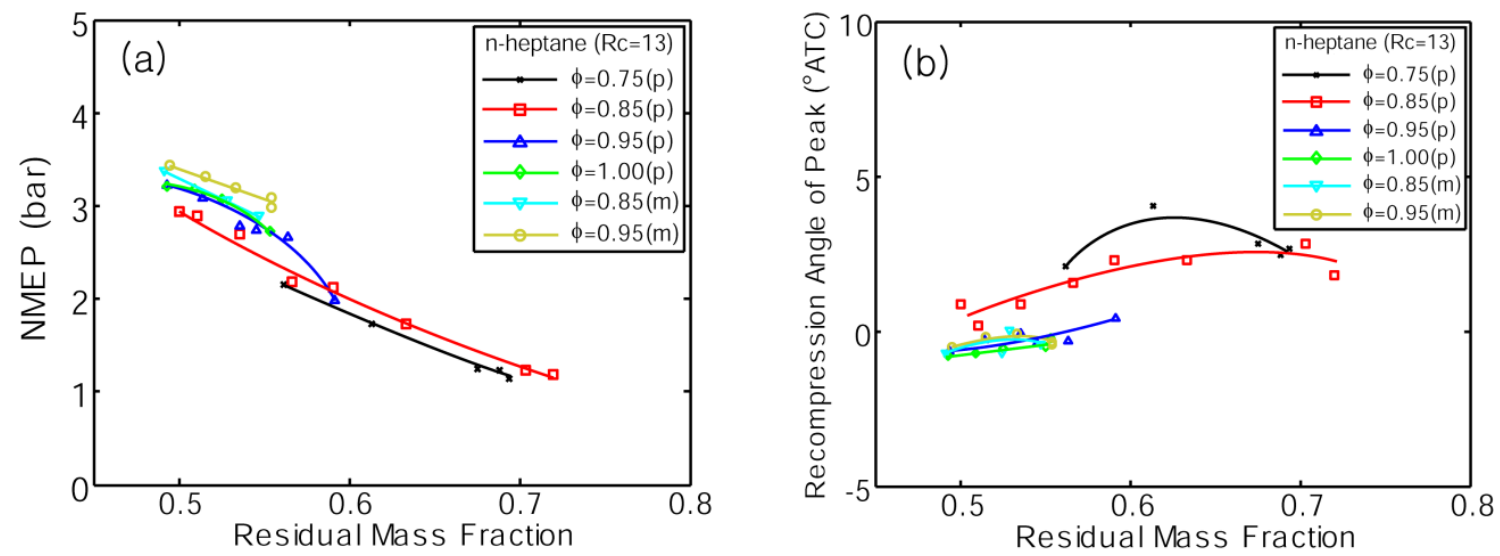

Figure 2: (a) Net indicated mean effective pressure (NMEP) plot. (b) Peak pressure timing during recompression.

To help clarify the relationship between recompression reaction and extension of the low-load-limit, Fig. $2 \mathrm{~b}$ shows peak pressure timing during the recompression stage of the engine cycle. In a typical recompression process (without fuel injection), peak pressure occurs slightly before top center because of heat loss. This is the case for all of the data using main injection. On the other hand, pilot injection with low equivalence ratios $(0.75,0.85)$ demonstrates significantly delayed peak pressure $(1-5$ degrees ATC), which can only be explained by exothermic reaction that compensates for the effects of charge cooling and heat loss. Considering that both fuel and oxidizer are required for exothermic reactions, low equivalence ratios such as 0.75 or 0.85 provide favorable conditions because there is significantly more oxygen available in the trapped exhaust gas from the previous cycle than at near-stoichiometric conditions. Comparing Figs. $2 \mathrm{a}$ and $2 \mathrm{~b}$, it can be deduced that there is a close relationship between the possibility of extending low-load operation and the occurrence of exothermic reactions.

Figure 3a shows net indicated efficiency as a function of residual fraction. There are two features to be noted: The main injection strategy shows overall higher efficiency than the pilot injection strategy by $3-8 \%$ (absolute), and for pilot injection, efficiency decreases as residual fraction increases (and NMEP decreases). Figure $3 \mathrm{~b}$ shows combustion efficiency based on measured emission data. It is observed that, for all pilot injection cases, the combustion efficiency decreases as the residual fraction increases. This trend is reflected in the indicated efficiency in Fig. 3a. Lower combustion efficiency with higher residual fraction is mostly due to lower post-combustion temperature. Figure $3 \mathrm{c}$ shows the overall heat loss from the engine as a percentage of fuel LHV. Comparing Figs. 3a and $3 \mathrm{c}$ shows a very close inverse relationship between indicated efficiency and heat loss. With pilot injection, heat transfer increases as residual fraction increases, and overall higher heat loss results in lower indicated efficiency compared to main injection. There are two main reasons for higher heat transfer with pilot injection. The first is combustion phasing. Figure $3 \mathrm{~d}$ shows the timing of peak pressure during the main combustion stage. Pilot injection results in a slightly advanced timing for main combustion which results in higher heat transfer. The second reason is that exothermic reactions during the recompression stage can lead to higher in-cylinder temperatures and hence significant heat transfer during the recompression stage itself. 

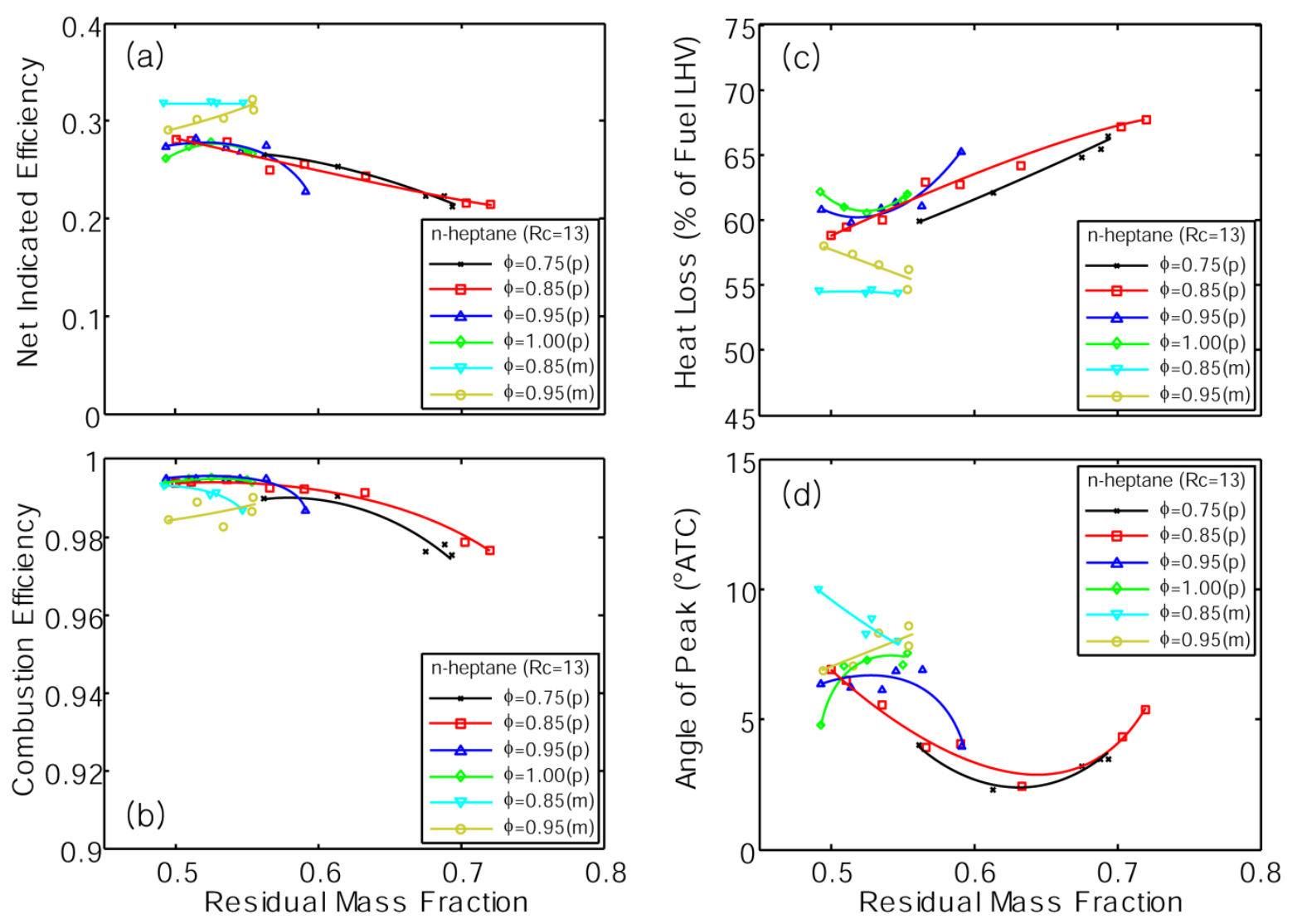

Figure 3: (a) Net indicated efficiency. (b) Combustion efficiency based on exhaust gas analyzer data. (c) Overall heat transfer. (d) Peak pressure timing during main combustion.

\section{Optimization/control of recompression reaction}

Experimental studies of three variables (compression ratio, pilot injection timing, and pilot injection amount) were conducted in order to identify the optimal use of control variables for recompression reaction and thus low-load extension. Especially, adjusting the timings and quantities of fuel injection has been known as a viable means of controlling engine operation on a real-time basis. Pilot injection timings affect fuel residence time during the recompression stage, while the pilot injection amount determines the fuel concentration available for recompression reaction. In this report, we include only part of the pilot injection timing study, as all other results are available in Ref. [2].

\section{Pilot start of injection (SOI) variation}

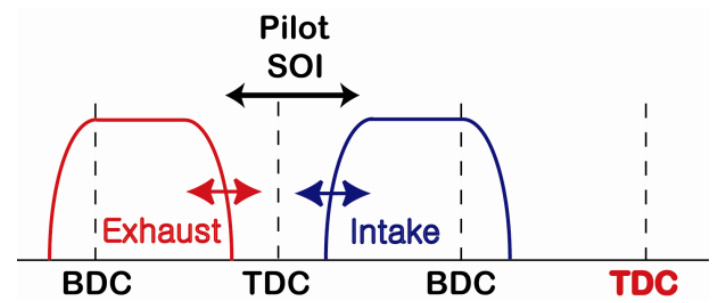

Figure 4: Valve and injection timings for the pilot injection timing variation studies. The pilot injection timing varies from $40^{\circ} \mathrm{BTC}$ to $70^{\circ} \mathrm{ATC}$ or the latest permissible for stable operation. 
Figure 4 illustrates the valve and injection timings used in this experiment. To isolate the effect of pilot injection timing on recompression reaction, we fixed the equivalence ratio and residual fraction for each set of injection timing variations. The pilot injection timings were varied from $40^{\circ} \mathrm{BTC}$ to $70^{\circ} \mathrm{ATC}$ or the latest timing after which stable operation (COV of NMEP under 15\%) was no longer possible. The geometric compression ratio was held fixed at 13:1 with n-heptane fuel.

At equivalence ratio 0.85 , four RMF conditions $(0.5,0.55,0.6$ and 0.65$)$ were explored for pilot injection timing variation. Figure 5a shows NMEP as pilot injection timing is varied. Higher residual fraction results in lower NMEP due to a higher dilution level. There are two noticeable effects of injection timing variation on NMEP. First, the latest injection timing for stable operation advances as residual fraction increases. This implies that longer residence time (or higher extent of recompression reaction) is required for mixtures with higher dilution. Second, NMEP varies only slightly across the range of injection timing variation, although it is observed that equivalence ratio 0.85 exhibits moderate (exothermic) recompression reaction in a different extent with the injection timing.

To elucidate the effect of pilot injection timing on recompression reaction and the subsequent main combustion process, Fig. 5b illustrates peak pressure timing during main combustion. It is noted that main combustion timings are significantly affected by the pilot injection timing. Since we have eliminated the possibility of mixture inhomogeneity in this range of injection timings, the variation of peak pressure timing, shown in Fig. 5b, is mainly attributable to a change in the in-cylinder residence time and an accompanying change in the extent of recompression reaction. Earlier injection timing leads to earlier main combustion, while later injection timing delays main combustion into the expansion strokeeventually leading to incomplete combustion and unstable cycles (except at RMF 0.5). Finally, the higher sensitivity of combustion timing to pilot injection timing observed for high residual fraction operation implies that recompression reaction becomes more critical for stable operation at higher dilution (residual fraction) levels.
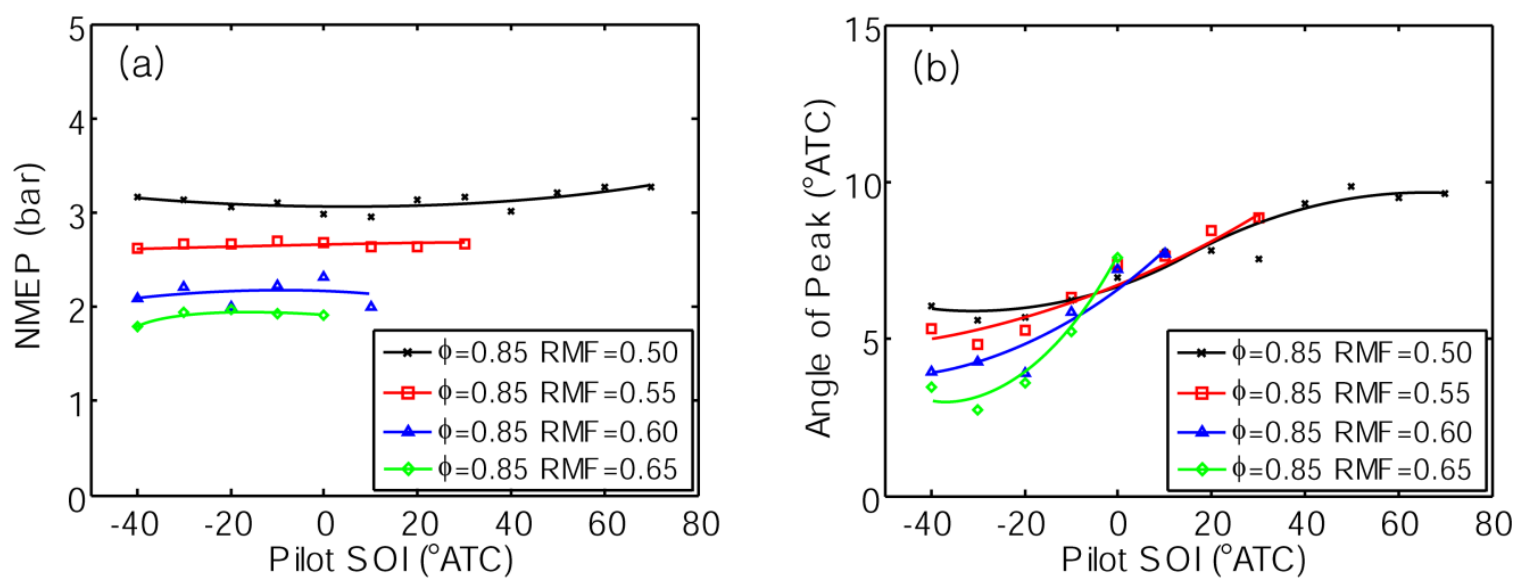

Figure 5: Pilot injection timing studies at equivalence ratio 0.85 .

\section{Understanding Chemical Effects of Recompression Reaction}

In an effort to elucidate the chemical and thermal effects involved in recompression reaction, model calculations of recompression reaction and ignition delay of the recompression products were performed using a reduced n-heptane mechanism (160 reactions, 1424 reactions). To establish a comprehensive understanding of recompression reaction effects under various operating conditions, seven important parameters were identified and calculations were performed in which each was varied. These parameters can affect recompression reaction in three different ways: through sensible energy (i.e., temperature), the 
chemical environment (e.g., the fuel-to-oxygen ratio), and through the duration of the recompression process (the reaction kinetics time). Table 1 shows the parameters varied in the left column, with their major effects in the middle column, and the range of variation in the right column. The parenthetical values in the right column show the base operating conditions about which variations were conducted. In this report, we include only three variables studies: initial recompression temperature, engine speed, and equivalence ratio. The complete study results can be found in Ref. [3].

Table 1: Recompression Stage Parameters

\begin{tabular}{lll}
\hline $\begin{array}{l}\text { Initial Recompression } \\
\text { Temperature }\end{array}$ & Sensible Energy & $\begin{array}{l}700-1000 \\
(900 \mathrm{~K})\end{array}$ \\
\hline $\begin{array}{l}\text { Initial Recompression } \\
\text { Pressure }\end{array}$ & Sensible Energy & $\begin{array}{l}\text { Fixed } \\
(1 \mathrm{bar})\end{array}$ \\
\hline Compression Ratio & Sensible Energy & $\begin{array}{l}\text { Fixed } \\
(13)\end{array}$ \\
\hline Engine Speed & Time & $\begin{array}{l}900-4500 \\
(1800 \mathrm{RPM})\end{array}$ \\
\hline Negative Valve Overlap & Sensible Energy & $\begin{array}{l}80-160 \\
(80 \mathrm{CAD})\end{array}$ \\
\hline Equivalence Ratio & and Time & $0.6-1$ \\
& Chemical & $(1)$ \\
\hline Residual Mass Fraction & Composition & $\begin{array}{l}\text { Fixed } \\
(0.5)\end{array}$
\end{tabular}

\section{Recompression stage modeling}

Initial temperature variation - Figures $6 \mathrm{a}$ and $6 \mathrm{~b}$ depict pressure and temperature profiles, respectively, as a function of crank angle position during recompression for various initial temperatures. Higher initial temperatures show lower overall pressure, an indicator of a process that is net-endothermic. This is confirmed by looking at the temperature profiles which show a significant asymmetry (even crossing) due to endothermic reactions. In order to quantify the extent of recompression reaction with pilot injection, the quantity energy fraction is introduced, which is evaluated at the end of the recompression stage (i.e., for the overall process). The calculation of energy fraction is based on the concept of cold gas efficiencydefined as a ratio of the lower heating value (LHV at $25^{\circ} \mathrm{C}, 1$ bar) of the particular species or overall composition to the LHV of fuel input to the process that generated the species or composition. For example, the $\mathrm{CO}+\mathrm{H}_{2}$ energy fraction represents the proportion of chemical energy stored in the form of $\mathrm{CO}$ and $\mathrm{H}_{2}$ at the end of recompression stage, which can be an indication of the extent of reforming reaction. Likewise, the fuel energy fraction shows the proportion of chemical energy left as un-reacted n-heptane. The small-HC energy fraction accounts for the chemical energy of the remaining species other than $\mathrm{n}$ heptane, $\mathrm{CO}$, and $\mathrm{H}_{2}$, which are mostly hydrocarbon fragments having lower carbon numbers than the fuel. Finally, the exothermicity energy fraction represents the proportion of the fuel chemical energy converted into sensible energy of the mixture during NVO.

In Fig. 6c, the energy fractions are depicted as a function of the initial temperature. It is shown that the original fuel accounts for more than $90 \%$ of the energy until the initial recompression temperature reaches $\sim 860 \mathrm{~K}$, at which point the fuel starts to be broken down into small hydrocarbon fragments (i.e., fuel pyrolysis). Generation of $\mathrm{CO}+\mathrm{H}_{2}$, (classical reforming) is not significant in this oxygen-deficient environment (unity equivalence ratio). Noting that pyrolysis processes are typically endothermic, the exothermicity fraction is slightly negative, reaching $-6 \%$ for an initial temperature of $1000 \mathrm{~K}$. To understand the potential effect of mole number change on pressure, Fig. $6 \mathrm{~d}$ shows the final mole number at the end of the recompression process with respect to the initial mole number at the start. Comparing Figs. $6 \mathrm{c}$ and $6 \mathrm{~d}$ reveals that pyrolysis of the fuel at higher temperatures leads to a small-but-non-negligible 
increase in mole number (approaching 5\%). Note, however, that this effect is overwhelmed by the endothermicity of pyrolysis, as evidenced by the overall lower pressure with higher initial temperature exhibited in Fig. 6a.
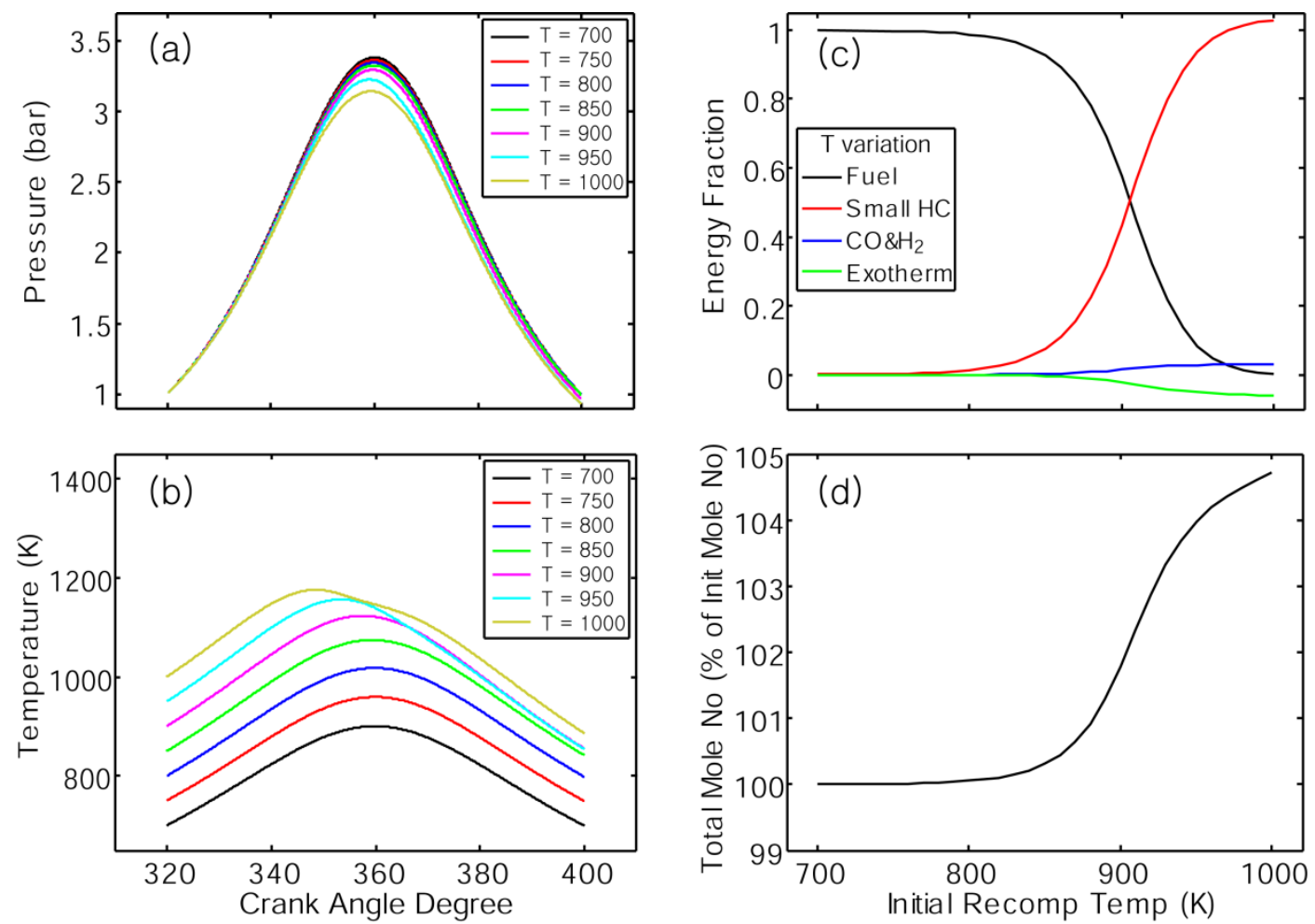

Operating Conditions: Init T Varied, Init P 1 bar, CR 13, 1800 RPM, NVO 80 CAD, Phi 1.0, RMF 0.5

Figure 6: Initial recompression temperature variation. (a) Pressure profile. (b) Temperature profile. (c) Energy fractions. (d) Mole number change.

Figure 7 shows detailed speciation results as a function of crank angle. Each sub-figure corresponds to a different initial temperature of 800 and $900 \mathrm{~K}$. At an initial temperature of $800 \mathrm{~K}$, less than $2 \%$ of the fuel reacts. As shown in Fig. 7a, the primary products of fuel pyrolysis are alkenes (mostly ethylene), followed by small amounts of methane and hydrogen $(<200 \mathrm{ppm})$. These alkenes are generated from heptyl radicals $\left(\mathrm{C}_{7} \mathrm{H}_{15}\right)$ by beta-scission, where the site of hydrogen abstraction determines the carbon-number of the alkene species. As depicted in Fig. 7b, the extent of fuel transformation increases significantly with an increase in temperature. Alkenes are still the dominant products, but the production of alkanes is enhanced and, finally, alkynes begin appearing in the list. The mass fraction of molecular hydrogen is small but evident under all conditions. 

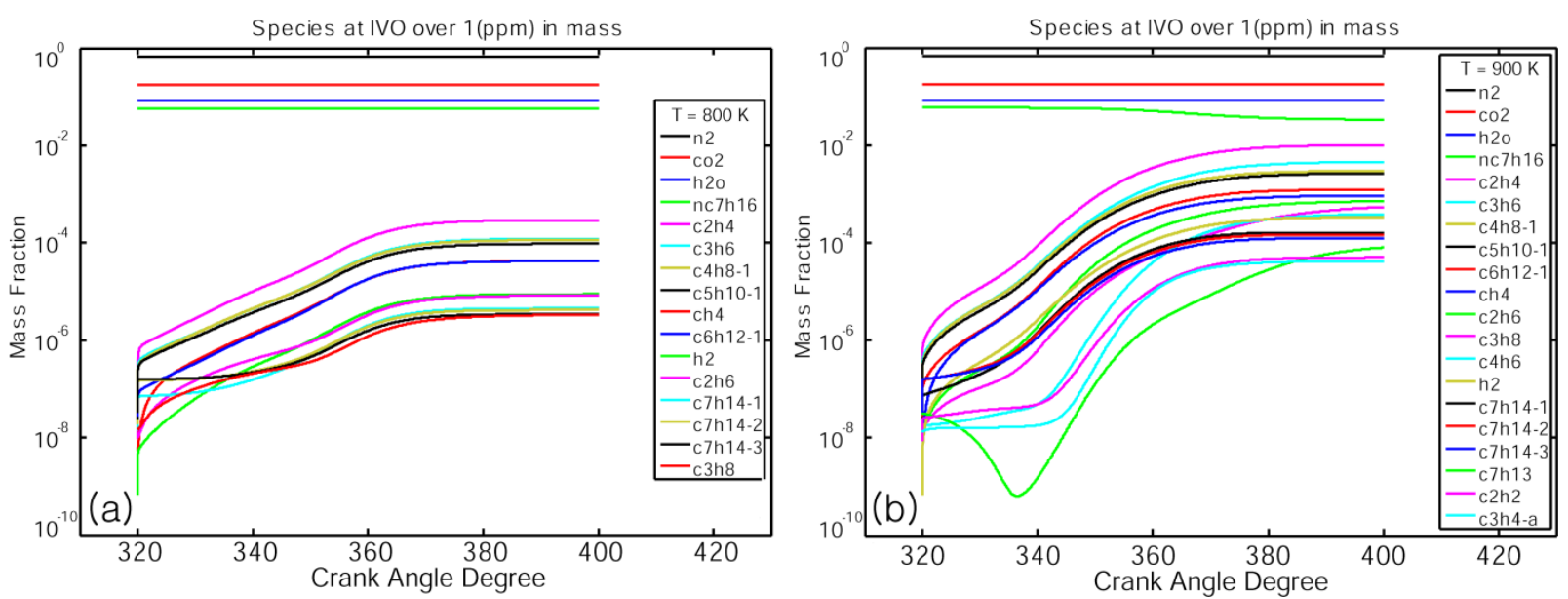

Figure 7: Mass fractions during NVO. (a) $800 \mathrm{~K}$ (b) $900 \mathrm{~K}$

Engine speed variation - Recompression reactions occur at a finite rate. In order to understand the effect of time on the extent of recompression reaction, the engine speed was varied while all other free parameters were held constant. Figures $8 \mathrm{a}$ and $8 \mathrm{~b}$ show the pressure and temperature profiles over the range of engine speeds explored. As engine speed is reduced (time for reaction increased) the pressure drops slightly and the temperature declines significantly. These observations are consistent with an increasing extent of endothermic reaction. The energy fractions are shown in Fig. 8c. A higher extent of fuel pyrolysis is observed with reduced engine speed, resulting in an exothermicity fraction of $-5 \%$ at the lowest speed (900 RPM). Note that this is generally a desirable trend since enhanced low-load operation is most likely to be desired at low engine speed (at or near idle). As depicted in Fig. 8d, the mixture mole number increases (up to $4 \%$ ) with increased pyrolysis, but again the effect on in-cylinder pressure (Fig. $8 \mathrm{a})$ is masked by endothermicity. Detailed speciation for the engine speed variation study is omitted in this report, but the general trends are very similar as observed in Fig. 7. An important but not surprising conclusion from this study is that recompression reaction is limited by chemical kinetics, not thermodynamics (equilibrium). 

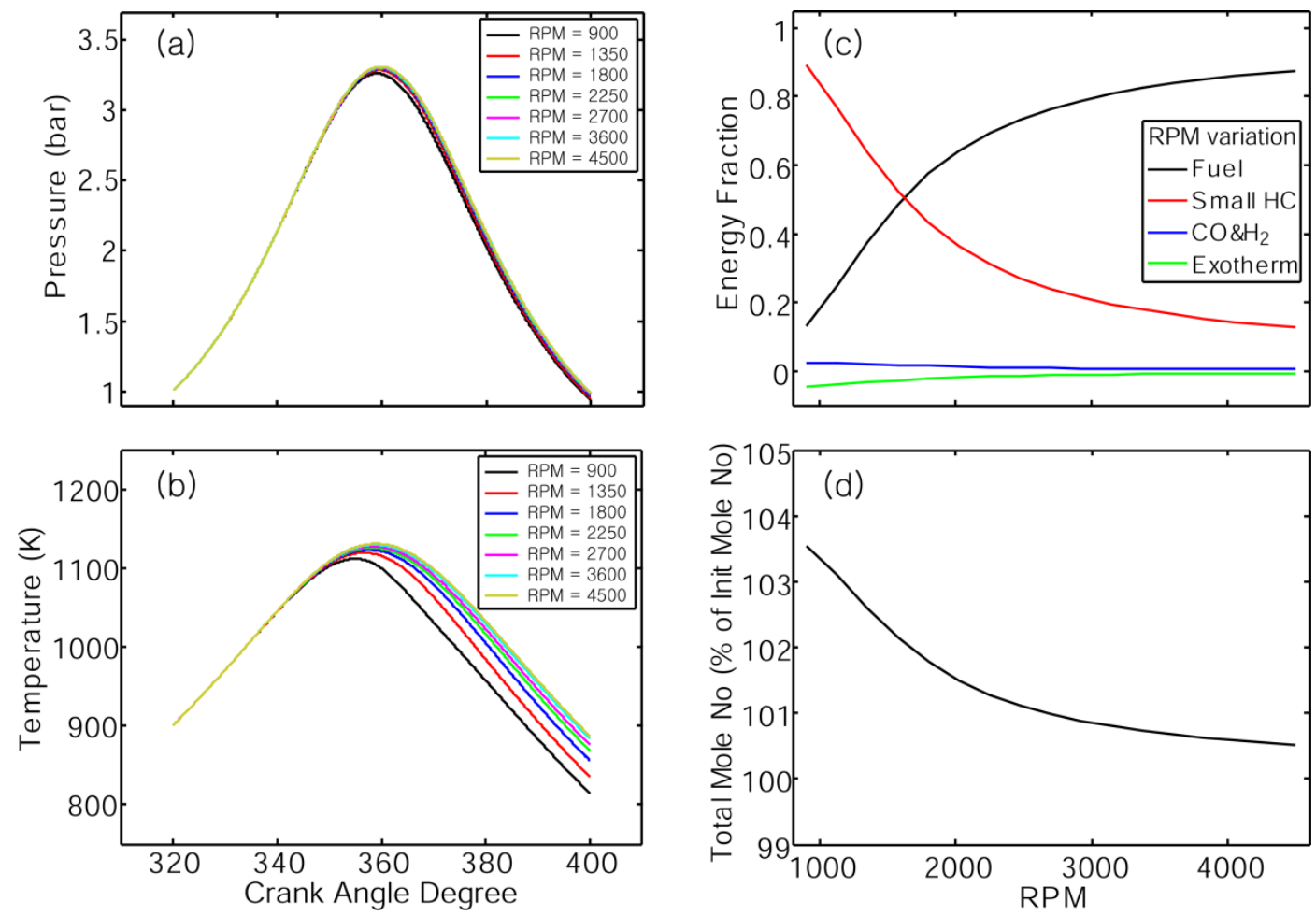

Operating Conditions: Init T 900 K, Init P 1 bar, CR 13, RPM Varied, NVO 80 CAD, Phi 1.0, RMF 0.5

Figure 8: Engine speed variation. fractions. (d) Mole number change.

(a) Pressure profile. (b) Temperature profile. (c) Energy

Equivalence ratio variation - To elucidate the effect of oxygen concentration in the trapped residual gas on recompression reaction, the metered equivalence ratio for the engine was varied over the ranges encountered in typical residual-effected HCCI experiments. The pressure and temperature profiles are plotted in Figs. 9a and 9b. The stoichiometric case shows slight endothermicity with the temperature dropping by approximately $50 \mathrm{~K}$ over the course of the process. At equivalence ratio 0.9 , the temperature still declines slightly $(\sim 25 \mathrm{~K})$, but the pressure rises to slightly over 1 bar due to the mole number increase of the mixture. Equivalence ratios of 0.8 or lower exhibit clear exothermicity in the temperature profile (and energy fraction). As shown in Fig. 9c, equivalence ratios of 0.6, 0.8, and 0.95 correspond to the effective ratios of $1.5,4$, and 19 , respectively. It is noted that the leanest condition of 0.6 still produces a fuel-rich environment during NVO despite being close to stoichiometric, while equivalence ratio of 0.9 or higher results in very rich conditions.

The resultant energy fractions, shown in Fig. 9d, are significantly affected by the equivalence ratio. For equivalence ratios of 0.85 or higher, exothermicity is negative, and fuel pyrolysis prevails during NVO. Completely reformed products are still under $5 \%$ of the fuel chemical energy; the bulk of the energy is contained in small HC fragments. For equivalence ratios between 0.8 and 0.85 , the extent of the pyrolysis is maximized with little fuel left after recompression, and the overall reaction is slightly exothermic. Formation of $\mathrm{CO}+\mathrm{H}_{2}$ increases but remains under $10 \%$. Finally, for equivalence ratios of 0.8 or lower, all of the pilot-injected fuel is transformed, and the energy fraction of small hydrocarbon fragments decreases at leaner conditions. As evident in the exothermicity and $\mathrm{CO}+\mathrm{H}_{2}$ energy fractions, the complete oxidation of fuel (including pyrolysis products) accelerates with increased oxygen in the residual gas. As depicted in Fig. 9e, mixture mole number increases with lower equivalence ratio to 0.7 and then decreases again. From stoichiometric to 0.8 , fuel pyrolysis contributes to the mole number increase, while from 0.8 to 0.7 , 
reforming reaction (by consuming pyrolysis products) further increases it. The decrease in mole number, below equivalence ratio of 0.7 , originates from increasing oxidation into final products, $\mathrm{CO}_{2}$ and $\mathrm{H}_{2} \mathrm{O}$.
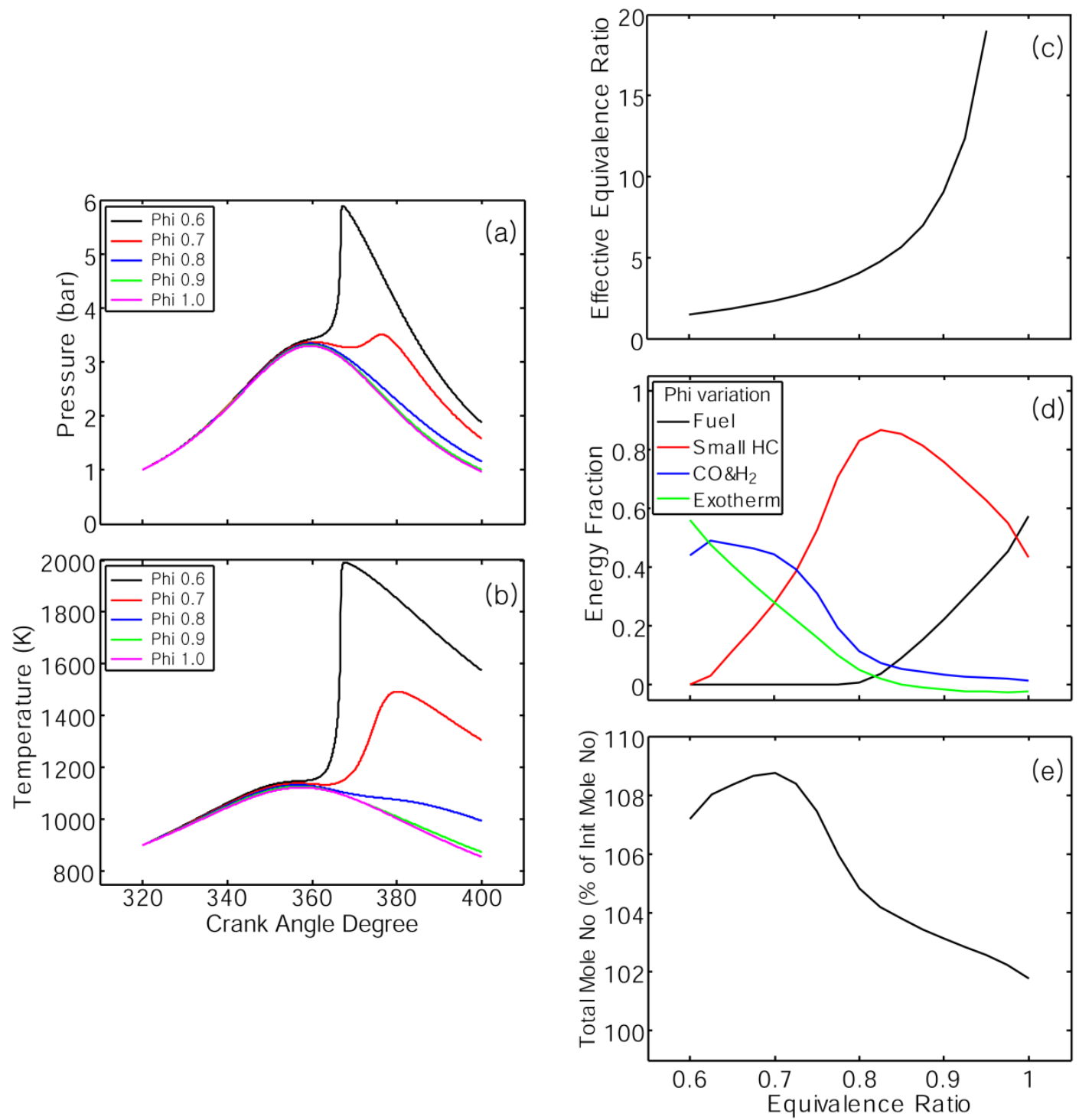

Operating Conditions: Init T 900 K, Init P 1 bar, CR 13, 1800 RPM, NVO 80 CAD, Phi Varied, RMF 0.5

Figure 9: Equivalence ratio variation. (a) Pressure profile. (b) Temperature profile. (c) Effective equivalence ratio. (d) Energy fractions. (e) Mole number change.

Figure 10 shows speciation results for two equivalence ratios (0.6 and 0.8 ; for equivalence ratio 1.0 , refer to Fig. 7b). At the leanest condition (Fig. 10a), fuel and oxygen are completely reacted, resulting in significant oxidation and $\mathrm{CO}+\mathrm{H}_{2}$ production. The oxidation process generates typical $\mathrm{H}_{2}$-chemistry radicals $(\mathrm{OH}$ and $\mathrm{H})$, which linger even until IVO due to the high mixture temperature (see Fig. 9b). At equivalence ratio 0.8 (Fig. 10b), recompression reaction is dominated by fuel pyrolysis (mostly ethylene), but the second most abundant product is $\mathrm{CO}$, which rises to $\sim 15 \%$ of the fuel energy (Fig. 9d). Due to the availability of oxygen in the residual gas, the pyrolysis products include aldehydes in addition to alkenes and alkanes. This study demonstrates that oxygen is the key to the extent and speciation of recompression reaction. 

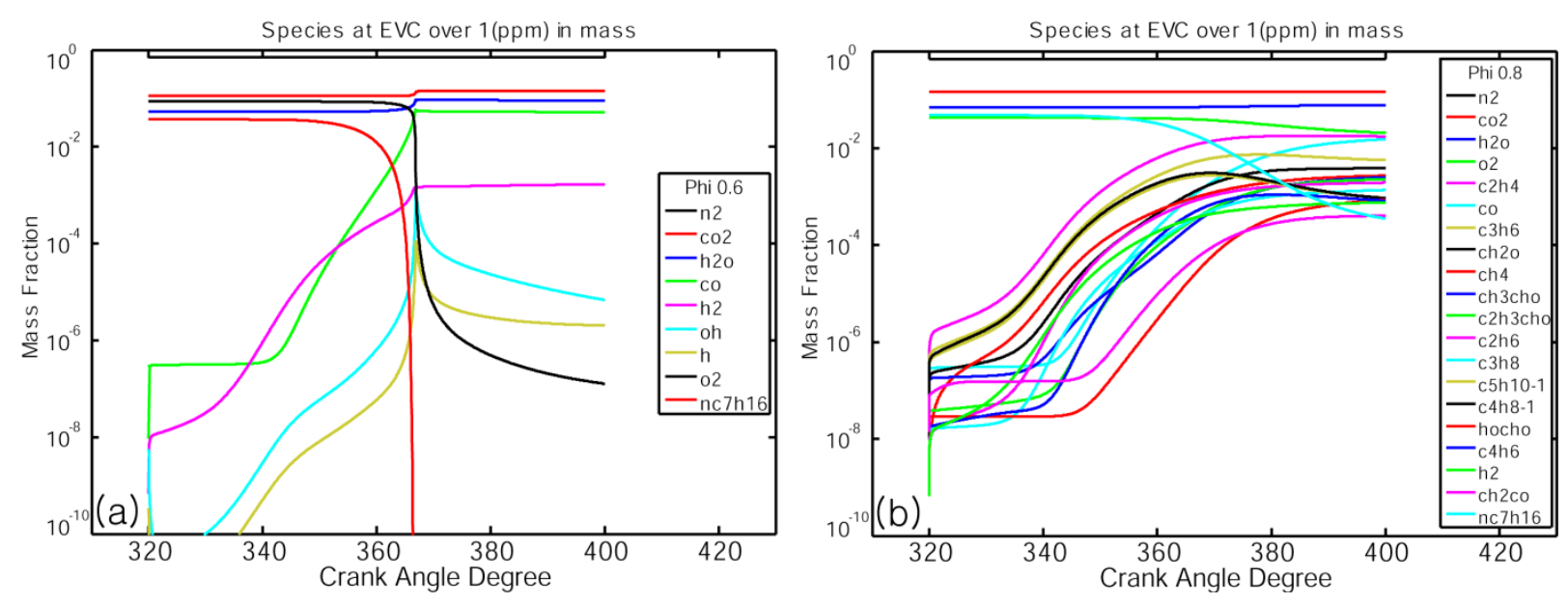

Figure 10: Mass fractions during NVO. (a) Equivalence ratio 0.6 (b) Equivalence ratio 0.8

\section{Ignition delay of recompression products}

In an effort to understand the composition effect of recompression reaction on main combustion phasing, ignition delay calculations were performed using the recompression products (mixed with air) as determined from the equivalence ratio study above. Since two injection strategies were performed in the experiments (pilot vs. main injection), the ignition delay for the mixture of recompression products and air is compared with that of un-reacted fuel, air, and exhaust residual (major products) at a given equivalence ratio and residual mass fraction. The former is designated as pilot injection (p) and the latter as main injection $(\mathrm{m})$ in keeping with designations from the experimental work.

Figure 11 shows the isochoric/adiabatic ignition delay of various mixtures as a function of initial temperature. Five equivalence ratios are shown for pilot injection (recompression reaction) and three for main injection (no pre-reaction). Considering the main injection cases (triangles), it can be seen that the ignition delay is shortest for the stoichiometric case and that negative-temperature-coefficient (NTC) behavior is observed near $800 \mathrm{~K}$, as expected for $\mathrm{n}$-heptane.

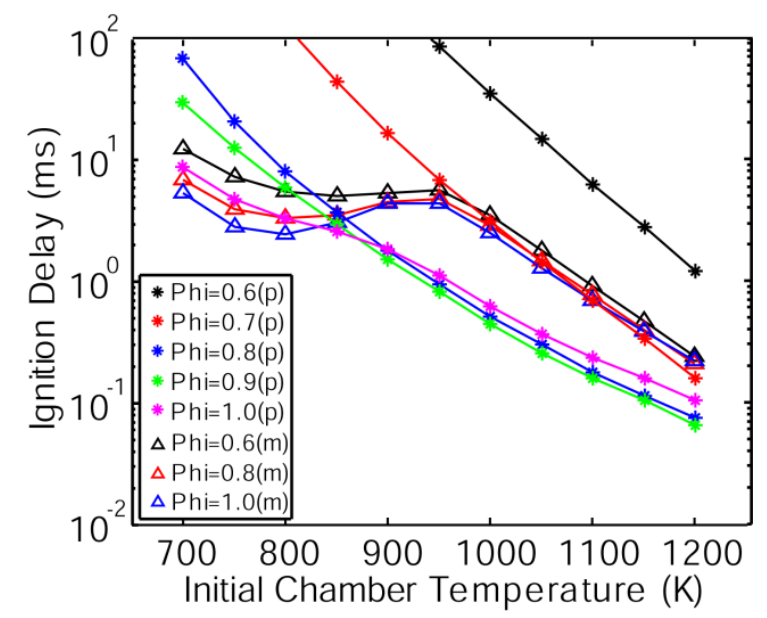

Figure 11: Ignition delays of pilot and main injection cases.

For pilot injection, several features should be noted. First, NTC behavior is absent with the recompression products due to the reduced n-heptane concentration. Second, at temperatures above $850 \mathrm{~K}$, stoichiometric 
pilot injection has a shorter ignition delay than stoichiometric main injection, which implies that even the pyrolysis products (Fig. 9d) have a higher auto-ignition propensity than the base fuel itself. Note too that for temperatures above $850 \mathrm{~K}$, the ignition delay for equivalence ratio of 0.9 is shorter than that for the stoichiometric case due to its higher extent of reaction (Fig. 9d). In considering these results, however, it should be kept in mind that fuel pyrolysis is endothermic, leading to a drop in temperature during NVO (Fig. 9b), such that the mixture temperature for main combustion would be lower, and thus lengthen the ignition delay. This is an important competing effect between chemical and thermal consequences of recompression reaction at (or near) stoichiometric operation. Third, pilot injection at equivalence ratio 0.8 shows a short ignition delay similar to that at 0.9 for temperatures above $850 \mathrm{~K}$. However, in this case moderate exothermicity (Fig. 9d) would raise the mixture temperature and thus further enhance the ignitability.

For the pilot injection case at equivalence ratio 0.7 , it is shown that the ignition delay is similar to that of main injection at temperatures above the NTC region $(950 \mathrm{~K})$. Considering that only $\sim 70 \%$ of the fuel chemical energy remains (Fig. 9d), this comparable ignition delay indicates that the recompression reaction mixture - which is significantly depleted of fuel-has improved ignitability of the remaining species. Adding in the effect of strong exothermicity under these conditions (Figs. 9b and 9d), leads to a much shorter ignition delay compared to un-reacted fuel. Finally, at the leanest condition (0.6), the ignition delay is long compared to all other conditions explored. As shown in Fig. 14d, strong oxidation converts about $60 \%$ of the fuel energy to final products $\left(\mathrm{H}_{2} \mathrm{O}, \mathrm{CO}_{2}\right)$ during $\mathrm{NVO}$, which results in a very weak mixture for main ignition. Although significant exothermicity occurs and this may compensate in part for the poor ignitability, these results indicate that there is a lean limit beyond which recompression reaction cannot aid in extending low-load operation.

In summary, above $850 \mathrm{~K}$ the isochoric/adiabatic ignition delay of recompression products is generally shorter than for a comparable, un-reacted fuel mixture at the same temperature. An exception to this observation occurs when significant oxidation of the fuel to final products occurs such that little chemical energy remains for the main combustion event. Although purposefully decoupled in this study, it is demonstrated that the thermal and chemical consequences of recompression reaction will tend to have competing effects on ignition delay. Fuel mixtures from pyrolysis or reforming are more reactive, but their formation is endothermic leading to a lower temperature. On the other hand, mixtures with strong exothermic reaction are generally less reactive due to low fuel concentration, but the resulting higher temperature can compensate, leading to improved low-load performance. This leads to a range of optimum conditions in terms of ignitablity, perhaps in the vicinity of 0.8 equivalence ratio.

\section{References:}

[1] H. H. Song, A. Padmanabhan, N. B. Kaahaaina, and C. F. Edwards, An Experimental Study of Recompression Reaction for Low-Load Operation in Direct-Injection HCCI Engines with n-Hpetane and iOctane Fuels, Submitted to the Internal Journal of Engine Research, 2008.

[2] H. H. Song and C. F. Edwards, Optimization of Recompression Reaction for Low-Load Operation of Residual-Effected HCCI, SAE 2008-01-0016, 2008.

[3] H. H. Song and C. F. Edwards, Understanding Chemical Effects in Low-Load-Limit Extension of HCCI Engines via Recompression Reaction, Submitted to the Internal Journal of Engine Research, 2008. 


\section{Task 6: Emission control devices for PPCI engines (UM)}

Objective: This task will encompass fundamental research of emission control (after-treatment) devices for the reduction of problematic emissions $\left(\mathrm{CO}, \mathrm{HC}, \mathrm{NO}_{\mathrm{x}}\right.$ and $\left.\mathrm{PM}\right)$ from Low Temperature Combustion (LTC) operation. The acquired fundamental knowledge will be incorporated into models at device and system level to determine optimal strategies and methodologies for best efficiency of each after-treatment device, based on desired LTC speed/load operating ranges and selected system configurations.

\section{DOC modeling}

The goal of this task is to develop successful after-treatment models and system models for low temperature applications in PCI. For this purpose a systematic methodology was developed to generate heterogeneous global reaction kinetics for hydrocarbons, $\mathrm{CO}, \mathrm{H}_{2}$ and NO under lean conditions and temperature ranges typically observed in oxidation catalysts. The methodology involves, bench reactor tests, optimization of kinetic parameters, modifying and reoptimization of the rate expressions and finally, validation by comparison with actual engine experimental light-off curves. So far the work has concentrated on diesel exhaust. The results for THC emissions are shown in Figure 1 for both PCI and conventional diesel operation. As seen in the figure, the model agrees well with the experimental data, and demonstrates the higher light-off

temperatures required for PCI operation. This is due to the higher levels of concentration of $\mathrm{CO}$ and $\mathrm{HC}$ that this mode produces. Good agreement is also obtained with $\mathrm{CO}$ (not shown). The methodology, experimental set-up and optimization algorithms can very easily be extended to other catalytic converter systems, specifically to oxidation catalysts which are intended to be used in gasoline LTC aftertreatment.

\section{Urea SCR modeling}

A second goal of this task was to develop a first generation model of a Urea SCR catalyst. This was done using AVL Boost with appropriate chemical equations drawn in part from previous work at UM by Dr. Chris Depcik. Additional reactions were added to take into account the

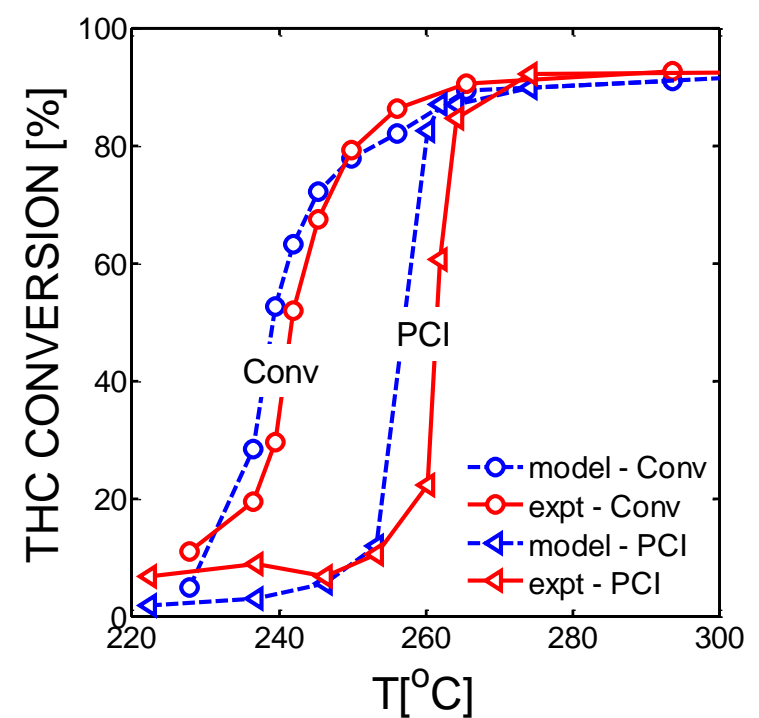

Fig. 1. After-treatment model comparison with experimental total hydrocarbon (THC) light-off curves for conventional diesel (Conv) and for PCI conditions. Model successfully predicts the shift in light-off temperature for PCI exhaust conditions.

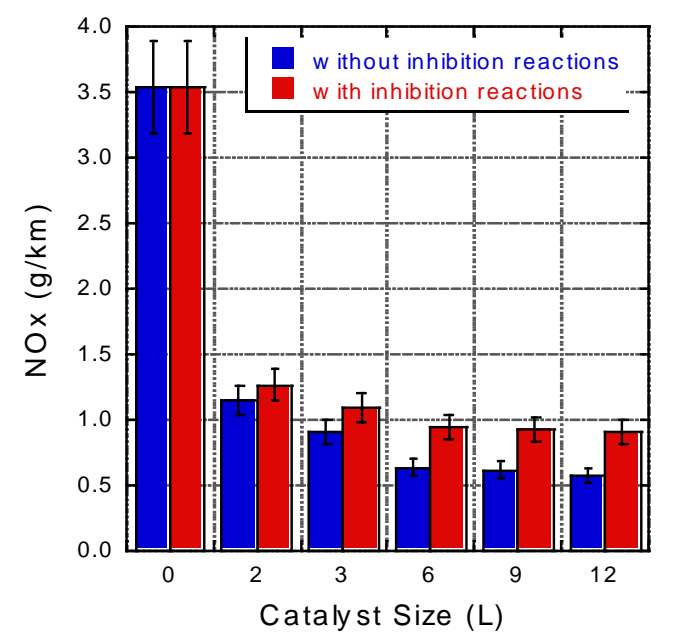

Figure 2. Simulated effect of catalyst size on FTP emissions, using the Urea SCR model both with and without inhibition terms. 
inhibition effect of $\mathrm{NH} 3, \mathrm{H} 2 \mathrm{O}, \mathrm{NO}$ and $\mathrm{NO} 2$ on NOx conversion reactions. The model was calibrated using literature data and used to simulate the effect of catalyst size on effectiveness in a typical engine application. Feedgas concentrations were taken from experimental data for a 6.0L International V-8 engine over an FTP 75 driving cycle. The results show that for larger catalyst volumes, the inhibition reactions decreased catalyst activity and increased exhaust NOx levels by up to $30 \%$. Figure 2 compares two cases run with and without the inhibition terms. 


\section{Task 7: Spark-assisted HCCI for enhancing range and control of LTC engine (UM)}

Objective: The objective of this task is to explore the Spark Assisted Homogeneous Charge Controlled Ignition (SA-HCCI) engine concept. SA-HCCI has the potential to combine the thermal efficiency and emissions potential of HCCI with the extended operating range and simpler control of conventional engine cycles. First and second law analysis and modeling will be used to guide the development of the concept followed by engine experiments.

\section{Accomplishments:}

Combustion Modes for LTC - Current SI engines operate under stoichiometric conditions to ensure three way catalyst treatment of both $\mathrm{HC}$ and NOx emissions. promises to operate lean enough to achieve low NOx emissions without aftertreatment, thereby opening up the possible efficiency gains of lean burn engines. However, HCCI engines are limited by combustion rates at high loads and timing control issues brought about by their reliance on autoignition. Spark Assisted Compression Ignition (SACI) may ease difficulties by offering timing control and combustion rate moderation.

In an attempt to better understand spark analytical work was carried out to delineate typical combustion regimes in of the local thermodynamic conditions (Lavoie et al., 2009). Fig. 1 shows the regimes mapped according to unburned

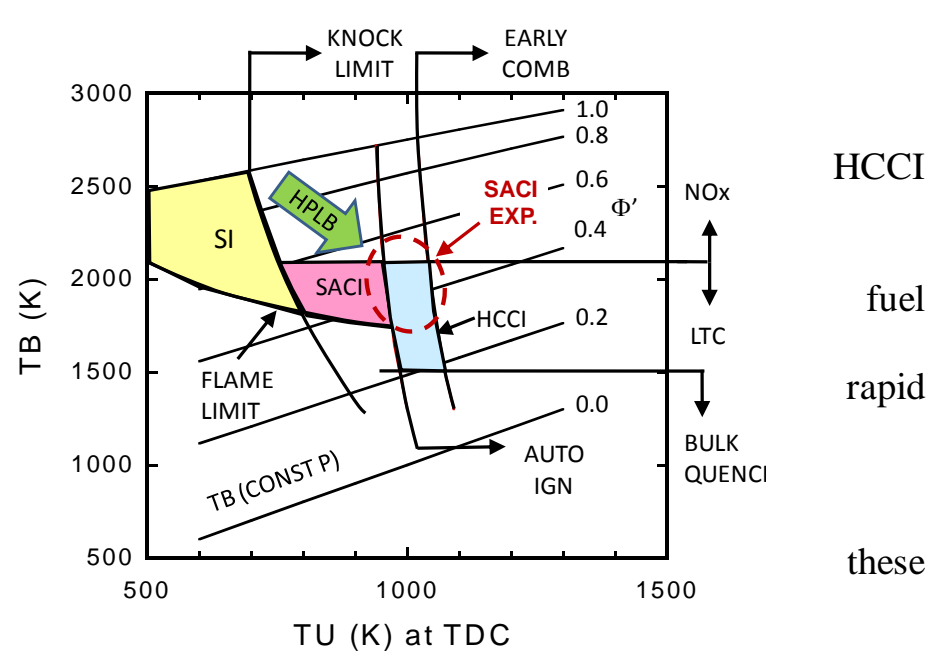

Fig. 1. Schematic map of combustion regimes for SI,

Spark Assist (SA), and HCCI determined by assist, constraints on unburned temperature (auto ignition, combustion phasing and knock); and on burned gas temperature (flame limit, quenching, and NOx limit). Dashed oval denotes available experimental data on SACI.

terms

$\left(\mathrm{T}_{\mathrm{U}}\right)$, and adiabatic burned gas temperatures $\left(\mathrm{T}_{\mathrm{B}}\right)$. Constant equivalence ratio lines progress from lower left to upper right. When EGR is present, equivalence ratio refers to the total diluents ratio, i.e. $\Phi$ ' represents $\Phi$ (1-RGF) as a relative measure of energy content of the charge. The rectangular HCCI region to the lower right of the figure is determined by ignition, misfire and NOx constraints. The SI region on the upper left is determined by requirements of good laminar flame propagation, lean or stoichiometric mixtures and borderline knock limits. The region where spark assist is feasible lies between the HCCI and the SI zones. In this zone both flame and autoignition processes are possible. The dashed oval indicates the area where spark assist has been observed in HCCI engines, both in metal engines and in optical engines. The trend toward boosted, leaner, i.e., High Pressure Lean Burn (HPLB) and more efficient engines can be visualized on the diagram by the green arrow moving from SI toward the leaner HCCI region. 
Optical engine experiments at UM are consistent with the diagram. As seen in Fig. 2 images with and without spark for high load conditions show clear flame propagation due to the spark leading to

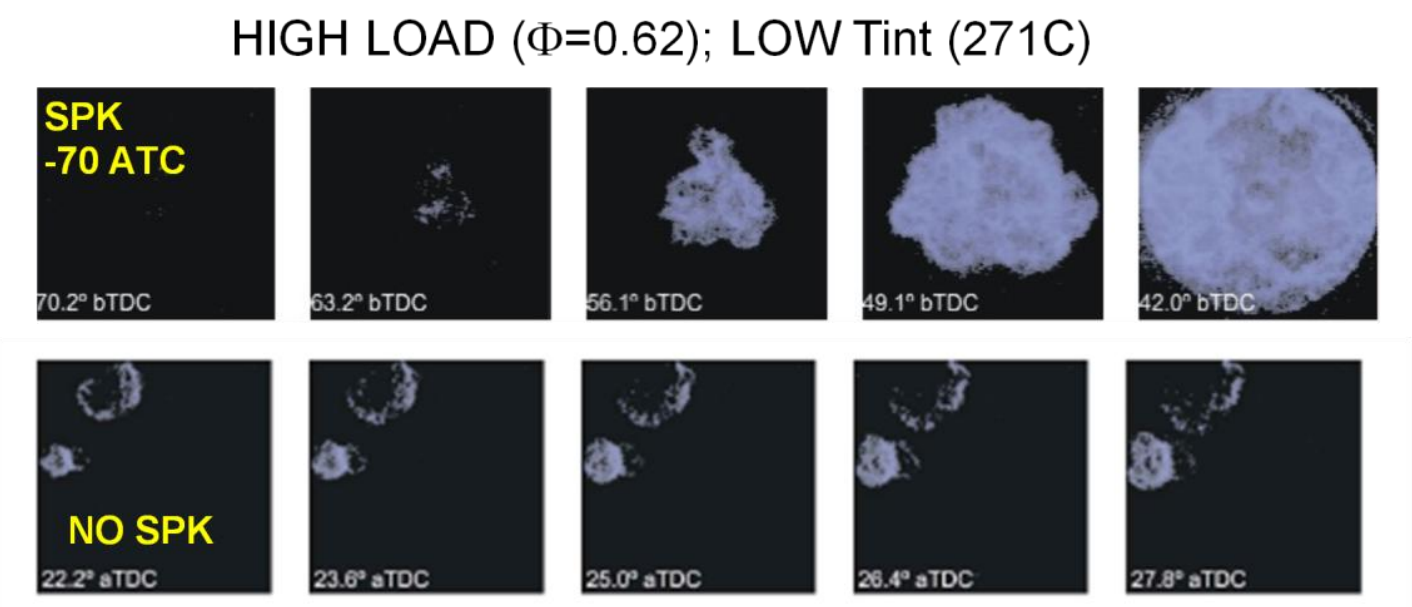

Fig. 2. The effect of spark at high load as observed in the UM optical engine

autoignition and strongly advancing combustion. Without spark, the autoignition appears at multiple sites throughout the cylinder but significantly later. These points would be higher in the combustion diagram and therefore have higher laminar flame speeds.

In Fig. 3 at low load, the effect of spark is negligible, and contributes moderately to the stability of the combustion but not to its timing. In this case the points are much lower on the combustion diagram with resulting low laminar flame speeds.

\section{LOW LOAD $(\Phi=0.40) ;$ HIGH Tint (321C)}
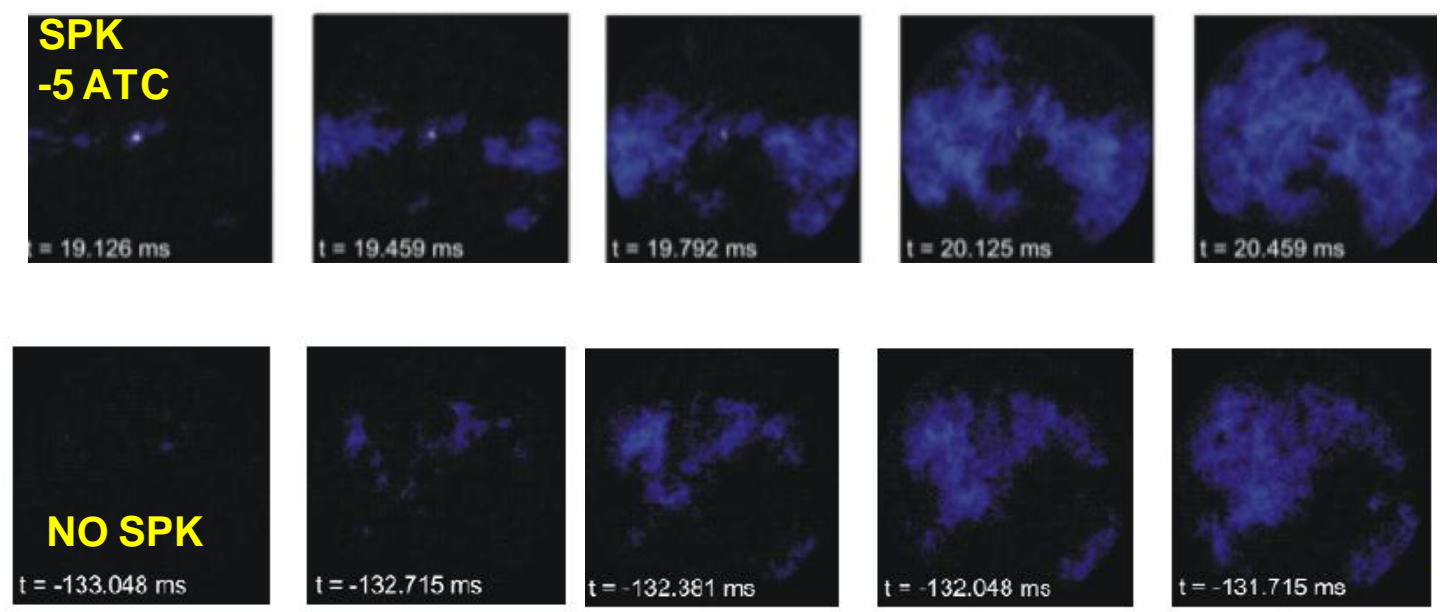

Fig 3. The effect of spark at low load conditions in the UM optical engine. 
Flame Speed Data Base -Because little or no experimental flame speed data are available in the SACI region we carried out an analytical study of flame speeds in this regime with a one dimensional transient HCT flame code. The range of initial conditions included $\mathrm{T}_{\mathrm{U}}$ up to $1000 \mathrm{~K}$; $0.1 \leq \Phi \leq 1.0$; and pressures up to 250 bar. Fig. 4 indicates the regions where experimental data is available and where the simulations were carried out.

The calculations were carried out with the HCT transient flame code because this permitted a close approach to conditions where autoignition was incipient. At room temperature, flames can propagate indefinitely without autoignition occurring in the upsteam gas. This makes it convenient to study in a lab setting. At higher unburned temperatures autoignition can occur and the time available for steady flame travel is diminished.

Fig. 5 shows a typical set of evolving temperature profiles. Initially the flame propagates in a steady manner and the flame speed is constant. Then the flame undergoes a brief acceleration followed by autoignition in the end gas. The results show that the flame and autoignition process are relatively independent until noticeable exothermicity begins as a result of the autoignition process; further, viable laminar flames should be possible down to equivalence ratios of $\sim 0.3-0.4$ provided that the unburned temperature is high enough to ensure a flame temperature of $1750 \mathrm{~K}$.

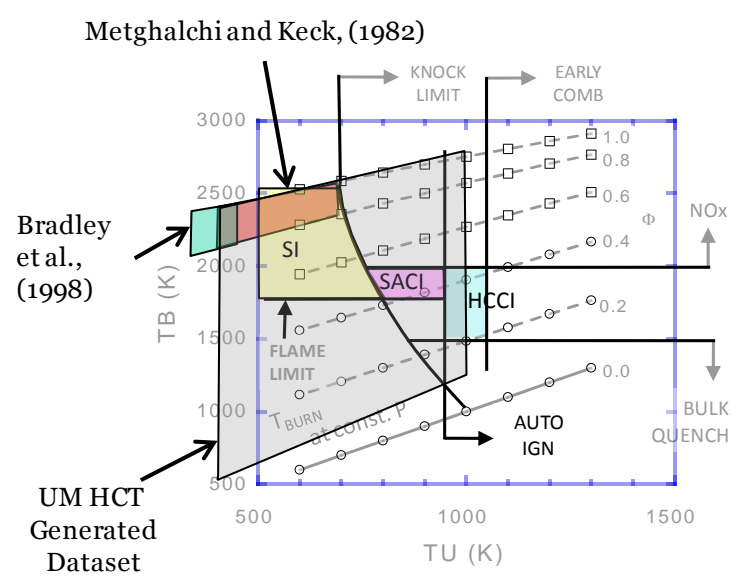

Fig. 4. Schematic of regions where experimental data is available showing range of calculations carried out with HCT. 
Recently the model generated flame speed data has been reduced into a practical set of numerical correlation expressions for general use over the portion of the range where viable flames were achieved in the simulated data set (Martz et al, 2010). Fig. 6 shows flame speed contours at 40 bar for both the original dataset and the correlation. Plans are to use the correlation in a CFD subgrid model of turbulent flame speed for use in SACI studies.

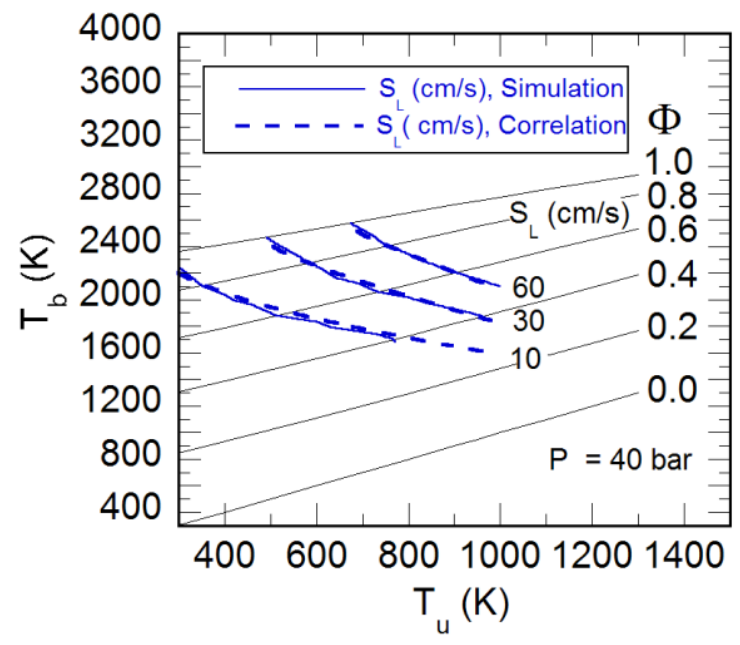

Fig. 6. Contour plots of flame speed mapped on the $\mathrm{Tu}-\mathrm{Tb}$ diagram at $40 \mathrm{bar}$. Solid curves are HCT simulation results; dashed lines are the numerical corraltion of these results. 


\section{Task 8: Fuel pre-treatment strategies, non-petroleum based fuels and fuel-blends for use in advanced LTC engine strategies (UM)}

Objective: The objective of this task is to understand the characteristics of reformed gasoline fuels, renewable fuels, and blends of conventional fuels with reformed and renewable fuels in order to propose viable fuel mixtures and fuel pretreatment strategies for use in advanced engines. Experimental and modeling efforts will be used to characterize ignition, combustion and pollutant formation of reformed fuels and fuel blends with/without EGR and oxygen-enriched air for extending stable LTC engine operation, and to characterize and optimize injection strategies.

\section{Accomplishments:}

The main results from this task relate to experiments carried out in the UM rapid compression facility shown in Fig. 1. The focus was on the ignition characteristics of reference oxygenated ester compounds. Although much smaller in molecular weight than practical biofuels, these molecules are representative of biofuels and differ only in the length of the hydrocarbon chain attached to the ester group.

We now have a library of ignition data for several prototypical ester structures representing varying degrees of chain length and levels of saturation. By

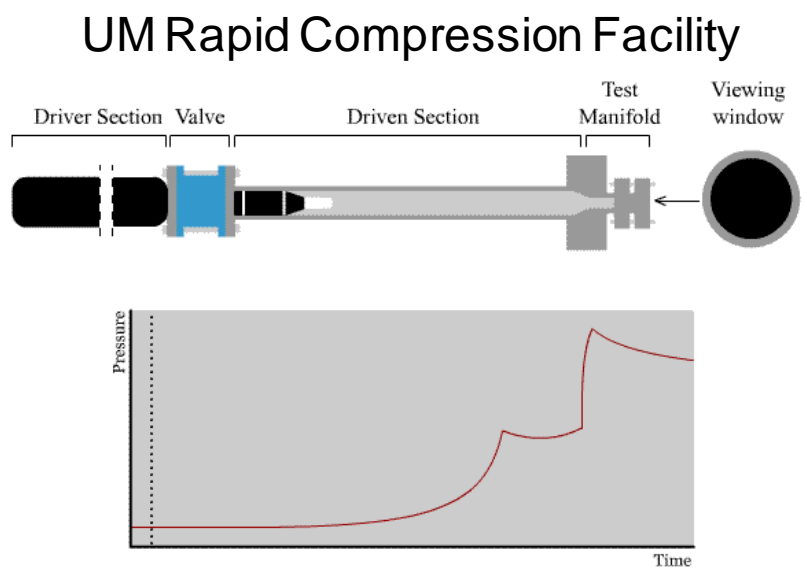

Figure 1. UM Rapid Compression Facility (above); typical pressure trace below. combining our data with the results of shock tube experiments found in the literature, we have developed new reaction mechanisms for two of the ester compounds which yield excellent agreement with the experimental data over a large range of temperatures $(900-1700 \mathrm{~K})$, pressures $(1-10 \mathrm{~atm})$ and equivalence ratios $(\phi=0.3-1.0)$. The mechanisms have been developed in collaboration with Dr. Charlie Westbrook, our partner at Lawrence Livermore National Laboratories (Walton, et al. 2008). These results are shown in Fig. 2 and indicate a factor of three difference in ignition delays between the esters at equivalent temperatures.

In addition, we conducted ignition studies of ester/n-heptane blends. Methyl trans-3-hexanoate was used as the reference ester compound due to the larger hydrocarbon chain and because it represents an unsaturated ester (which are typically more prevalent in biodiesels than saturated esters). The results indicate negative temperature coefficient behavior for blends containing larger amounts of n-heptane and non-linear blending behavior as seen in Fig. 3 These data are also the first of their kind and provide understanding of the fundamental reaction chemistry important during combustion of oxygenated compounds and blends with hydrocarbon fuels. 


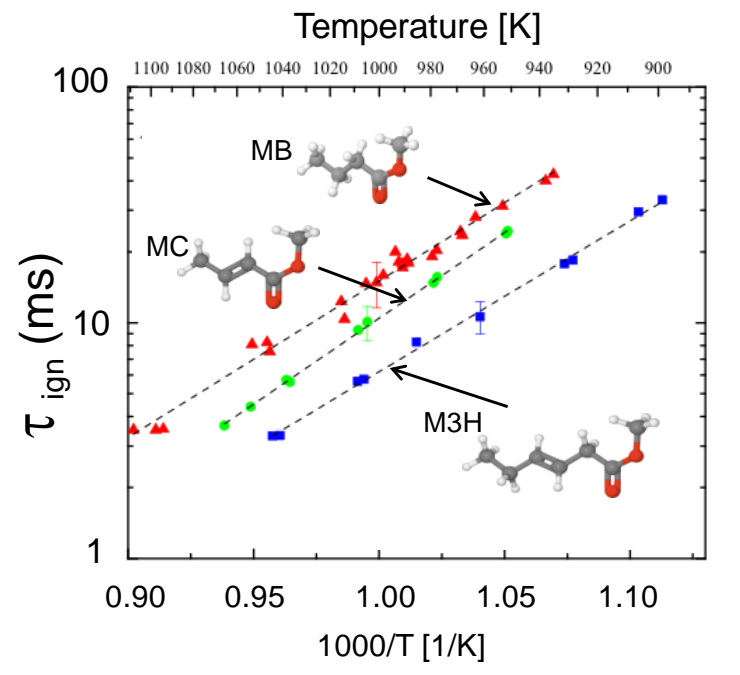

Fig. 2. Ignition delay times for three biofuel ester measured in the RCF: methyl butanoate (MB) with th longest delay times comparable to isooctane, methy crotanoate (MC), and methyl trans-3-hexanoate (M3H the most reactive.

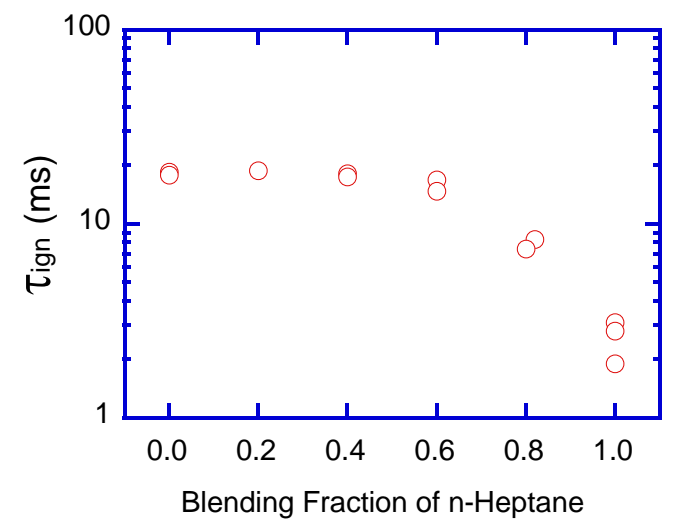

Fig. 3. Measured ignition delay times of nheptane/ methyl trans-3-hexanoate $(\mathrm{M} 3 \mathrm{H})$ blends at $\Phi=0.3, \quad \mathrm{P}=10.5 \mathrm{~atm}, \quad \mathrm{~T}=925 \mathrm{~K}$, Inert $/ \mathrm{O}_{2}=3.76$. Non linear behavior is seen at higher blending fractions of $n$-heptane. Blends also exhibit NTC in this region.

Additionally, speciation studies were carried out on intermediates formed during ignition of methylbutanoate/air mixtures using the UM RCF. The results are the first of their kind to provide quantitative insight into the reaction pathways important during ester combustion. These data are also the first of their kind and provide understanding of the fundamental reaction chemistry important during combustion of oxygenated compounds. We also continue to work with Dr. Charlie Westbrook, our partner at Lawrence Livermore National Laboratories to develop new chemical reaction mechanisms to represent combustion of these compounds. Figure 4 shows a recent RCF data for the intermediate ethene compared to the predictions of the LLNL model for methylbutanoate autoignition. In addition, we conducted preliminary UM RCF ignition studies of ester/n-heptane blends. Methyl 3-hexanoate was used as the reference ester compound due to the larger hydrocarbon chain and because methyl-3-hexanoate represents an unsaturated ester (which are typically more prevalent in biodiesels than saturated esters). The results indicate negative temperature coefficient behavior for blends containing larger amounts of n-heptane.

Our approach focused on understanding the specific reactions controlling oxygenate ignition for our reference fuel methylbutanoate, and developing reaction sensitivity coefficients. The results for the sensitivity analysis of methylbutanoate show that $\mathrm{HO}_{2}$ and $\mathrm{H}_{2} \mathrm{O}_{2}$ reactions are the most important reactions controlling ignition at HCCI conditions. Rate of production analyses show that the fuel is consumed primarily by $\mathrm{H}$-atom abstraction via the hydroxyl radical. Together these results indicate potential pathways to further control

\section{METHYLBUTANOATE AUTOIGNITION}

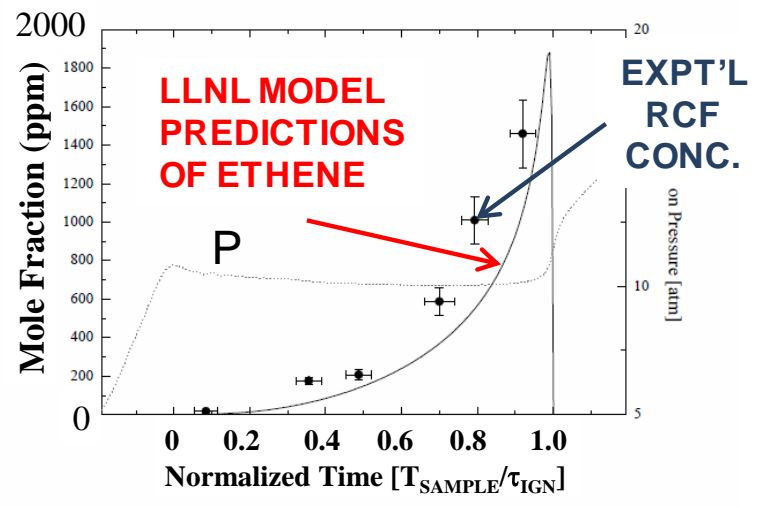

Fig. 4. Concentration measurements of the intermediate species ethene, during autoignition of methylbutanoate in the UM RCF compared to predictions using the LLNL detailed kinetic model. 
HCCI ignition using $\mathrm{OH}$ chain carriers (e.g. fuel blends, fuel additives, etc.). The results for the sensitivity analysis of methylbutanoate show that $\mathrm{HO}_{2}$ and $\mathrm{H}_{2} \mathrm{O}_{2}$ reactions are the most important reactions controlling ignition at HCCI conditions. Rate of production analyses show that the fuel is consumed primarily by $\mathrm{H}$-atom abstraction via the hydroxyl radical. Together these results indicate potential pathways to further control HCCI ignition using $\mathrm{OH}$ chain carriers (e.g. fuel blends, fuel additives, etc.). We are now working to extend our capabilities to heavier (higher molecular weight) fuels which are more representative of real fuels and real fuel blends. 


\section{Publications}

\section{6-2009}

Aceves, S. M., Flowers, D. L., Chen, J.-Y., Babajimopoulos, A. (2006) "Fast Prediction of HCCI Combustion with an Artificial Neural Network Linked to a Fluid Mechanics Code," SAE paper Number SAE paper 2006-01-3298

Andreae, M., Cheng, W. K., Kenney, T., Yang, J. (2007) "Effect of Air Temperature and Humidity on Gasoline HCCI Operating in the Negative-Valve-Overlap Mode," SAE Paper 2007-01-0221.

Andreae, M., Cheng, W. K., Kenney, T., Yang, J. (2007) "On HCCI Engine Knock," SAE Paper 2007-01-1858, SAE/JSAE Joint Powertrain and Fluid Systems Meeting, Kyoto, Japan, June, 2007.

Angelos, J., Puignou, M., Andreae, M., Cheng, W., Green, W., Singer, M., "Detailed Chemical Kinetic Simulations of Homogeneous Charge Compression Ignition Engine Transients," Int. J. of Engine Research, Vol. 9, No.2, pp. 149 - 164, April, 2008.

Angelos, J.P., Andreae, M.M., Green, W.H., Cheng, W.K., Kenney, T., Xu, Y. (2007) "Effects of Variations in Market Gasoline Properties on HCCI Load Limits," SAE Paper 2007-01-1859, SAE/JSAE Joint Powertrain and Fluid Systems Meeting, Kyoto, Japan, June, 2007.

Assanis, D., Babajimopoulos, A., Filipi, Z., Lavoie, G., and Prasad, C. (2007) Valve Actuation Strategies for HCCI and Their Effect on Load Limits. SAE HCCI Symposium, Lund, Sweden, Sept. 12-14, 2007.

Babajimopoulos, A., Challa, P., Lavoie, G. A., and Assanis, D. N. (2009) Model-based assessment of two variable cam timing strategies for HCCI engines: recompression vs. rebreathing. Proceedings of the ASME Internal Combustion Engine Division 2009 Spring Technical Conference, ICES2009, May 3-6, 2009, , Milwaukee, Wisconsin, USA, Paper ICES2009-76103,

Babajimopoulos, A., Lavoie, G. A., and Assanis, D. N. (2007) ON THE ROLE OF TOP DEAD CENTER CONDITIONS IN THE COMBUSTION PHASING OF HOMOGENEOUS CHARGE COMPRESSION IGNITION ENGINES. Combustion Science and Technology, Vol. 179, No. 9, 2039 - 2063.

Bansal G and Im H G, (2007) Time Scales in Unsteady Premixed Flame Extinction with Composition Fluctuations, Combustion and Flame, v. 150, pp. 404-408.

Bansal G, Im H G, and Lee S R, (2007) Auto-ignition in Homogeneous Hydrogen/Air Mixture subjected to Unsteady Temperature Fluctuations, 2007 Fall Technical Meeting of Eastern States Section of Combustion Institute, Charlottesville, VA, October 21-24, 2007.

Bansal G, Im H G, and Lee S R, (2008) Unsteady Scalar Dissipation Rate Effects on Nonpremixed $n$-Heptane Autoignition in Counterflow, 46th AIAA Aerospace Sciences Meeting and Exhibit, Reno, NV, Jan 7-10, 2008.

Bansal G. and Im H. G., Autoignition of Hydrogen-Air Mixture with Temperature and Composition Inhomogeneities, AIAA Paper 2009-1559, 47th AIAA Aerospace Sciences Meeting and Exhibit, January 5-8, 2009, Orlando, FL

Bansal G. and Im H. G., Direct Numerical Simulation of Autoignition and Front Propagation in Hydrogen-Air Mixture with Thermal and Compositional Inhomogeneities, Proceedings of the 6th US National Combustion Meeting, May 

17 - 20, 2009, Ann Arbor, MI
Bansal G., Im H. G., and Lee S. R, Autoignition of Homogeneous Hydrogen/Air Mixture subjected to Unsteady Temperature Fluctuations, Combustion Theory and Modelling (in press) (2009).
Bansal G., Im H. G., and Lee S. R., Autoignition of Nonpremixed n-Heptane Counterflow subjected to Unsteady Scalar Dissipation Rate, Proceedings of the Combustion Institute, v. 32, pp. 1083-1090 (2009).
Bansal G., Im H. G., and Lee S. R., Effects of Scalar Dissipation Rate Fluctuations on Autoignition of Hydrogen-Air Mixture, AIAA Journal, v. 47, No. 2, pp. 468-472 (2009).

Bansal G., Im H. G., and Sutherland J. C., Modeling of Autoignition in Inhomogeneous Turbulent Mixtures using Principal Component Analysis, Proceedings of the 6th US National Combustion Meeting, May 17 - 20, 2009, Ann Arbor, MI

Bogin Jr., G.E., "Characterization of Ion Production Using Gasoline, Ethanol, and NHeptane in a Homogeneous Charge Compression Ignition (HCCI) Engine," PhD thesis, University of California - Berkeley, Berkeley, California, USA, 2008.

Bogin, G., Chen, J.Y., Dibble, R.W. (2007) "Numerical and Experimental Investigation of Ions in a Homogeneous Charge Compression Ignition Engine," Western States Section of the Combustion Institute, Fall 2007.

Bogin, G.E., J.H. Mack, and R.W. Dibble, "Spark Plug Modifications for Improving Ion Sensing Capabilities in a Homogeneous Charge Compression Ignition (HCCI) Engine," Proceedings of the 2009 ASME ICE Spring Conference, submitted for publication, 2008.

Chang, J., et al. (2005) Characterizing the Thermal Sensitivity of a Gasoline HCCI Engine with Measurements of Instantaneous Wall Temperature and Heat Flux. International Journal of Engine Research, Vol. 6, No. 4, 289.

Chang, J., Filipi, Z. ; Kuo, T.-W., Assanis, D., Najt, P., Rask, R.,'Investigation of Mixture Preparation Effects on Gasoline HCCI Combustion Aided by Measurements of Wall Heat Flux", ASME Journal of Eng. Gas Turbines Power 130, (2008), pp. 062806-1 to 062806-9

Chang, K., Babajimopoulos, A., Lavoie, G. A., Filipi, Z. S., and Assanis, D. N. (2006) "Analysis of Load and Speed Transitions in an HCCI Engine Using 1-D Cycle Simulation and Thermal Networks" SAE Paper No. 2006-01-1087.

Chen, J.-Y. Chen, Y.-H., Choi, Y. (2006), "Development and Validation of Isooctane Skeletal Mechanisms Based on LLNL Detailed Mechanism" International Journal of Vehicle Design, (in press).

Flowers, D. L., Aceves, S. M., and Babajimopoulos, A. (2006) "Effect of Charge NonUniformity on Heat Release and Emissions in PCCI Engine Combustion" SAE Paper 2006-01-1363.

Guralp, O. A., et al. (2006) Characterizing the Effect of Combustion Chamber Deposits on a Gasoline HCCI Engine. SAE Paper No. 2006-01-3277.

Guralp, O., et al. (2009) Thermal Characterization of Combustion Chamber Deposits on the HCCI Engine Piston and Cylinder Head Using Instantaneous Temperature Measurements. SAE Paper No. 2009-01-0668.

He, X., Donovan, M. T., Zigler, B. T., Palmer, T. R., Walton, S. M., Wooldridge, M. S., and Atreya, A., (2005) "An Experimental Study of Isooctane Ignition Delay Times at HCCI Operating Conditions Using a Rapid Compression Facility," Combustion and Flame, 142, 266-275.

He, X., Walton, S. M., Zigler, B. T., Wooldridge, M. S., and Atreya, A., (2007) "An 


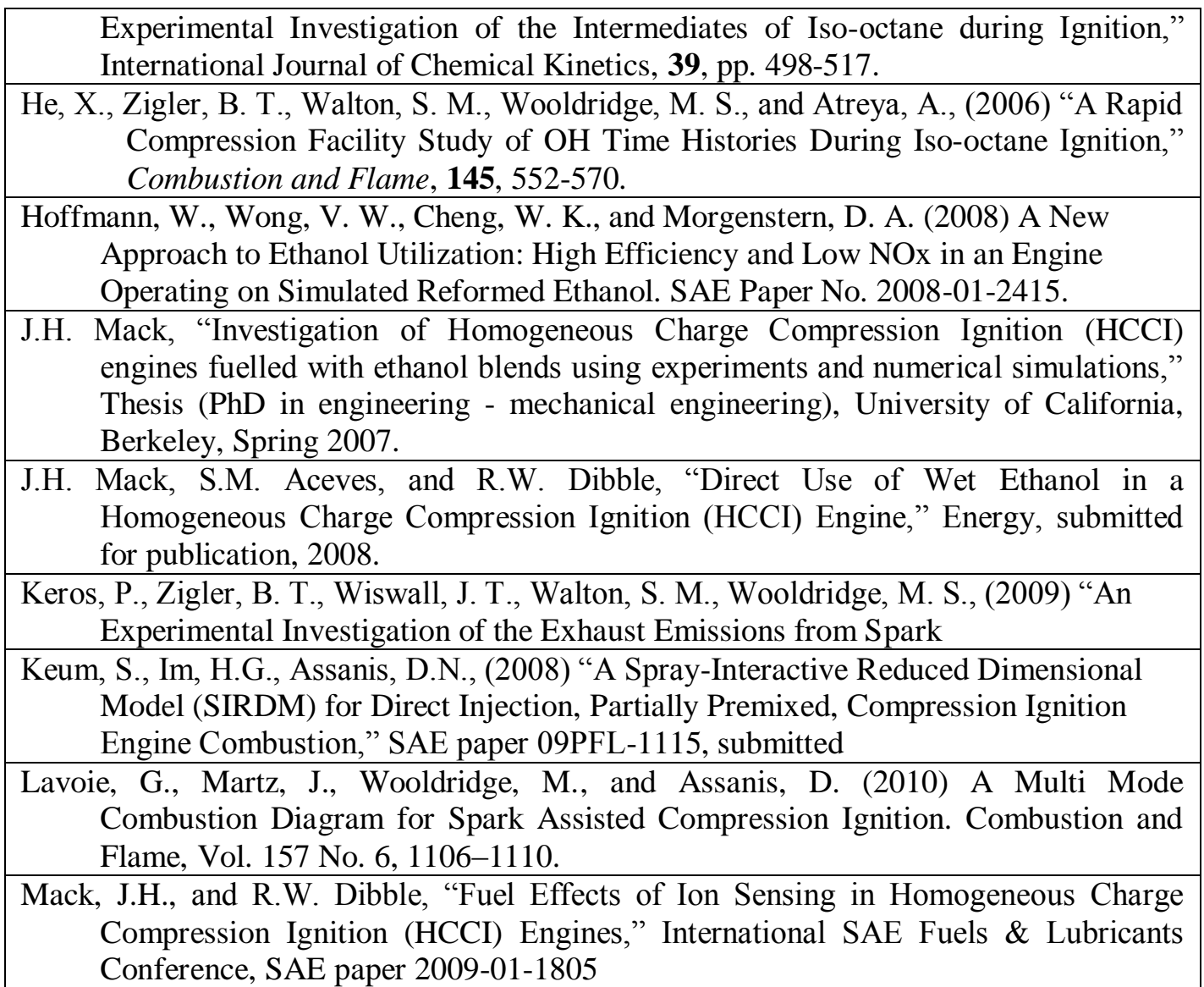

Mack, J.H., Flowers, D.L., Aceves, S.M., Dibble, R.W. (2007) "Direct Use of Wet Ethanol in a Homogeneous Charge Compression Ignition (HCCI) Engine: Experimental and Numerical Results," Western States Section of the Combustion Institute, Fall 2007.

Martz, J. B., Kwak, H., Im, H. G., Lavoie, G. A., and Assanis, D. N. (2010) Combustion Regime of a Reacting Front Propagating into an Auto-Igniting Mixture. Proceedings of the Combustion Institute, Vol. 33.

Martz, J., Middleton, R., Lavoie, G., Babajimopoulos, A., and Assanis, D. (2010) A computational study and correlation of premixed laminar flame properties for lean, high pressure, low temperature isooctane-air mixtures. Vol. (submitted to Combustion and Flame).

Montgomery, C. J., Yang, C., Parkinson, A. R., and Chen, J.-Y. (2006) "Selecting the optimum quasi-steady-state species for reduced chemical kinetic mechanisms using a genetic algorithm" Combustion and Flame, Vol. 144, No. 1-2, 37-52.

Ogura, T., Angelos, J.P., Green, W.H., Cheng, W.K., Kenney, T.E., Xu, Yi "Primary Reference Fuel Behavior in a HCCI Engine near the Low-Load Limit," SAE Transactions, 116, Journal of Fuels and Lubricants, Paper 2008-01-1667, 2008

Sampara, C. S.; Bissett, E. J.; Chmielewski, M.; Assanis, D., (2007) "Global Kinetics for Platinum Diesel Oxidation Catalysts” Ind. Eng. Chem. Res.; 46(24); 7993-8003.

Sampara, Chaitanya S., Bissett, Edward J., and Chmielewski, Matthew (2007) "Global Kinetics for a Commercial Diesel Oxidation Catalyst with Two Exhaust Hydrocarbons", Presented at the Diesel Engine - efficiency and Emissions Research (DEER) Conference, August 13-16, Detroit, MI

Sankaran, R., Im, H. G., and Hewson, J. C. (2007) ANALYTICAL MODEL FOR 


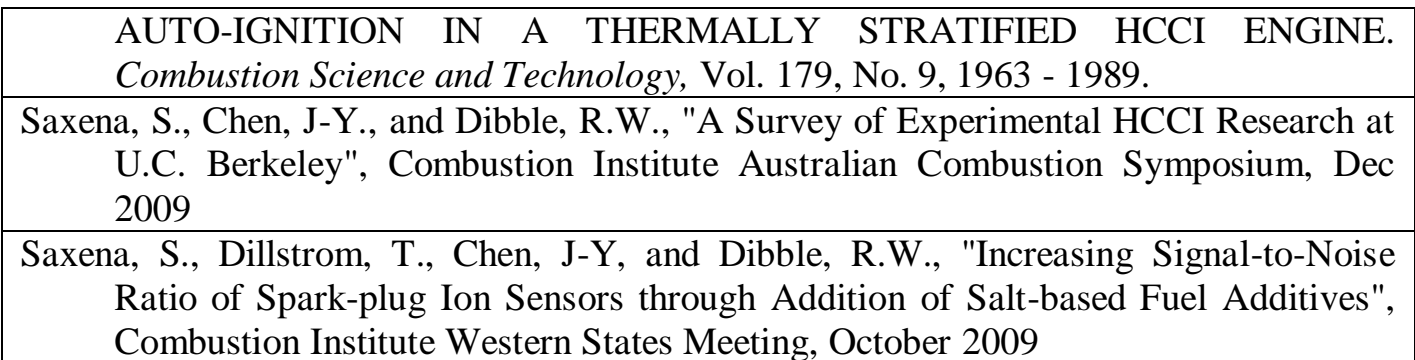

Saxena, S., Mack, J.H. and Dibble, R.W. "Increasing Indicated Mean Effective Pressure (IMEP) of a Homogeneous Charge Compression Ignition (HCCI) Engine", Combustion Institute US National Meeting, May 2009

Scaringe, R. J., Wildman, C. B., and Cheng, W. (2010) On the High Load Limit of Boosted Gasoline HCCI Engine Operating in NVO Mode. SAE Paper No. 201001-0162.

Shaver, G. M., Roelle, M. J., Caton, P.A., Kaahaaina, N. B., Ravi, N., Hathout, J-P., Ahmed, J., Kojic, A., Park, S., Edwards, C. F., and Gerdes, J. C. (2006) "A Physics Based Approach to the Control of Homogeneous Charge Compression Ignition Engines with Variable Valve Actuation," Int'l Journal of Engine Research, Vol. 6, No. 4, pp. 361-375, 2005.

Song, H. H., and Edwards, C. F. (2008) "Optimization of Recompression Reaction for Low-Load Operation of Residual-Effected HCCI”, SAE paper 2008-01-0016

Song, H. H., and Edwards, C. F. (2009) Understanding chemical effects in low-load-limit extension of homogeneous charge compression ignition engines via recompression reaction. International Journal of Engine Research, Vol. 10, No. 4, 231-250.

Song, H. H., Padmanabhan, A., Kaahaaina, N. B., and Edwards, C. F. (2009) Experimental study of recompression reaction for low-load operation in directinjection homogeneous charge compression ignition engines with n-heptane and ioctane fuels. International Journal of Engine Research, Vol. 10, No. 4, 215-229.

Stefan Klinkert, John W. Hoard, Sakthish R. Sathasivam, Dennis N. Assanis, Stanislav V. Bohac (2009), Design of a Flow Reactor for Testing Multi-Brick Catalyst Systems Using Rapid Exhaust Gas Composition Switches, Paper ICEF 2009-14016, Proceedings of the ASME Internal Combustion Engine Division 2009 Fall Technical Conference, ICEF2009, September 20-24, 2009, Lucerne, Switzerland.

Walton, S. M., He, X., Zigler, B. T., and Wooldridge, M. S., (2006) "An Experimental Investigation of the Ignition Properties of Hydrogen and Carbon Monoxide Mixtures for Syngas Turbine Applications," accepted to the $31^{\text {st }}$ Proceedings of the Combustion Institute, (in press).

Walton, S. M., He, X., Zigler, B. T., Wooldridge, M. S., and Atreya, A., (2006) "An Experimental Investigation of Iso-octane Ignition Phenomena," accepted to Combustion and Flame, in press.

Walton, S. M., He, X., Zigler, B. T., Wooldridge, M. S., and Atreya, A., (2007) "An Experimental Investigation of Iso-octane Ignition Phenomena," Combustion and Flame, 150, pp. 246-262.

Walton, S. M., Perez, C., Wooldridge, M. S. (2007) "An Experimental Investigation of the Auto-Ignition Properties of Two C5 Esters: Methyl Butanoate and Butyl Methanoate," Technical Publication ASME IMECE2007-41944.

Walton, S. M., Wooldridge M. S., and Westbrook C. K., (2008) "An Experimental Investigation of Structural Effects on the Auto-Ignition Properties of Two $\mathrm{C}_{5}$ Esters" Proceedings of the Combustion Institute, 32, pp. 1-8 (in press, doi:10.1016/j.proci.2008.06.208). 
Walton, S. M., Wooldridge, M. S., and Westbrook, C. K., (2009) "An Experimental Investigation of Structural Effects on the Auto-Ignition Properties of Two $\mathrm{C}_{5}$ Esters" Proceedings of the Combustion Institute, 32, pp. 255-262.

Wildman, C., Scaringe, R.J., Cheng, W. (2009) "On the Maximum Pressure Rise Rate in Boosted HCCI Operation," SAE Paper 2009-01-2727.

Zigler, B. T., Walton, S. M., Assanis, Dimitris, Perez, E., Wooldridge, M. S., and Wooldridge, S. T., (2008) "An Imaging Study of Compression Ignition Phenomena of Iso-Octane, Indolene, and Gasoline Fuels in a Single-Cylinder Research Engine," ASME Journal of Engineering for Gas Turbines and Power, 130, pp. 052803-1-052803-11.

Zigler, B. T., Walton, S. M., Karwat, D. M., Assanis, Dimitris, Wooldridge, M. S., and Wooldridge, S. T., (2006), "A Multi-Axis Imaging Study of Spark-Assisted Homogeneous Charge Compression Ignition Phenomena in a Single-Cylinder Research Engine" Proceedings of ICEF2007, Paper No. ICEF2007-1762.

Zigler, B. T., Walton, S. M., Wiswall, J. T., and Wooldridge, M. S., (2006) "Crank-angle resolved imaging of homogeneous charge compression ignition phenomena in single-cylinder research engine," The Central States Meeting of the Combustion Institute, May 21-23, 2006, Paper \#, pp. 1-5.

\section{DISCLAIMER}

This report was prepared as an account of work sponsored by an agency of the United States Government. Neither the United States Government nor any agency thereof, nor any of their employees, makes any warranty, express or implied; or assumes any legal liability or responsibility for the accuracy, completeness, or usefulness of any information, apparatus, product, or process disclosed, or represents that its use would not infringe privately owned rights. Reference herein to any specific commercial product, process, or service by trade name, trademark, manufacturer, or otherwise does not necessarily constitute or imply its endorsement, recommendation, or favoring by the United States Government or any agency thereof. The views and opinions of authors expressed herein do not necessarily state or reflect those of the United States Government or any agency thereof. 